\title{
EVOLUCIÓN DE LA OFERTA Y MATRÍCULA DE CARRERAS IMPARTIDAS POR UNIVERSIDADES E INSTITUTOS PROFESIONALES EN CHILE ENTRE 1999 Y 2004
}

Paula Mena*

Karina Rojas* 



\section{EVOLUCIÓN DE LA OFERTA Y MATRÍCULA DE CARRERAS IMPARTIDAS POR UNIVERSIDADES E INSTITUTOS PROFESIONALES EN CHILE ENTRE 1999 Y 2004}

\section{Introducción}

Desde hace algún tiempo, el Consejo Superior de Educación (CSE) viene desarrollando una línea de investigación y análisis, cuyo objetivo es caracterizar el sistema de educación superior chileno. Parte de este esfuerzo ha sido posible gracias a la información acumulada a lo largo de los últimos años en la base de datos INDICES ${ }^{1}$, la cual constituye, en la actualidad, una fuente esencial de consulta para los interesados en iniciar una descripción sincrónica y diacrónica de las instituciones, programas y usuarios en lo que respecta, por ejemplo, a la distribución geográfica de las alternativas académicas y el uso de las mismas.

Ante la necesidad de conocer cómo se ha expandido la oferta educacional en la educación superior chilena, el CSE se abocó al análisis de la base INDICES para caracterizar dicho crecimiento en términos cuantitativos. Los resultados iniciales obtenidos motivaron una revisión en profundidad de la información recogida, pasando desde una descripción cuya unidad de análisis eran las instituciones de educación superior, a uno donde fuera posible explorar la expansión del sistema en términos de programas con una mirada tanto nacional como regional.

Evidentemente, la idea de estudiar la expansión del sistema desde el punto de vista de la oferta y la matrícula de carreras responde

1 Indicadores, Números y Datos sobre Instituciones y Carreras de Educación Superior. 
a ciertas intuiciones e inquietudes en torno a cuál es la medida del crecimiento, si éste exhibe patrones distinguibles dependiendo de la zona geográfica y si su desarrollo ha implicado o no una mayor diversificación de las áreas del conocimiento que entran a jugar en el mercado. Junto con estas interrogantes, surgen otras relativas al comportamiento de los proveedores ante la evolución de la matrícula y viceversa, lo que conlleva un desafío interpretativo, ya que muchas de las que parecieran ser señales de transformaciones futuras sólo aparecen los últimos dos años, abriendo más preguntas que respuestas respecto de qué dirección tomarán las transformaciones que se han comenzado a delinear desde 1999.

Desde el punto de vista del CSE, indagar en los temas enunciados a través de un estudio descriptivo adquiere sentido por dos razones. En primer lugar, como herramienta para aquellos involucrados en la gestión del sistema, ya sea que actúen desde las instituciones de educación superior o como parte de entidades gubernamentales o privadas que siguen de cerca la marcha de la educación terciaria. La segunda razón, y quizás la más importante, es contribuir a la transparencia, por la vía de sistematizar información que pudiera ser relevante para toda la ciudadanía interesada en conocer más sobre los cambios que ha experimentado parte fundamental de la provisión de educación en Chile.

En definitiva, este informe pretende caracterizar, cuantitativamente, el comportamiento general de la oferta y la matrícula en los programas dictados por universidades e institutos profesionales entre los años 1999 y 2004, considerando el eje distribución geográfica y distinguiendo áreas del conocimiento y tipo de institución que las dicta. Con el fin de facilitar la lectura del informe, primero se exponen y analizan los datos nacionales para luego describir, en más detalle, el panorama por región y por áreas del conocimiento, tratando de encontrar patrones o tendencias comunes cuando corresponde. 


\section{Consideraciones metodológicas}

El informe es de corte descriptivo y cubre un periodo de seis años, desde 1999 a 2004. Los cruces estadísticos, que sirven para establecer la evolución de oferta y matrícula en el periodo escogido, derivan de seis bases de datos que contienen la información proporcionada por los institutos profesionales y universidades para la publicación anual de INDICES. Acerca de la confiabilidad de los datos, baste decir que, por el hecho de ser facilitados por instituciones que voluntariamente participan del proceso de recogida, probablemente no estén exentos de errores que, sin embargo, no modifican las tendencias más visibles. También es clave señalar que esta publicación aparece en noviembre con la denominación del año próximo, por ejemplo, INDICES 2003 registró los datos correspondientes a $2002^{2}$. La lista de carreras incluye oferta futura, es decir, los programas nuevos disponibles a partir del 20033. Por ello, este informe diferencia entre:

- "Oferta": carreras informadas para el año siguiente.

- "Carreras impartidas": programas que aparecen con datos de matrícula para el año indicado.

- "Matrícula": expresada a través del ingreso a primer año (o nuevo). La matrícula total sólo se considera en el primer capítulo.

Los centros de formación técnica (CFT) quedaron fuera de esta investigación debido a que el CSE no recibió información de ellos (o sólo en bajo número) sino hasta los últimos dos años. Algo similar ocurre con la categorización por tipos de programa (profesional, licenciatura, técnico de nivel superior, por ejemplo),

2 Los datos de origen para el periodo 1999-2004 fueron publicados en INDICES 2000 al 2005.

3 Ocurre que ciertas instituciones no envían los datos de matrícula de las carreras. Tomando en cuenta lo anterior, se debe asumir que la diferencia entre "oferta" y "carreras impartidas" puede deberse a esa omisión y no a la emergencia de oferta nueva. Más aún, dado que la participación en INDICES es voluntaria, el número de instituciones que hace llegar información ha ido variando en el tiempo, lo que también incide en que no todas las carreras impartidas durante un año hayan sido previamente anunciadas como parte de la oferta. 
pues antes de 2002 no se solicitaba que las carreras explicitaran el título o grado al que conducían. Sin perjuicio de lo anterior, más adelante se alude a algunos datos nacionales sobre la composición de la oferta y matrícula según estos criterios.

En cuanto al eje "áreas del conocimiento" 4 , se exponen los resultados de los cruces estadísticos para dar cuenta de la oferta y la matrícula de primer año de las 10 áreas de conocimiento y de 14 subáreas seleccionadas. Estas últimas fueron escogidas atendiendo a que son las subáreas que más oferta y matrícula atraen para el año 2004 y porque, sumadas, representan el 60\%, aproximadamente, de la oferta y la matrícula de primer año. Se pensó, entonces, examinar con mayor detención cómo han evolucionado estos grupos de carreras dentro de los que se encuentra la mayoría de las llamadas "carreras tradicionales" (Derecho, Psicología, Ingeniería Comercial, entre otras) con el fin de hallar posibles regularidades o indicios de tendencia futura en sus mercados respectivos. El apartado donde se exponen los resultados incluye una enumeración de los tipos de carreras comprendidas en cada subárea estudiada.

\section{Estructura de presentación de resultados}

Los resultados nacionales y regionales del análisis descriptivo para el periodo 1999-2004 se presentan siguiendo tres ejes que constituyen los capítulos del documento, estos son:

1. Análisis de la evolución de la oferta y de la matrícula para el conjunto de carreras del país, según tipo de institución, áreas del conocimiento y distribución regional.

2. Análisis de patrones regionales de oferta y matrícula de primer año, considerando el tipo de institución.

3. Análisis de la evolución de la oferta y de la matrícula de primer año de carreras, según área del conocimiento y tipo de institución.

4. Análisis de la evolución de la oferta y la matrícula de primer año para cada una de las 14 subáreas del conocimiento seleccionadas.

4 Las áreas del conocimiento obedecen a la clasificación que el propio Consejo utiliza. 


\section{Oferta y matrícula de carreras en universidades e institutos profesionales (IP) entre los años 1999 y 2004}

Esta sección presenta los datos generales en relación con la oferta y matrícula en los programas de los dos grupos de instituciones estudiadas. Previo a esto, es necesario añadir algunos datos más generales que permitan apreciar el peso relativo de los distintos tipos de instituciones, tanto en la oferta como en la matrícula. A pesar de que no se expone todo el periodo, sino sólo 2004, la tabla 1 sirve para establecer el marco de cifras general, incluyendo los centros de formación técnica.

Tabla 1: Oferta y matrícula de las instituciones de educación superior en Chile al año 2004

\begin{tabular}{|l|c|c|c|c|}
\hline Tipo de institución & Oferta de carreras & $\%$ & Matrícula de primer año & $\%$ \\
\hline Universidades & 2.633 & $49 \%$ & 99.259 & $61 \%$ \\
\hline IP & 1.427 & $30 \%$ & 37.029 & $23 \%$ \\
\hline CFT & 944 & $21 \%$ & 25.690 & $16 \%$ \\
\hline Total & 5.054 & $100 \%$ & 161.978 & $100 \%$ \\
\hline
\end{tabular}

De un total de 5.054 programas el año 2004, las universidades ofrecen la mitad de las carreras y captan el $61 \%$ de la matrícula nueva. Por su parte, los IP aportan el 30\% de programas y captan $23 \%$ de la matrícula de primer año. Los CFT participan del 21\% de la oferta, inscribiendo al $16 \%$ de los estudiantes de primer año en sus carreras.

Volviendo al conjunto de carreras de que se ocupa este documento, que excluye los CFT, el gráfico 1 muestra la evolución de la oferta de programas universitarios y de institutos profesionales. 
Gráfico 1: Evolución de la oferta de institutos profesionales

y universidades del país entre los años 1999 y 2004

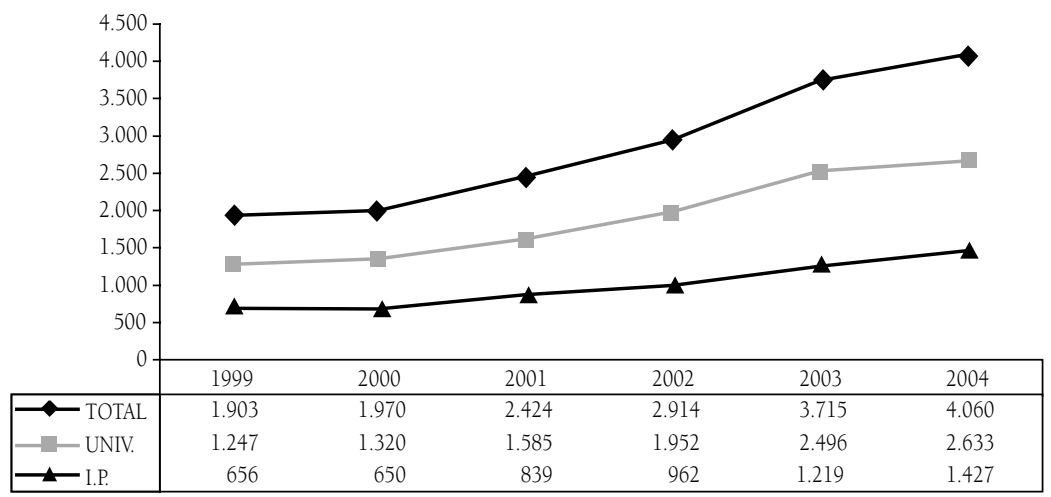

\begin{tabular}{|c|c|c|c|c|r|r|r|}
\cline { 2 - 8 } \multicolumn{1}{c|}{} & $\begin{array}{c}\text { Tipo de } \\
\text { Institución }\end{array}$ & $1999-2000$ & $2000-2001$ & $2001-2002$ & $2002-2003$ & $2003-2004$ & Promedio \\
\hline \multirow{2}{*}{$\begin{array}{c}\% \text { de } \\
\text { Variación }\end{array}$} & Total & $3,5 \%$ & $23 \%$ & $20,2 \%$ & $27,5 \%$ & $9,3 \%$ & $16,7 \%$ \\
\cline { 2 - 8 } & Universidades & $5,9 \%$ & $20,1 \%$ & $23,2 \%$ & $27,9 \%$ & $5,5 \%$ & $16,5 \%$ \\
\cline { 2 - 8 } & $\begin{array}{l}\text { Institutos } \\
\text { Profesionales }\end{array}$ & $-0,9 \%$ & $29,1 \%$ & $14,7 \%$ & $26,7 \%$ & $17,1 \%$ & $17,3 \%$ \\
\hline
\end{tabular}

Como se aprecia, el \% de variación promedio de la oferta de educación superior (IP + universidades) del país es de un $16,7 \%$ entre 1999 y 2004, porcentaje que aumenta levemente al considerar sólo los institutos profesionales (17,3\%). Entre los años 1999 y 2000 la variación es de un 3,5\%, mientras que entre 2000 y 2003 ésta sobrepasó el 20\%, para decaer nuevamente entre 2003 y 2004 con un 9,3\%. Este mismo patrón se observa en la oferta de las universidades, mientras que en los institutos profesionales la distribución es más pronunciada.

Si bien la tendencia a la expansión del sistema es clara, no se observa un incremento regular que pueda realmente resumirse en una tasa de variación promedio para todo el periodo. Sí se puede hipotetizar que la aceleración de crecimiento entre 2000 y 2003 parece estar asociada a la estrategia de expansión del sector privado autónomo. 
En términos de participación de los institutos profesionales y universidades en la oferta de educación superior del país, no se evidencian variaciones a lo largo de estos seis años, donde el \% de la oferta de las universidades es superior al de los institutos profesionales (aproximadamente 65\% v/s 35\%). Tal regularidad en la proporción de presencia en el mercado podría estar hablando de estrategias de expansión similares entre los dos tipos de instituciones, en este caso, del aprovechamiento de todas las señales de demanda disponible, siempre y cuando los proyectos se perciban como económicamente rentables.

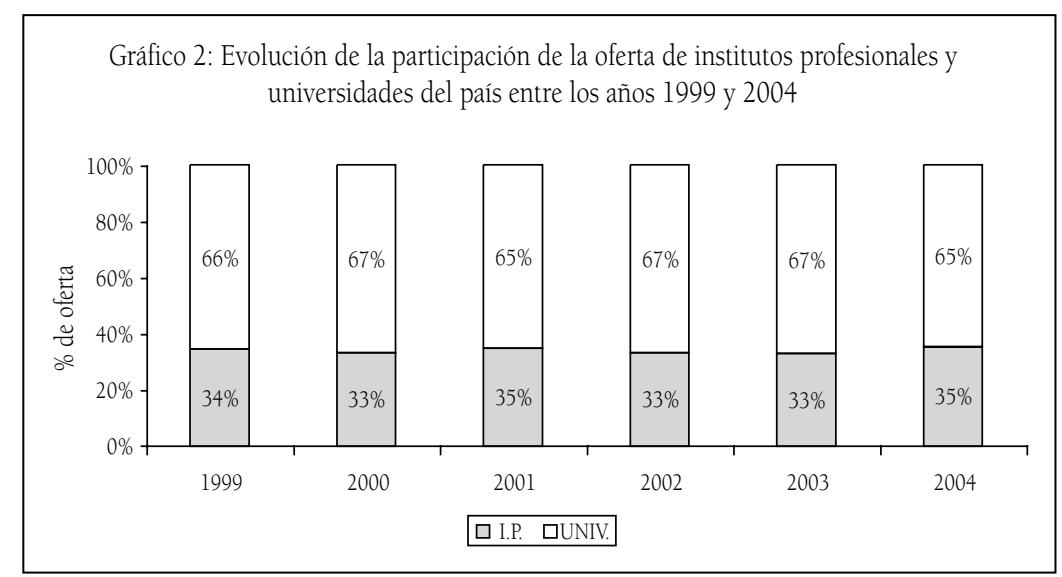

En este punto, vale la pena hacer un paréntesis para consignar que un eje adicional que se podría haber tomado en cuenta es el tipo de títulos que ofrecen los programas y su evolución diferencial de oferta según la clase de institución. Es de rigor recordar que las universidades entregan tanto el grado de licenciado como títulos profesionales y técnicos, mientras que los institutos profesionales sólo otorgan las últimas dos categorías de certificación. La tabla 2 facilita información sobre la distribución de la oferta según este criterio en los últimos tres años. 
Tabla 2. Porcentaje de la oferta según tipo de título

\begin{tabular}{|c|c|c|c|c|c|c|}
\cline { 2 - 7 } \multicolumn{1}{c|}{} & Bachillerato & Licenciatura & $\begin{array}{c}\text { Plan común y } \\
\text { ciclo básico }\end{array}$ & $\begin{array}{c}\text { Profesional con } \\
\text { licenciatura }\end{array}$ & Profesional & $\begin{array}{c}\text { Técnico } \\
\text { superior }\end{array}$ \\
\hline 2002 & $0,9 \%$ & $1,8 \%$ & $0,5 \%$ & $44,9 \%$ & $38,6 \%$ & $12,9 \%$ \\
\hline 2003 & $0,8 \%$ & $1,7 \%$ & $0,4 \%$ & $48,6 \%$ & $32,9 \%$ & $15,3 \%$ \\
\hline 2004 & $0,8 \%$ & $1,8 \%$ & $1,4 \%$ & $47,8 \%$ & $29,5 \%$ & $18,6 \%$ \\
\hline
\end{tabular}

De las tres categorías con participación significativa en la oferta, profesional con licenciatura, profesional y técnico de nivel superior (TNS), sólo las últimas dos pueden ser dictadas por IP, vale decir, cerca del $50 \%$ de la oferta es exclusivamente universitaria, mientras que el otro $50 \%$ se distribuye entre los dos tipos de instituciones. Lo anterior conlleva una ventaja para el sector universitario a la hora de ampliar y diversificar su oferta más allá de la entrega de grados académicos. Así, la distribución dentro del segmento profesional (sin licenciatura) es de un 30\% universidades y $70 \%$ institutos profesionales a lo largo de los últimos tres años. Al menos a simple vista, los IP han ganado terreno en la oferta de programas técnicos de nivel superior (48\% el 2002, 64\% el 2003 y $73 \%$ el 2004). No obstante, cabe preguntarse cuánto del retroceso de la oferta universitaria en este sentido tiene su origen en que algunas universidades han creado CFT donde "trasladar el nicho" de carreras técnicas. Finalmente, el avance relativo de los IP en oferta requiere un examen más exhaustivo de los cambios en la matrícula y en los aranceles 5 . Lamentablemente, el estudio de los tipos de título constituye una dimensión que quedará pendiente, por el momento, a la espera de una mayor acumulación de información o de cohortes donde aparezcan los datos pertinentes.

Tras este paréntesis, es necesario retomar la línea de exposición anterior. El gráfico 3 complementa lo ya dicho sobre la oferta de carreras en universidades e IP con los datos de la matrícula total en las carreras de ambas instituciones en conjunto.

5 Los datos de INDICES 2005 consignan un arancel promedio anual de $\$ 739.663$ en los CFT; \$ 857.713 en los IP y \$ 1.528.775 en las universidades. 
Gráfico 3. Evolución de la matrícula total y de las carreras impartidas por instituciones de educación superior entre los años 1999 y 2004

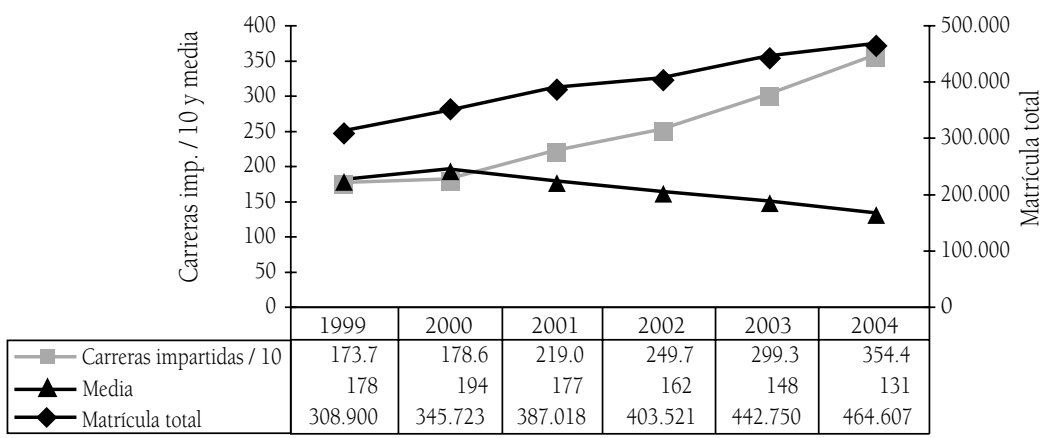

\begin{tabular}{|c|l|r|r|r|r|r|r|}
\cline { 2 - 8 } \multicolumn{2}{c|}{} & $1999-2000$ & $2000-2001$ & $2001-2002$ & $2002-2003$ & $2003-2004$ & Promedio \\
\hline \multirow{2}{*}{$\begin{array}{c}\% \text { de } \\
\text { Variación }\end{array}$} & Matr. & $11,9 \%$ & $11,9 \%$ & $4,3 \%$ & $9,7 \%$ & $4,9 \%$ & $8,6 \%$ \\
\cline { 2 - 8 } & Carrera & $2,8 \%$ & $22,6 \%$ & $14 \%$ & $19,9 \%$ & $18,4 \%$ & $15,5 \%$ \\
\hline
\end{tabular}

Si bien la matrícula total se eleva sostenidamente entre 1999 y 2004, el porcentaje de crecimiento de 2003-2004 es menor que el de $1999-2000$ (11,9 v/s 4,9\%), mientras que el porcentaje de crecimiento en el número de programas que reciben estudiantes ha aumentado de un 2,8\% en 1999-2000 a un 18,4\% en 2003-2004, lo que provoca que el promedio de alumnos por carrera disminuya a lo largo de estos años. Aparentemente, mientras la matrícula se desacelera, la oferta intensifica la magnitud de su incremento. Finalmente, de la observación de las diferencias entre los datos de los gráficos 1 y 3 se desprende que el promedio de variación en los últimos seis años es muy similar para la "oferta" de carreras para el año siguiente y las "carreras impartidas" durante el año indicado. Nuevamente, el crecimiento del sistema es irregular a lo largo del periodo.

Para entender mejor cómo se traduce lo que revela el gráfico anterior sobre matrícula, en cada uno de los dos tipos de instituciones estudiadas, es necesario revisar por separado su crecimiento desigual de matrícula total. El gráfico 4 muestra cómo, entre 2001 y 2003, la matrícula de las universidades se eleva con mayor intensidad que la de IP, aunque esta tendencia se revierte en 2004. 
Gráfico 4. Evolución de la matrícula total de universidades e institutos profesionales entre los años 1999 y 2004

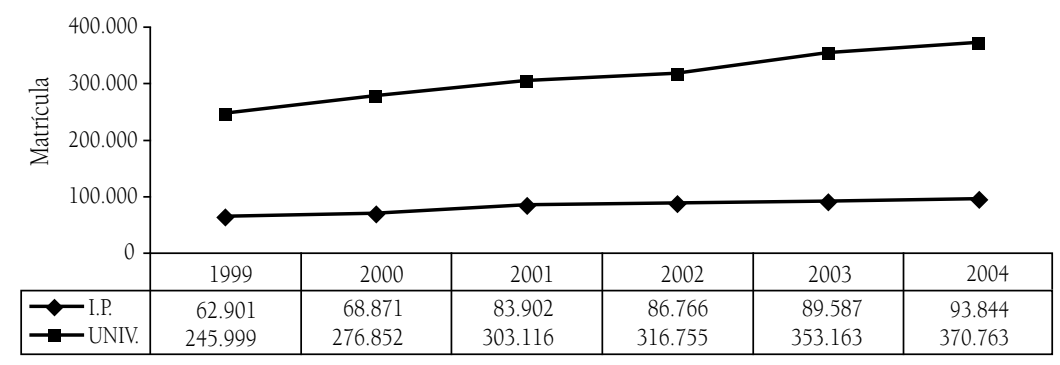

\begin{tabular}{|l|l|c|c|c|c|c|c|}
\cline { 2 - 8 } \multicolumn{1}{c|}{} & $\begin{array}{l}\text { Tipo de } \\
\text { institución }\end{array}$ & $1999-2000$ & $2000-2001$ & $2001-2002$ & $2002-2003$ & $2003-2004$ & Promedio \\
\hline \multirow{2}{*}{$\begin{array}{l}\text { \% de } \\
\text { Variación }\end{array}$} & $\begin{array}{l}\text { Institutos } \\
\text { Profesionales }\end{array}$ & $9,5 \%$ & $21,8 \%$ & $3,4 \%$ & $3,3 \%$ & $4,8 \%$ & $8,5 \%$ \\
\cline { 2 - 9 } & Universidades & $12,5 \%$ & $9,5 \%$ & $4,5 \%$ & $11,5 \%$ & $5,0 \%$ & $8,6 \%$ \\
\hline
\end{tabular}

Entre 2000 y 2001 se observa un aumento claro de participación en la matrícula total por parte de los IP, que se desacelera en los años siguientes. Por el contrario, las universidades elevan su porcentaje de matrícula entre 2002 y 2003. En 2004 ambos tipos de instituciones crecen a una tasa muy similar. Al margen de lo que se pueda comentar sobre las variaciones en el crecimiento absoluto de cada tipo de institución, el gráfico 5 muestra una distribución bastante estable de la participación en la matrícula total en los últimos seis años, con un claro predominio del sector universitario (80\%).

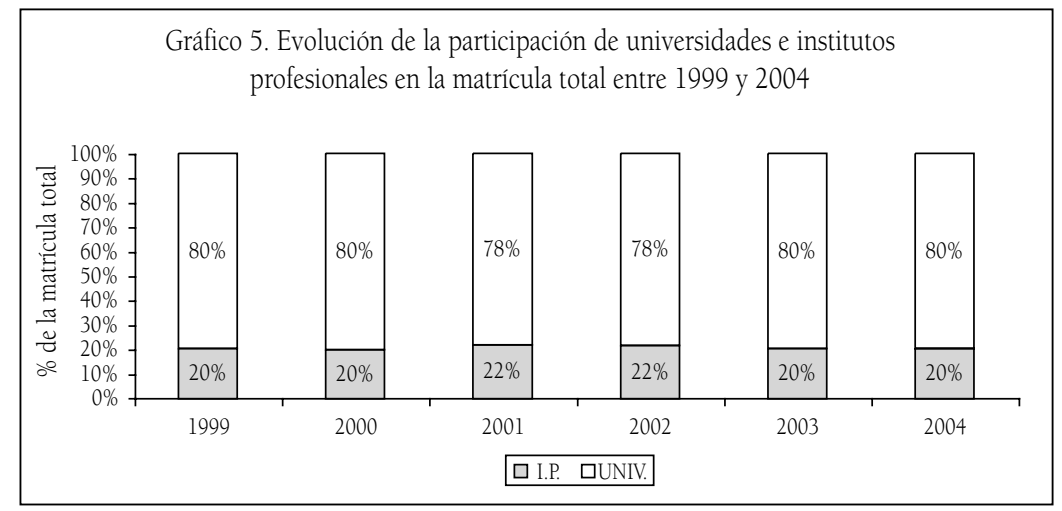


En términos generales, el comportamiento de los indicadores de la matrícula total en comparación con la de primer año es muy similar, sólo parece un poco más fluctuante en algunos casos debido a que la de primer año es obviamente menor a la total.

Gráfico 6. Evolución de la matrícula de $1^{\text {er }}$ año y de las carreras impartidas por instituciones de educación superior entre los años 1999 y 2004

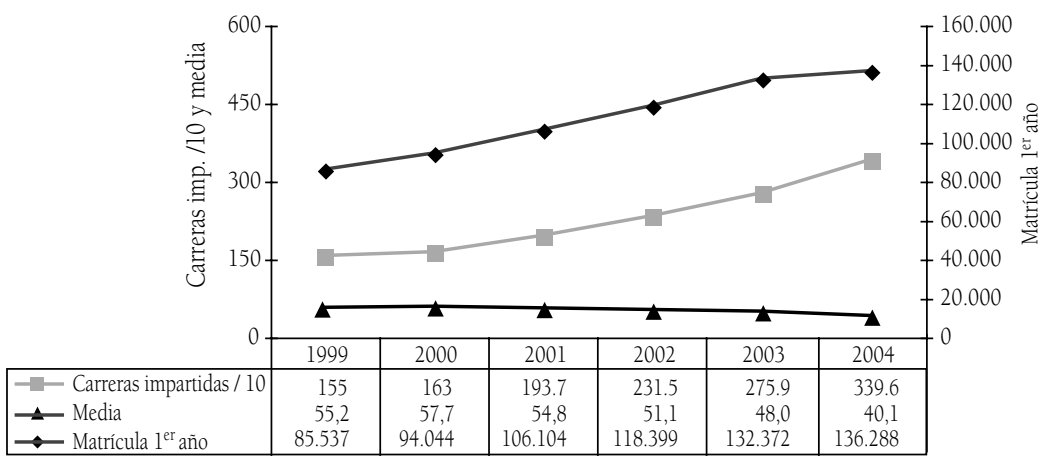

\begin{tabular}{|c|c|c|c|c|c|c|c|}
\cline { 3 - 8 } \multicolumn{2}{c|}{} & $1999-2000$ & $2000-2001$ & $2001-2002$ & $2002-2003$ & $2003-2004$ & Promedio \\
\hline \multirow{2}{*}{$\begin{array}{c}\text { \% de } \\
\text { Variación }\end{array}$} & Matr. 1 $^{\circ}$ & 9,9 & 12,8 & 11,6 & 11,8 & 3,0 & 9,8 \\
\cline { 2 - 8 } & Carreras & 5,2 & 18,8 & 19,5 & 19,2 & 23,1 & 17,2 \\
\hline
\end{tabular}

En la misma línea de lo que muestra el gráfico 5 sobre matrícula total para el conjunto de carreras (universidades e IP sumados), el gráfico 6 sobre matrícula de primer año reproduce las tendencias, sólo que éstas se acentúan producto del universo menor de casos al que refiere. La caída de la media de alumnos por carrera confirma que los porcentajes de incremento de programas son de magnitud superior a los de matrícula.

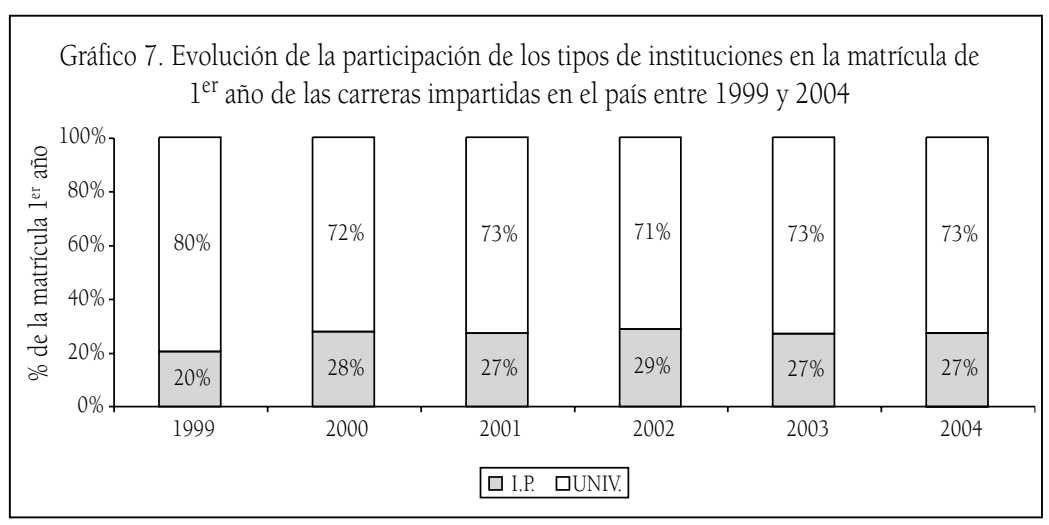


La participación de los IP en la matrícula de primer año del país es un poco mayor que en la total (cerca de un $27 \%$ v/s 20\%), pero con el mismo nivel de estabilidad a lo largo del tiempo. A su vez, esta distribución del porcentaje de matrícula se acerca más a la situación que exhibe la oferta de carreras, donde los IP tienen un 33\%.

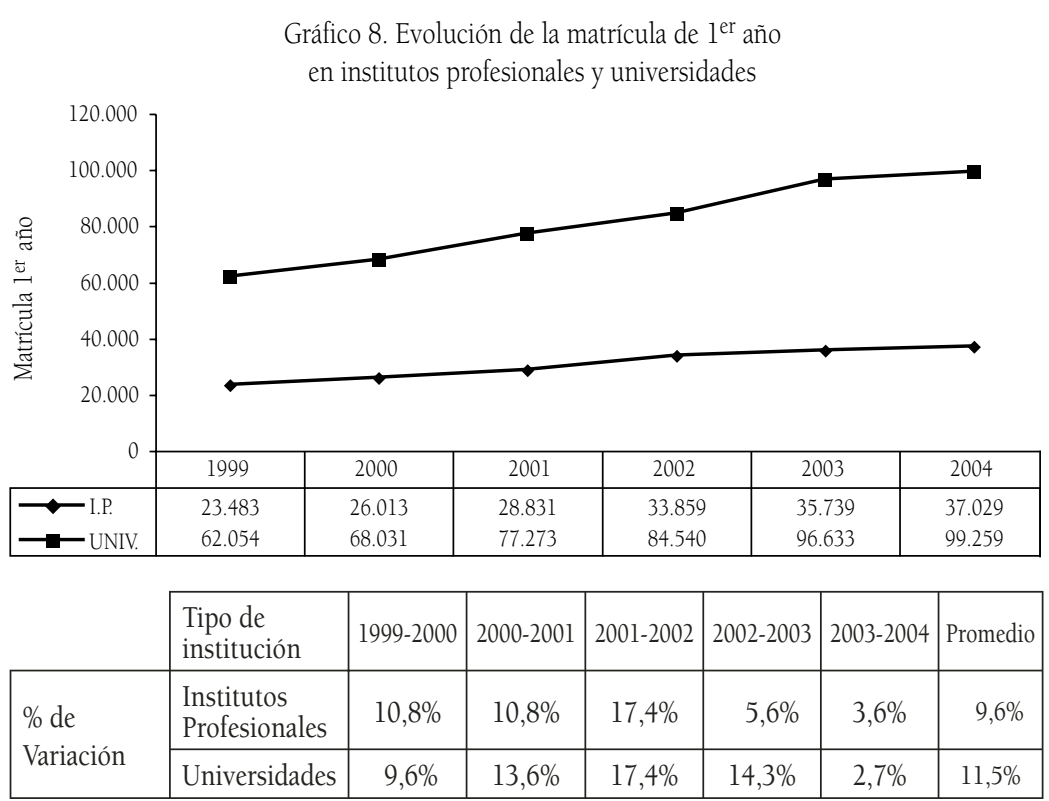

El punto de inflexión, o de mayor crecimiento, se observa entre 2001 y 2003, así como el 2004 constituye el punto de desaceleración más claro del periodo para el conjunto de carreras. Al comparar los gráficos 4 y 8 se aprecia que la tasa de crecimiento promedio de la matrícula total es menor que la de primer año, para ambos tipos de instituciones, sobre todo en el caso de las universidades ( 8,6 y $11,5 \%$, respectivamente).

Sin perjuicio de ello, se puede hablar de una similitud global en las tendencias que muestra la matrícula total y la de primer año en los gráficos. Las caracterizaciones posteriores, según área del conocimiento y región, se centrarán en la matrícula nueva en orden a cautelar la claridad del informe y en virtud de la sensibilidad que la matrícula de primer año parece tener respecto de las variaciones 
de la oferta, y de esta última en relación con la matrícula nueva. Una razón adicional para postergar, por ahora, el estudio acabado de la matrícula total, es que otros factores que este estudio no aborda podrían subyacer a la variación, por ejemplo, la diferente duración de las carreras y la tasa de deserción.

\section{Distribución regional de la oferta y la matrícula}

Los resultados antes presentados proporcionan una idea de la situación global, que debe complementarse con una mirada al desarrollo de los mismos procesos en mercados más acotados como el caso de las regiones. A través de esta revisión, es posible encontrar similitudes y particularidades que pueden orientar nuevas preguntas concernientes a las tendencias de expansión del sistema y las formas que adopta. La tabla 3 resume la distribución de la oferta de carreras por región y el porcentaje que cada una representa en todo el país.

Tabla 3 . Evolución de la distribución regional de la oferta entre los años 1999 y 2004

\begin{tabular}{|c|r|r|r|r|r|r|r|r|r|r|r|r|}
\hline \multirow{2}{*}{ Región } & \multicolumn{2}{|c|}{1999} & \multicolumn{2}{|c|}{2000} & \multicolumn{2}{|c|}{2001} & \multicolumn{2}{|c|}{2002} & \multicolumn{2}{|c|}{2003} & \multicolumn{2}{|c|}{2004} \\
\cline { 2 - 15 } & Frec. & $\%$ País & Frec. & \% País & Frec. & \% País & Frec. & $\%$ País & Frec. & $\%$ País & Frec. & $\%$ País \\
\hline I & 64 & $3,4 \%$ & 75 & $3,8 \%$ & 88 & $3,6 \%$ & 116 & $4,0 \%$ & 164 & $4,4 \%$ & 159 & $3,9 \%$ \\
\hline II & 103 & $5,4 \%$ & 97 & $4,9 \%$ & 118 & $4,9 \%$ & 115 & $3,9 \%$ & 198 & $5,3 \%$ & 202 & $5,0 \%$ \\
\hline III & 23 & $1,2 \%$ & 27 & $1,4 \%$ & 34 & $1,4 \%$ & 35 & $1,2 \%$ & 40 & $1,1 \%$ & 39 & $1,0 \%$ \\
\hline IV & 94 & $4,9 \%$ & 95 & $4,8 \%$ & 100 & $4,1 \%$ & 147 & $5,0 \%$ & 179 & $4,8 \%$ & 171 & $4,2 \%$ \\
\hline V & 315 & $16,6 \%$ & 289 & $14,7 \%$ & 338 & $13,9 \%$ & 444 & $15,2 \%$ & 503 & $13,5 \%$ & 569 & $14,0 \%$ \\
\hline VI & 21 & $1,1 \%$ & 19 & $1,0 \%$ & 21 & $0,9 \%$ & 18 & $0,6 \%$ & 67 & $1,8 \%$ & 79 & $1,9 \%$ \\
\hline VII & 49 & $2,6 \%$ & 55 & $2,8 \%$ & 77 & $3,2 \%$ & 74 & $2,5 \%$ & 188 & $5,1 \%$ & 186 & $4,6 \%$ \\
\hline VIII & 235 & $12,3 \%$ & 252 & $12,8 \%$ & 310 & $12,8 \%$ & 359 & $12,3 \%$ & 489 & $13,2 \%$ & 562 & $13,8 \%$ \\
\hline IX & 78 & $4,1 \%$ & 93 & $4,7 \%$ & 127 & $5,2 \%$ & 136 & $4,7 \%$ & 163 & $4,4 \%$ & 164 & $4,0 \%$ \\
\hline X & 77 & $4,0 \%$ & 83 & $4,2 \%$ & 97 & $4,0 \%$ & 133 & $4,6 \%$ & 183 & $4,9 \%$ & 239 & $5,9 \%$ \\
\hline XI & 7 & $0,4 \%$ & 7 & $0,4 \%$ & 8 & $0,3 \%$ & 9 & $0,3 \%$ & 8 & $0,2 \%$ & 2 & $0,0 \%$ \\
\hline XII & 24 & $1,3 \%$ & 26 & $1,3 \%$ & 51 & $2,1 \%$ & 51 & $1,8 \%$ & 71 & $1,9 \%$ & 74 & $1,8 \%$ \\
\hline RM & 813 & $42,7 \%$ & 852 & $43,2 \%$ & 1.055 & $43,5 \%$ & 1.277 & $43,8 \%$ & 1.462 & $39,4 \%$ & 1.614 & $39,8 \%$ \\
\hline Total & 1.903 & $100,0 \%$ & 1.970 & $100,0 \%$ & 2.424 & $100,0 \%$ & 2.914 & $100,0 \%$ & 3.715 & $100,0 \%$ & 4.060 & $100,0 \%$ \\
\hline
\end{tabular}

Fuente: CSE 2000-2005 
Un poco menos de la mitad de la oferta educativa se encuentra en la Región Metropolitana (RM) (39,8\%), seguida por la VIII y V regiones con una participación en torno al 15\%. Las regiones II, IV, VII, IX y X tienen cerca de un 5\% de la oferta, mientras que las regiones III, VI, XI y XII sólo participan en aproximadamente un 1\% del total de la oferta de educación superior.

La evolución de la oferta parece estar en sintonía con la distribución demográfica del país ${ }^{6}$, con la evidente excepción de la VI Región, donde la cobertura ha sido siempre muy baja en relación con la cantidad de habitantes (780.627), debido, presumiblemente, a la cercanía con la RM y su amplia gama de alternativas académicas. Al examinar con detención la tabla 3 se observa que, con excepción de los años 2001 y 2002, la II Región (493.984 hab.) ofrece más carreras que otras de mayor tamaño como la IX (869.536 hab.). A su vez, la VII Región destaca por el alza de su participación en la oferta, desde un $2,6 \%$ en 1999 a un $5,1 \%$ en 2003 . Similar es el caso de la X, que sube del 4\% en 1999 a un 5,9\% en 2004.

Ahora bien, para tener una idea de las transformaciones por regiones, es necesario consultar la tabla 4, que resume frecuencias y porcentajes de participación en la matrícula de primer año. Ésta muestra que la captación se eleva en casi todas las regiones y que el porcentaje de participación en la matrícula nueva del país se mantiene estable durante estos últimos seis años, en términos generales. En otras palabras, el sistema crece sin que con ello se transforme substantivamente la distribución porcentual de matrícula entre regiones. En la RM se concentra casi la mitad de los estudiantes de carreras de pregrado, seguido por las regiones V y VIII con cerca de un 15 y 13\% respectivamente, mientras que en el resto de las regiones no se supera el $4 \%$. Como se ha comentado, la evolución de los porcentajes de participación en los últimos seis años no revela cambios significativos, excepto en el caso de la V Región, que subió dos puntos porcentuales desde 1999, todo lo contrario de la disminución que revelan los datos de oferta para la misma región.

6 Los datos demográficos a los que se alude en esta sección provienen del Censo 2002. 
Tabla 4. Evolución de la distribución regional de la matrícula de $1^{\text {er }}$ año entre 1999 y 2004

\begin{tabular}{|c|r|r|r|r|r|r|r|r|r|r|r|r|}
\hline \multirow{2}{*}{ Región } & \multicolumn{2}{|c|}{1990} & \multicolumn{2}{|c|}{2000} & \multicolumn{2}{|c|}{2001} & \multicolumn{2}{|c|}{2002} & \multicolumn{2}{|c|}{2003} & \multicolumn{2}{|c|}{2004} \\
\cline { 2 - 14 } & Frec. & $\%$ País & Frec. & $\%$ País & Frec. & $\%$ País & Frec. & $\%$ País & Frec. & $\%$ País & Frec. & $\%$ País \\
\hline I & 3.054 & $4 \%$ & 3.195 & $3 \%$ & 4.113 & $4 \%$ & 4.005 & $3 \%$ & 4.112 & $3 \%$ & 4.571 & $3 \%$ \\
\hline II & 4.146 & $5 \%$ & 4.243 & $5 \%$ & 3.936 & $4 \%$ & 4.325 & $4 \%$ & 5.459 & $4 \%$ & 4.949 & $4 \%$ \\
\hline III & 580 & $1 \%$ & 1.016 & $1 \%$ & 1.079 & $1 \%$ & 879 & $1 \%$ & 778 & $1 \%$ & 1.187 & $1 \%$ \\
\hline IV & 3.380 & $4 \%$ & 3.330 & $4 \%$ & 3.137 & $3 \%$ & 3.667 & $3 \%$ & 4.875 & $4 \%$ & 4.333 & $3 \%$ \\
\hline V & 11.297 & $13 \%$ & 11.101 & $12 \%$ & 13.975 & $13 \%$ & 17.066 & $14 \%$ & 19.272 & $15 \%$ & 20.168 & $15 \%$ \\
\hline VI & 457 & $1 \%$ & 842 & $1 \%$ & 695 & $1 \%$ & 503 & $0 \%$ & 1.600 & $1 \%$ & 1.766 & $1 \%$ \\
\hline VII & 2.473 & $3 \%$ & 2.498 & $3 \%$ & 2.636 & $2 \%$ & 2.118 & $2 \%$ & 4.018 & $3 \%$ & 4.766 & $3 \%$ \\
\hline VIII & 10.377 & $12 \%$ & 11.749 & $12 \%$ & 12.306 & $12 \%$ & 15.272 & $13 \%$ & 18.274 & $14 \%$ & 17.400 & $13 \%$ \\
\hline IX & 4.094 & $5 \%$ & 4.472 & $5 \%$ & 5.524 & $5 \%$ & 5.156 & $4 \%$ & 4.463 & $3 \%$ & 5.247 & $4 \%$ \\
\hline X & 3.362 & $4 \%$ & 3.624 & $4 \%$ & 3.698 & $3 \%$ & 4.612 & $4 \%$ & 5.168 & $4 \%$ & 5.601 & $4 \%$ \\
\hline XI & 327 & $0 \%$ & 206 & $0 \%$ & 275 & $0 \%$ & 95 & $0 \%$ & 138 & $0 \%$ & 44 & $0 \%$ \\
\hline XII & 579 & $1 \%$ & 636 & $1 \%$ & 1.070 & $1 \%$ & 1.286 & $1 \%$ & 1.355 & $1 \%$ & 2.122 & $2 \%$ \\
\hline RM & 41.411 & $48 \%$ & 47.132 & $50 \%$ & 53.660 & $51 \%$ & 59.415 & $50 \%$ & 62.860 & $47 \%$ & 64.134 & $47 \%$ \\
\hline Total & 85.537 & $100 \%$ & 94.044 & $100 \%$ & 106.104 & $100 \%$ & 118.399 & $100 \%$ & 132.372 & $100 \%$ & 136.288 & $100 \%$ \\
\hline
\end{tabular}

Fuente: CSE 2000-2005

De la tabla 3 se desprende que las instituciones instaladas en la VII y X regiones parecen estar apostando por elevar su oferta de carreras. De acuerdo con los elementos que sugiere la tabla 4 , parece que dicha decisión encuentra asidero en la respuesta positiva de los estudiantes, incluso cuando la proporción de la región en la matrícula total no ha variado significativamente en el periodo estudiado. Los incrementos absolutos son, en general, irregulares, pero se observa que en la V, VIII y X regiones se producen alzas más marcadas de matrícula a partir de 2002, mientras que en la II, IV y VII ello ocurre un año después (2003). La única región que, por el contrario, disminuye su matrícula en este punto es la IX, lo que llama la atención si, además, se compara su participación en la matrícula total con regiones menos pobladas como la II. En 2003, la RM comienza a desacelerar la expansión que venía experimentando, llegando incluso a bajar su peso relativo en la captación de estudiantes en todo el país. 


\section{Comentarios conclusivos sobre la primera sección}

La evolución del sistema, desde el punto de vista de la oferta, muestra crecimiento sostenido y muy fuerte entre 2000 y 2003, tras lo cual sobreviene, en 2004, una desaceleración aguda del sector universitario y una mucho menos marcada de los IP. De todos modos, el peso relativo en la oferta de programas de estos dos grupos de instituciones (que representan el $75 \%$ de la oferta nacional) se mantiene relativamente estable, en $65 \%$ para las universidades y $35 \%$ para los IP.

Los datos sobre evolución del número de carreras impartidas, en relación con la matrícula total y de primer año, confirman que de 2003 a 2004 se produjo una caída en la cantidad de estudiantes que se incorporaron al sistema, y que esta situación no fue prevista por las instituciones de educación superior, a juzgar por la cantidad de carreras impartidas ese año. Si consideramos lo que ocurre con la oferta del año siguiente, pareciera que las universidades reaccionan a esta disminución de matrícula reduciendo su oferta de carreras en mayor medida que los IP. Cabe preguntarse, entonces, cuál es la capacidad de los distintos tipos de instituciones para ajustarse a las variaciones del mercado o cuál es su margen de maniobra para "sostener la oferta" en espera de un repunte de matrícula.

La distribución de oferta y matrícula regional es relativamente proporcional a los tamaños de sus poblaciones, excepto en el caso de la VI Región. En el sentido contrario, llama la atención la mayor oferta de la II en comparación con una región más densa como la IX. En términos gruesos, aparece que los incrementos de matrícula más agudos se producen primero en las regiones grandes (RM en 2001, V y VIII en 2002) y al año siguiente en otras regiones con menos habitantes pero con una sistema universitario consolidado (II, IV y VII).

Las regiones Metropolitana, V, IX y XII experimentan un alza de estudiantes matriculados pero, lo que más destaca, es el crecimiento agudo de oferta en la VII y, en menor grado, en la V 
a partir de 2003. Esta apuesta obtiene una respuesta positiva en términos de matrícula el año 2004, aunque es difícil saber cuánto se proyectará ese crecimiento armónico. Al menos en el caso de la II, IV y VIII regiones el alza de oferta hasta 2003 no fue seguido de un alza de matrícula.

\section{Oferta y matrícula en cada región según tipo de institución}

Esta sección revisa integralmente cada mercado regional, de manera que la evolución de la oferta y la matrícula puedan apreciarse en relación. Si bien el primer capítulo adelanta algunos elementos sobre la participación de cada región en el crecimiento del sistema, es pertinente poner a disposición del público la información y gráficos que ilustran los desarrollos particulares de cada unidad administrativa, dado que no siempre la impresión que resulta de los datos agregados es representativa del acontecer regional.

En 2003 se observa un peak de 128 en la oferta de universidades de la I Región, cantidad que durante 2004 disminuye a 118. La oferta de institutos profesionales crece levemente. Durante estos seis años, la participación de las universidades en la oferta de la región ha ido aumentando, mientras que la de los IP ha ido disminuyendo.

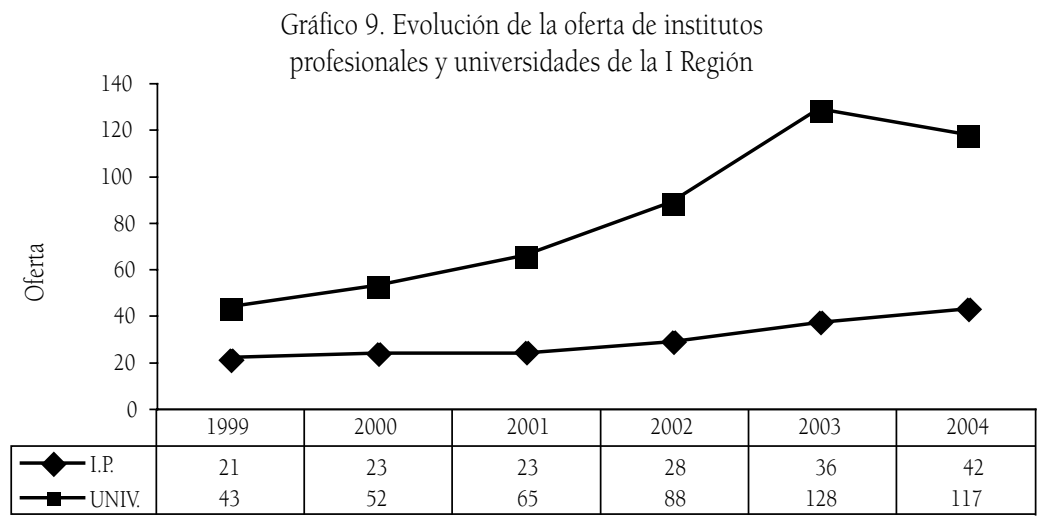




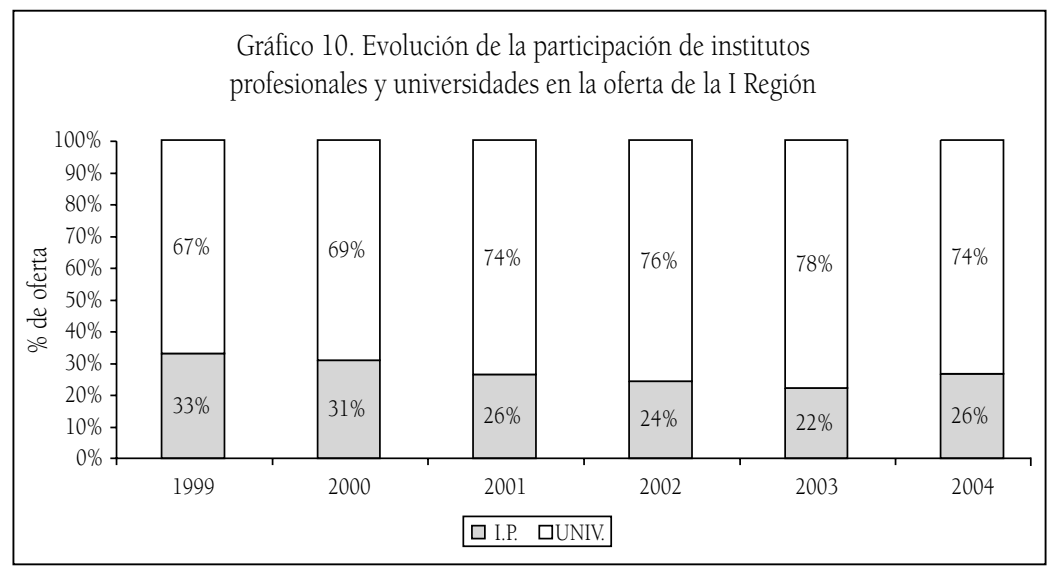

En la I Región se observa un aumento sostenido en el número de carreras impartidas y el estancamiento de la matrícula desde 2001, por lo que la media de estudiantes por carrera disminuye a partir del mismo año. En términos de participación en la matrícula según tipo de institución, las universidades ocupan el mayor espacio y, más aún, han ido aumentando levemente, haciendo que la participación de los IP en la matrícula de las carreras impartidas descienda desde un 22\% en 2000 a un 12\% en 2004.

Gráfico 11. Evolución de la matrícula de $1^{\text {er }}$ año y de las carreras impartidas por instituciones de educación superior entre los años 1999 y 2004 en la I Región

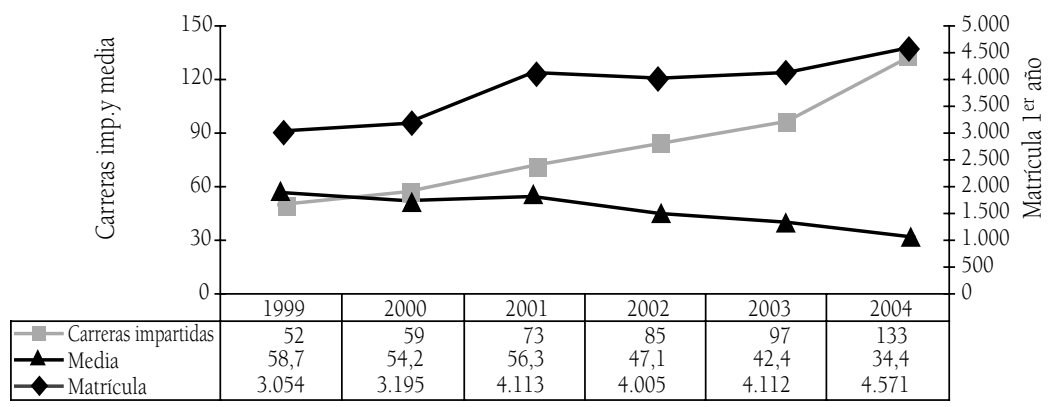




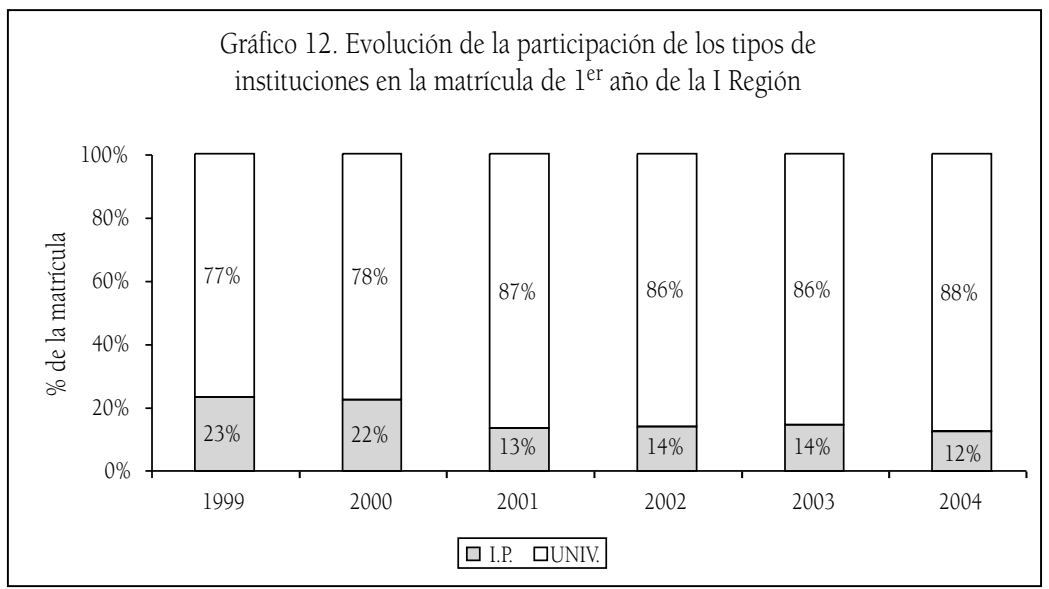

Del mismo modo que en la I Región, en 2003 se observa un peak en la oferta universitaria de la II Región, llegando a 137 programas en 2003 y disminuyendo a 118 en 2004. La oferta que proviene de institutos profesionales se mantiene entre los años 1999 y 2002 y comienza a crecer con un porcentaje de variación de un 65\% entre los años 2002 y 2003, y un 38\% entre 2003 y 2004.

Gráfico 13.Evolución de la oferta de institutos profesionales y universidades de la II Región

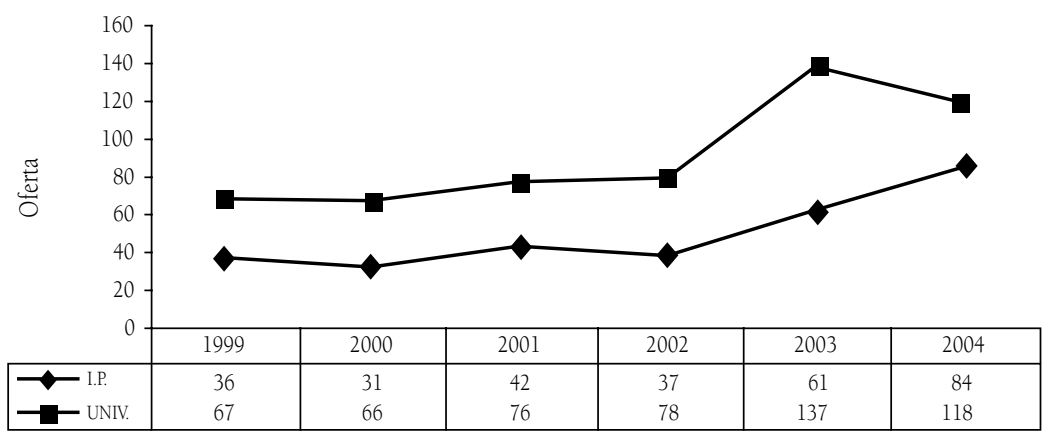




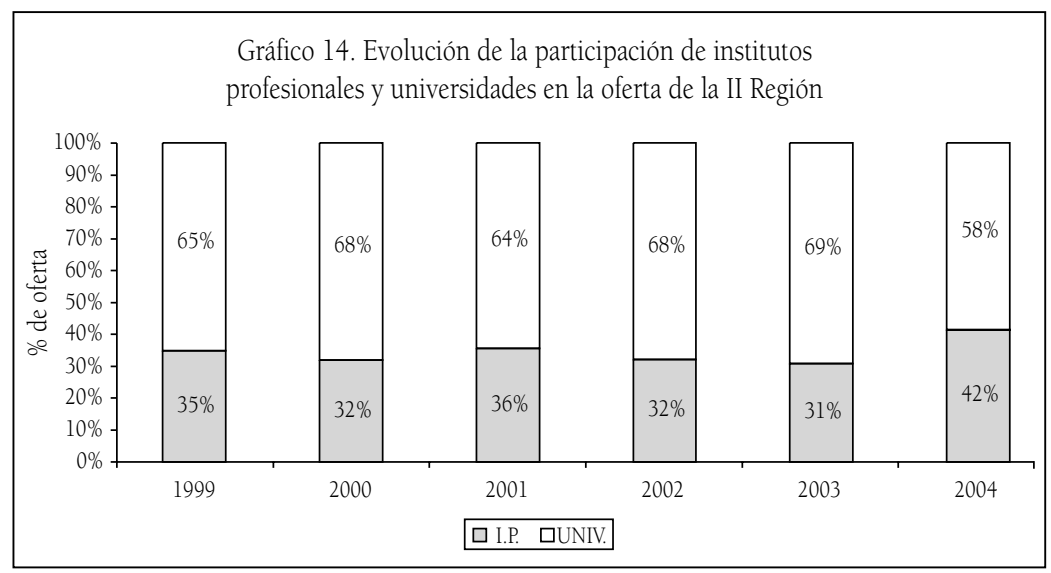

Para el conjunto de carreras impartidas en la II Región, se observa que en 2003 se produce un alza en el número de carreras impartidas y de matrícula; sin embargo, esta última no se sostiene en 2004. La participación de los IP en la matrícula total se ha mantenido en el tiempo con cerca de un $30 \%$.

Gráfico 15. Evolución de la matrícula de $1^{\text {er }}$ año y de las carreras impartidas por instituciones de educación superior entre los años 1999 y 2004 en la II Región

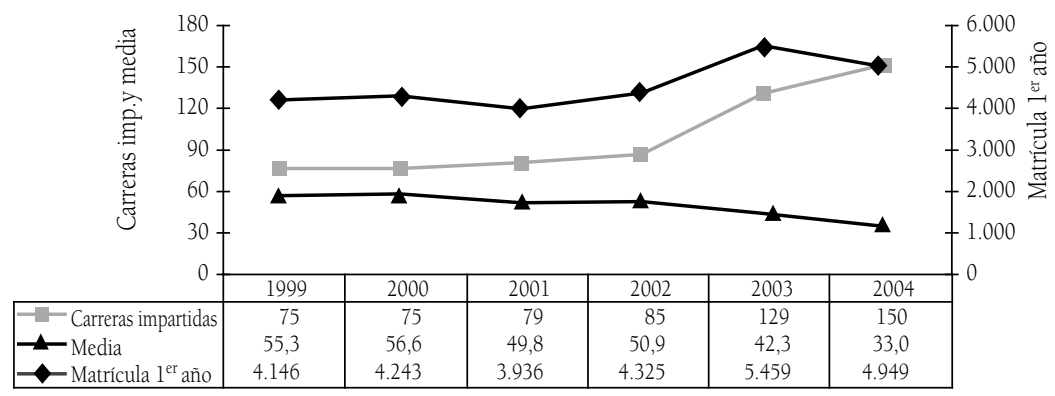


Gráfico 16. Evolución de la participación de los tipos de instituciones en la matrícula de las carreras impartidas en la II Región entre los años 1999 y 2004

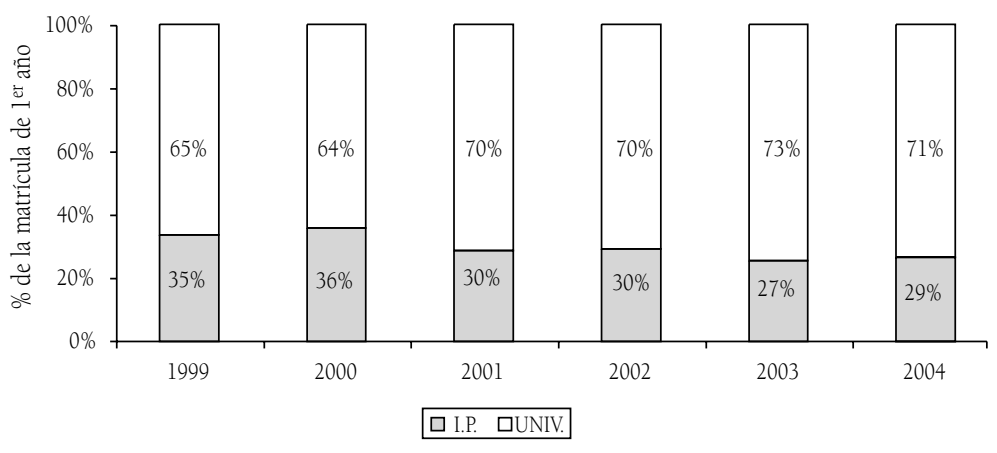

La III Región es una de las con menos participación en el país. Se observa un peak de la oferta de universidades en 2003 y un aumento menos pronunciado de la oferta de los institutos profesionales. La participación de las universidades en la oferta oscila entre un 63 y un $74 \%$.

Gráfico 17. Evolución de la oferta de institutos profesionales y universidades de la III Región

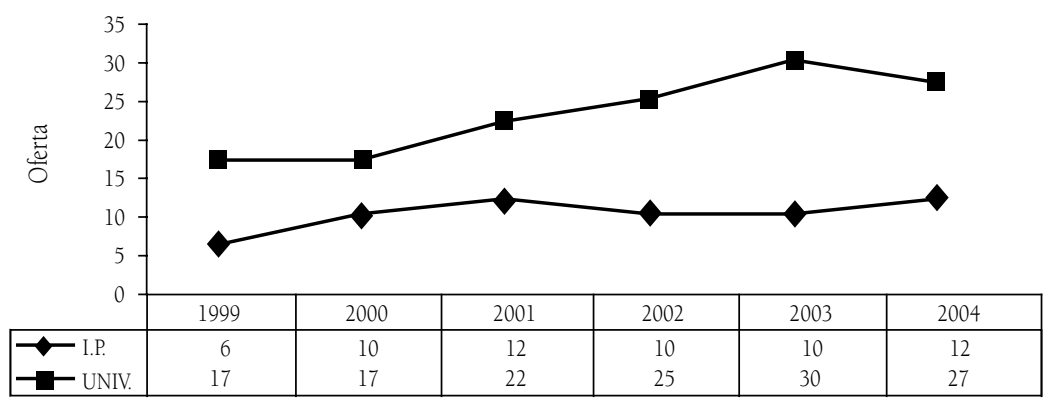




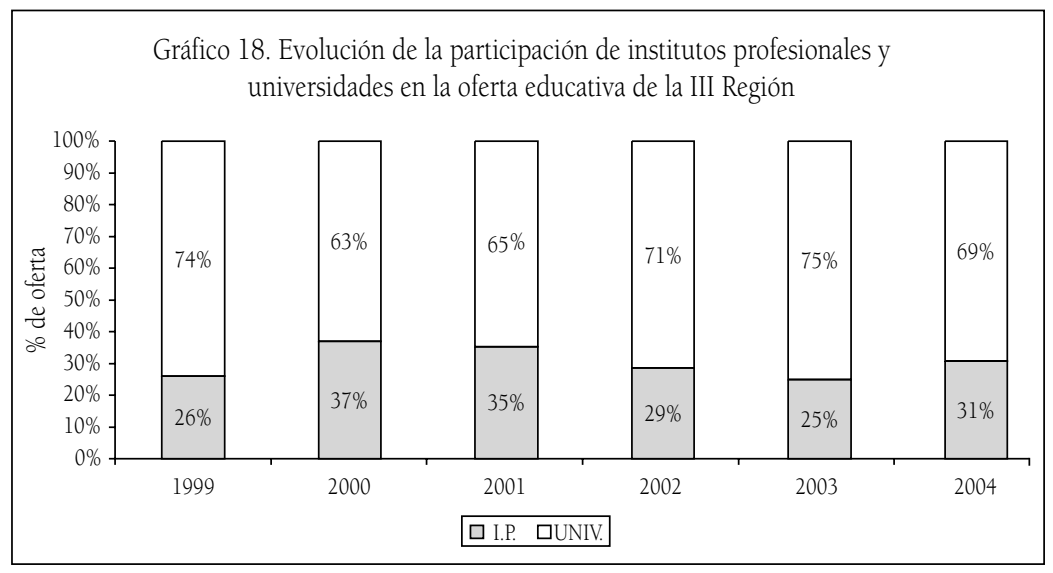

Se observa que en la III Región, entre 1999 y 2001, la tasa de crecimiento de la matrícula es mayor a la de las carreras impartidas. A partir de 2002 ésta tiende a bajar mientras que el número de carreras impartidas sube levemente, produciendo una baja en la media de alumnos por programa. La participación de los IP v/s la de universidades en la matrícula fluctúa en el tiempo, aunque el cambio más drástico se produce en 2003, cuando la participación de instituciones universitarias baja al 51\% para luego volver a subir a cerca del $70 \%$, en perjuicio de los IP que aun así elevan su oferta en 2004, como lo muestran los gráficos 17 y 18.

Gráfico 19. Evolución de la matrícula de $1^{\text {er }}$ año y de las carreras impartidas por instituciones de educación superior entre los años 1999 y 2004 en la III Región

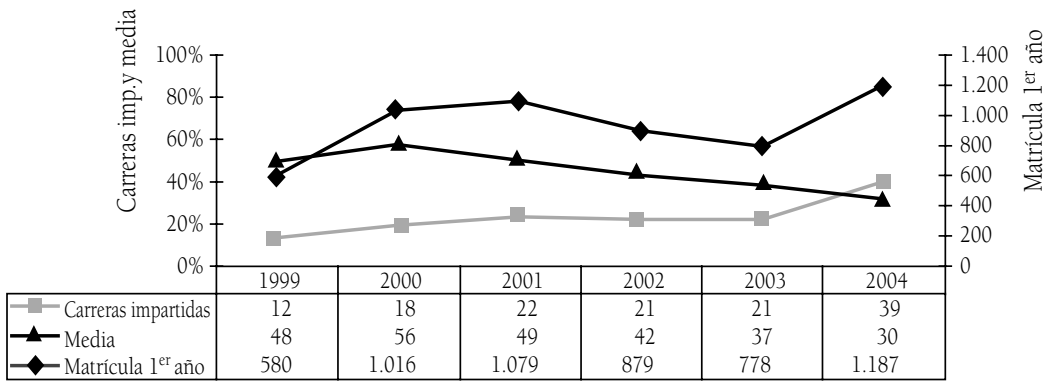




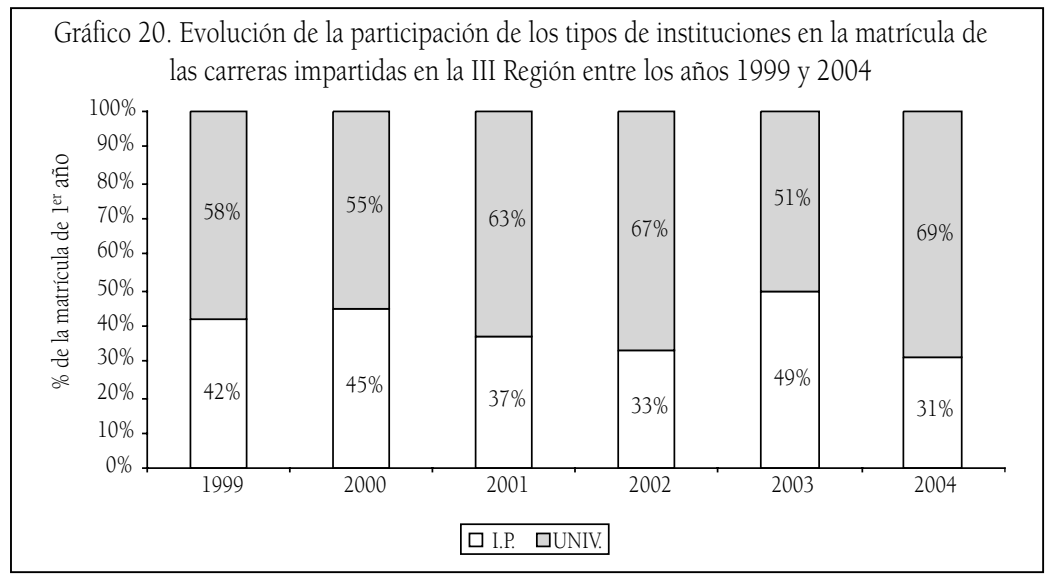

La oferta de la IV Región se mantiene muy estable entre 1999 y 2001, pero aumenta notablemente desde entonces. La tasa de crecimiento de la oferta proveniente de IP varía desde un $2 \%$, en 2000, a un 28\%, entre 2001 y 2002, mientras las universidades pasan de una tasa de crecimiento nula en 2000 a una de $61 \%$ durante los años posteriores. El crecimiento se estanca en 2004. La proporción de participación de las universidades en la oferta ha ido aumentando progresivamente durante los años, desde 56 a $68 \%$, quitándoles participación relativa a los IP.

Gráfico 21. Evolución de la oferta de institutos profesionales y universidades de la IV Región

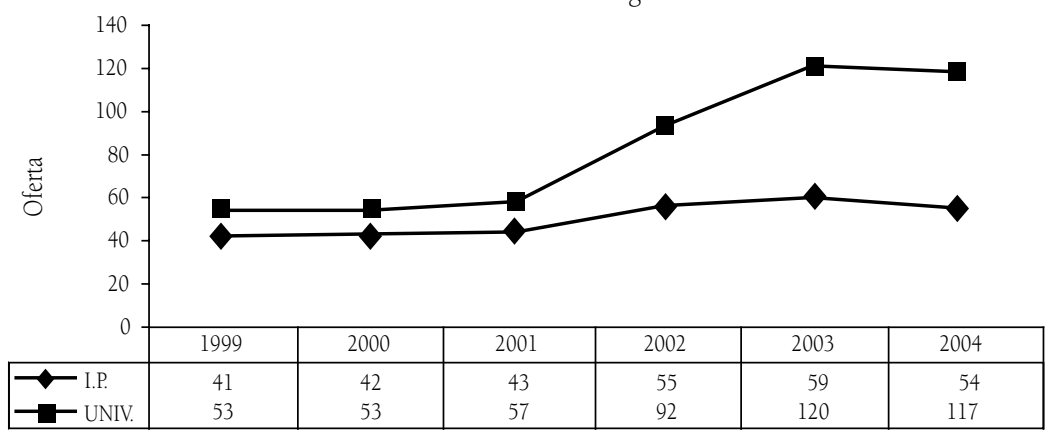




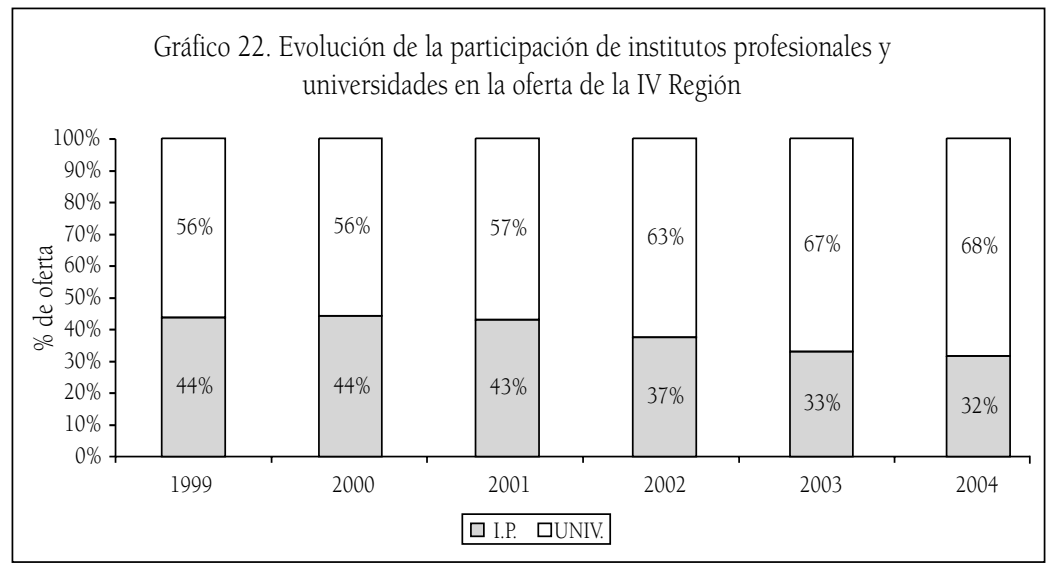

En la IV Región, la matrícula y el número de carreras impartidas tienen un crecimiento parecido a lo largo del tiempo hasta que en 2004 las carreras impartidas continuaron en aumento sin que ello se reflejara en más estudiantes matriculados, lo que provocó la disminución del promedio de estudiantes por carrera. La participación relativa de las universidades en la matrícula ha subido en el periodo, exceptuando el año 2002. Lo anterior implica que los IP captan un porcentaje menor de la matrícula en comparación con su participación en la oferta, si bien ésta también va disminuyendo tal y como indica el gráfico 22.

Gráfico 23. Evolución de la matrícula de $1^{\text {er }}$ año y de las carreras impartidas por instituciones de educación superior entre los años 1999 y 2004 en la IV Región

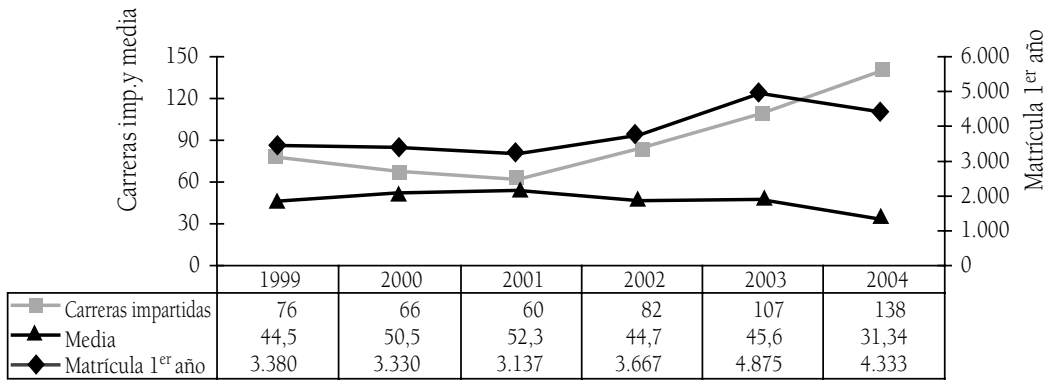




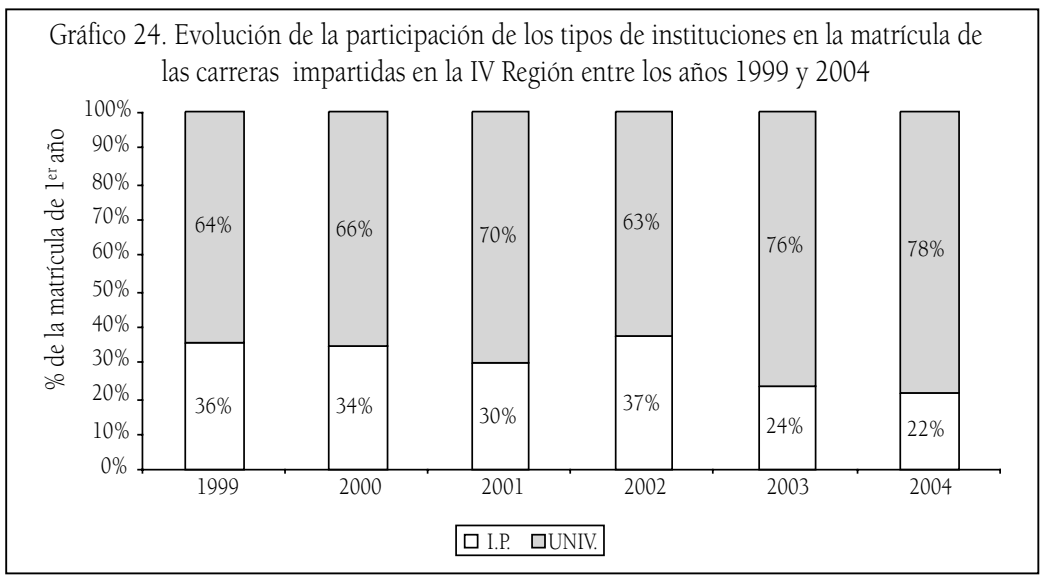

En la V Región, las universidades acaparan el mayor porcentaje de participación en la oferta (75\%), sobrepasando en $10 \%$ la participación nacional de las universidades (65\%). La tasa de variación de la oferta de universidades e IP ha ido incrementándose a un ritmo promedio de 13 y $16 \%$ respectivamente.

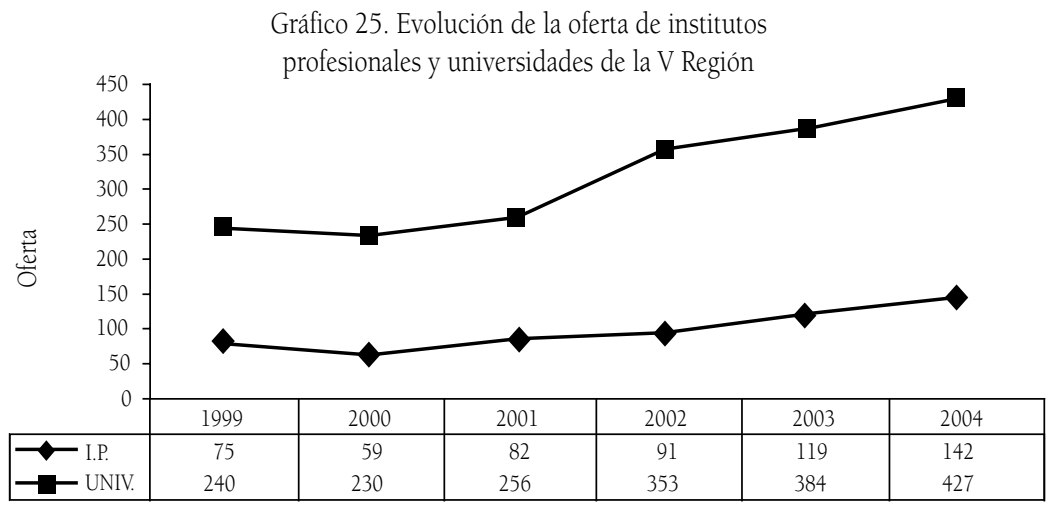




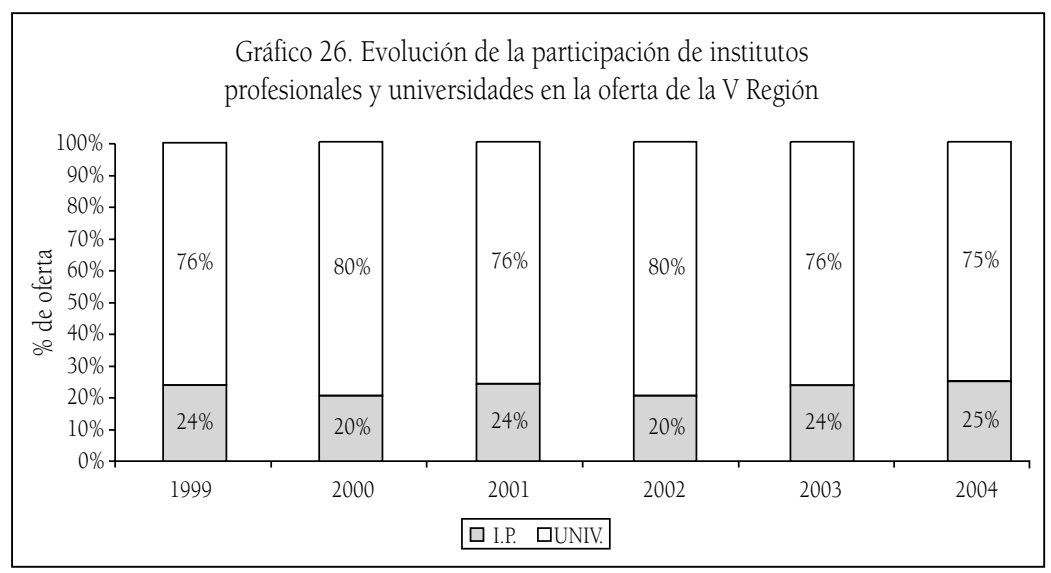

Del mismo modo que en la IV Región, en la V la matrícula y las carreras impartidas parecen crecer de modo sintónico a lo largo del tiempo, aunque el incremento de matrícula parece detenerse hacia el 2004. La distribución de la participación en la matrícula, según tipo de institución, es estable con un $80 \%$ aproximado de estudiantes en universidades y un $20 \%$ en IP.

Gráfico 27. Evolución de la matrícula de 1er año y de las carreras impartidas por instituciones de educación superior entre los años 1999 y 2004 en la V Región

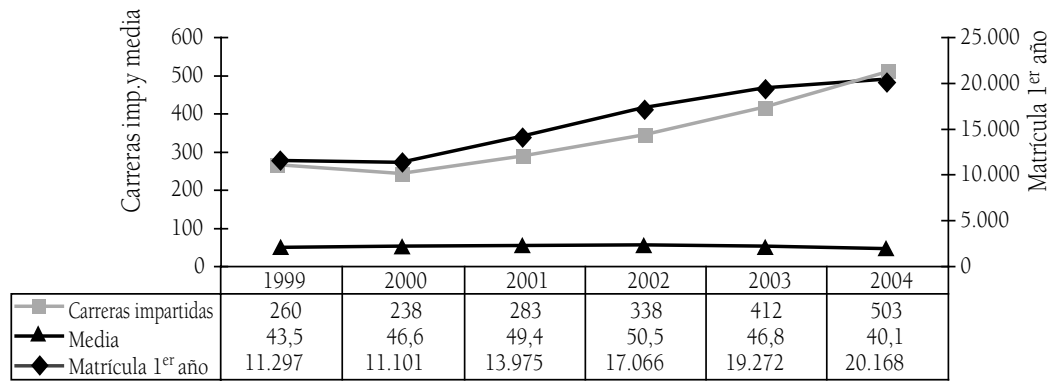




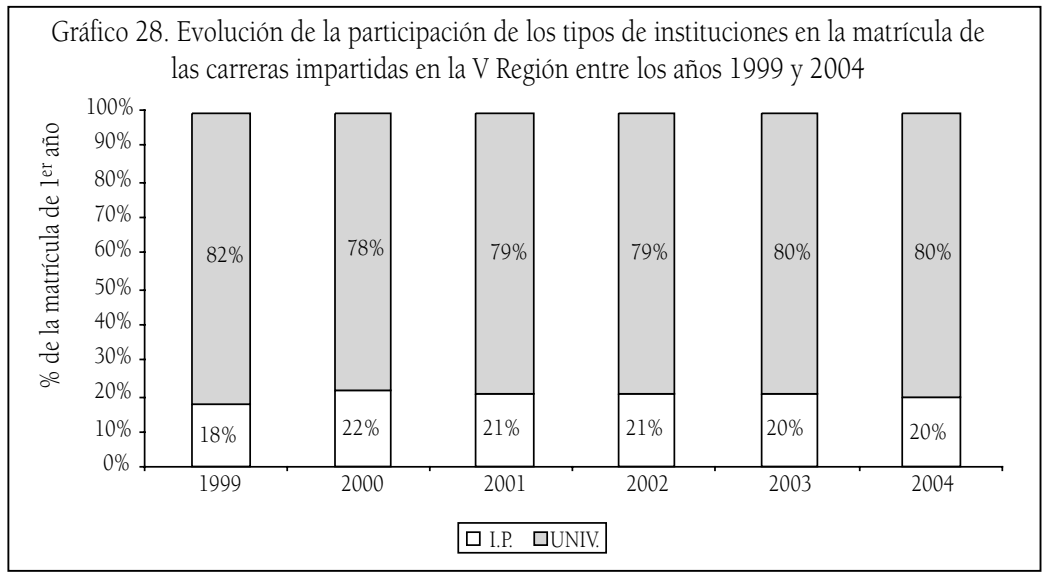

La oferta de la VI Región se mantuvo estable entre 1999 y 2002 y se expandió abruptamente desde 2003, manteniendo un crecimiento menos acentuado en 2004. En esta región, la distribución de la participación en la oferta, según el tipo de centros de educación superior, es a la inversa que en las otras, donde los IP ocupan el $76 \%$ de la oferta total de la región, dejando sólo un $26 \%$ a las universidades.

Gráfico 29. Evolución de la oferta de institutos profesionales y universidades de la VI Región

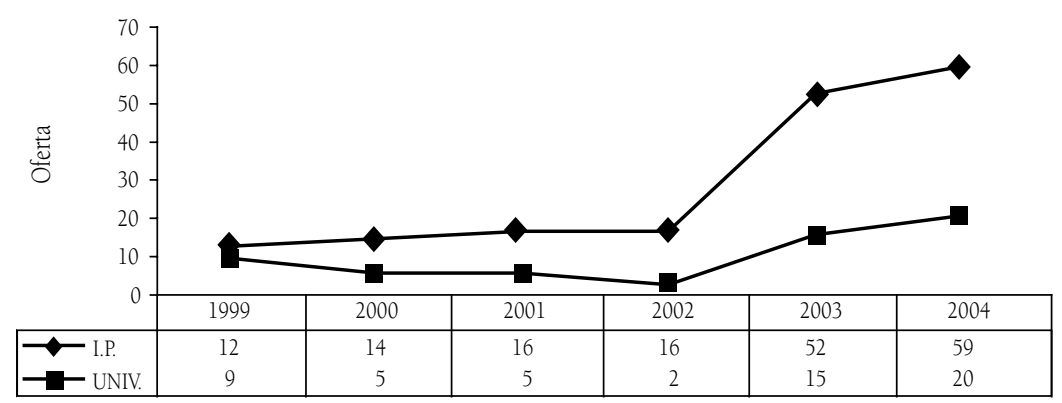




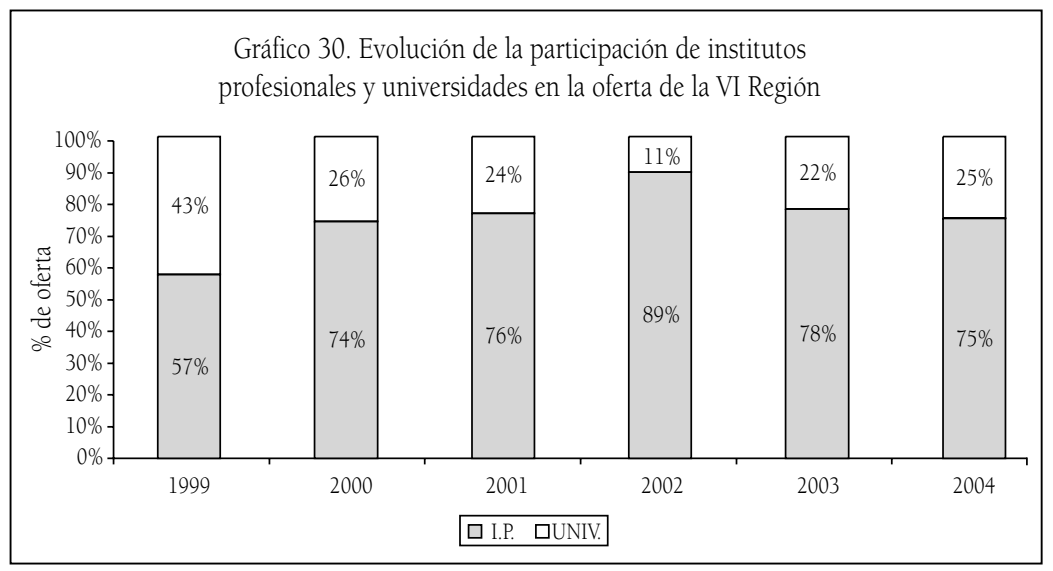

Hasta 2002, el porcentaje de crecimiento de la matrícula y de las carreras impartidas era muy similar; sin embargo, en 2003 se produce un quiebre aumentando en un $67 \%$ la matrícula y en un $400 \%$ las carreras impartidas, lo que se traduce en una gran disminución en el promedio de estudiantes por carrera. Al igual que con la oferta, en la VI Región existe un mayor porcentaje de estudiantes matriculados en institutos profesionales que en universidades.

Gráfico 31. Evolución de la matrícula de $1^{\text {er }}$ año y de las carreras impartidas por instituciones de educación superior entre los años 1999 y 2004 en la VI Región

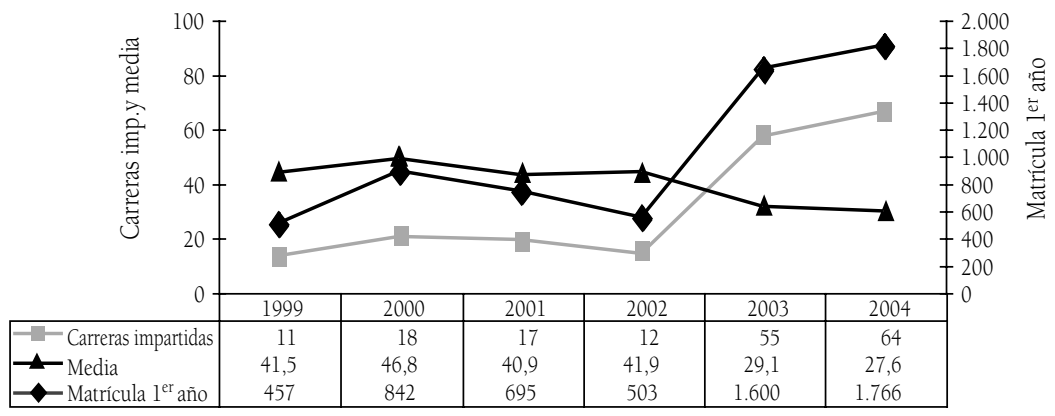


Gráfico 32. Evolución de la participación de los tipos de instituciones en la matrícula de las carreras impartidas en la VI Región entre los años 1999 y 2004

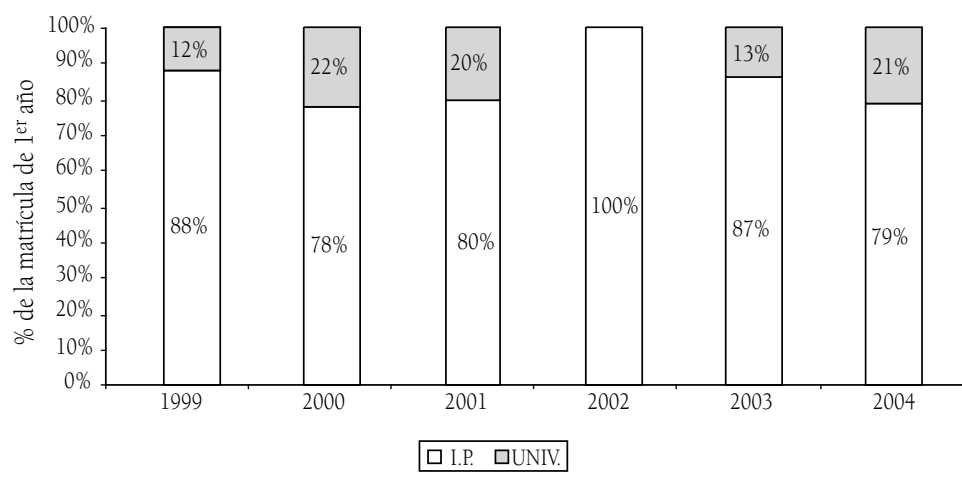

Entre 1999 y 2000, en la VII Región la participación en la oferta de institutos profesionales y universidades era relativamente pareja y estable. Sólo desde 2001 comenzaron a expandirse y diferenciarse, ocupando mayor participación los IP que las instituciones universitarias ( $61 \% \mathrm{v} / \mathrm{s} 39 \%$ ), situación que se mantuvo hasta 2002. En 2003 fue el momento del gran crecimiento de la oferta universitaria (286\%), pasando a ocupar un $62 \%$ de la oferta de educación superior de la región y dejando un 38\% a los IP.

Gráfico 33. Evolución de la oferta de institutos profesionales y universidades de la VII Región

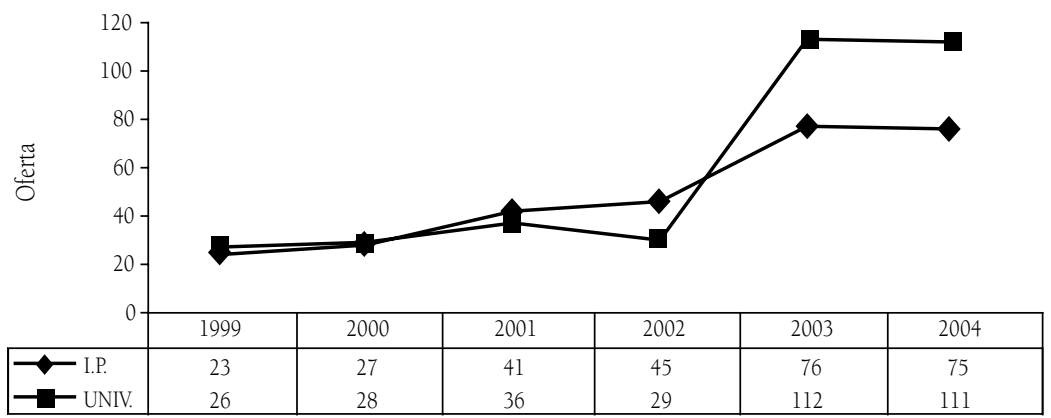




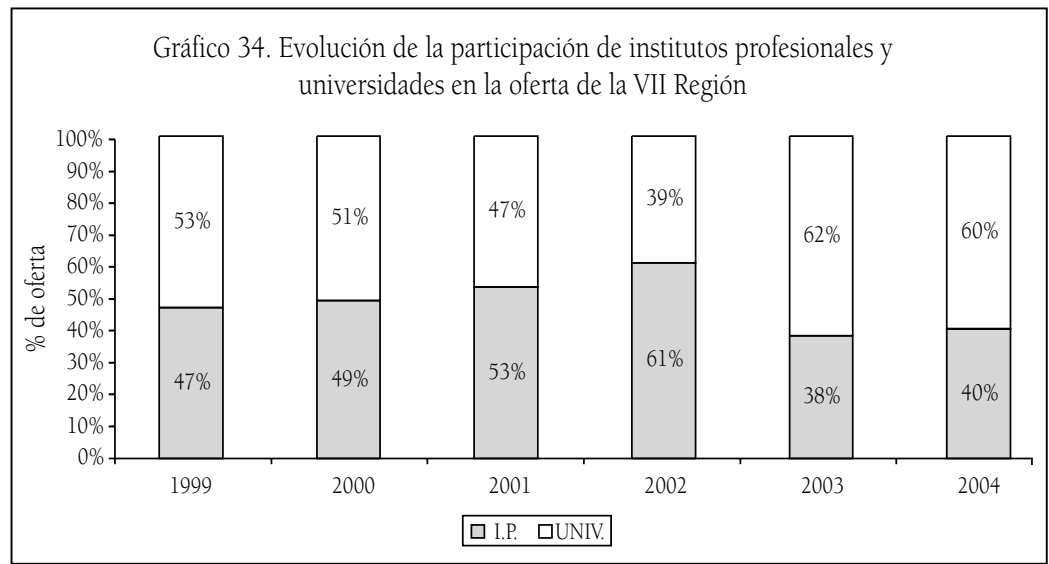

El año 2003 se observa un punto de inflexión en lo concerniente a la matrícula y al número de carreras impartidas, ya que se presenta un gran aumento de programas y estudiantes inscritos. En términos de participación relativa, según tipo de institución, también se observa un cambio desde 2002, cuando los IP llegaron a captar un 63\% de los estudiantes, bajando en los años siguientes a cerca del $20 \%$, proporción mucho menor a su participación en la oferta, incluso si se considera que ésta también baja los últimos dos años.

Gráfico 35. Evolución de la matrícula de $1^{\text {er }}$ año y de las carreras impartidas por instituciones de educación superior entre los años 1999 y 2004 en la VII Región

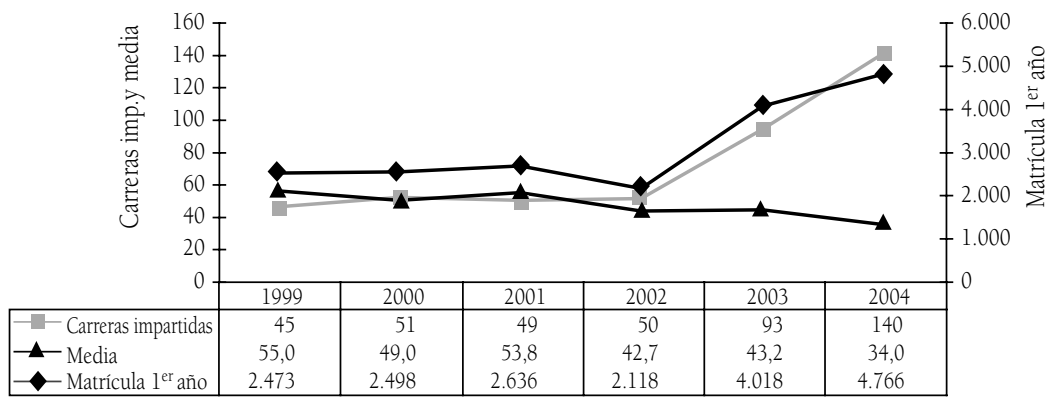


Gráfico 36. Evolución de la participación de los tipos de instituciones en la matrícula de las carreras impartidas en la VII Región entre los años 1999 y 2004

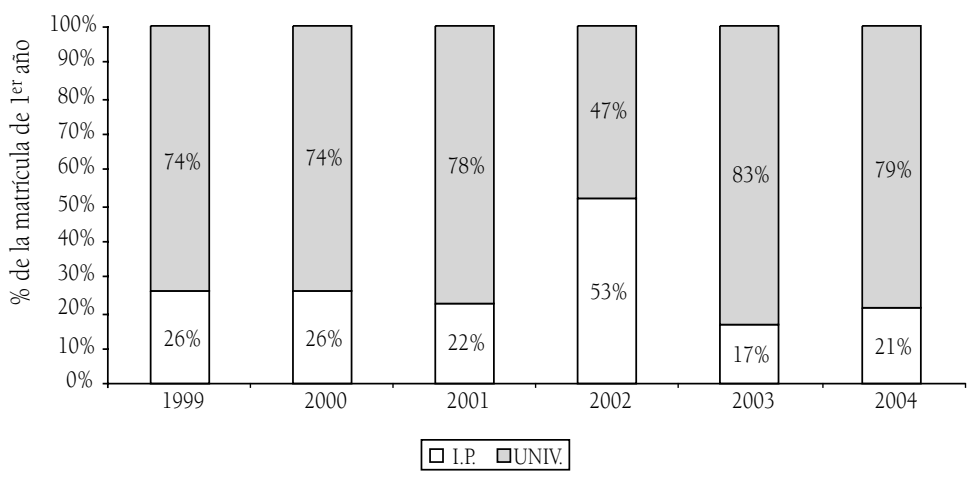

La distribución de la participación en la oferta, según tipo de institución, en la VIII Región se ha mantenido estable durante estos últimos seis años, con un $60 \%$ de participación de las universidades y un $40 \%$ de los institutos profesionales. Entre 1999 y 2002 el crecimiento ha sido relativamente parejo. Sólo a partir de 2003 aumentó el crecimiento de la oferta universitaria de la región, llegando casi a triplicar la oferta que estas instituciones tenían el año 1999, y a duplicar la de los IP.

Gráfico 37. Evolución de la oferta de institutos profesionales y

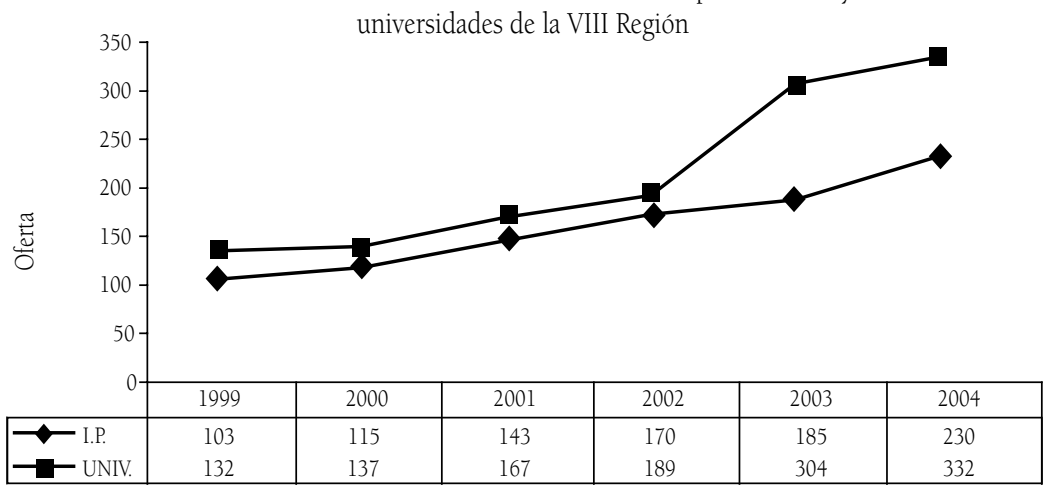




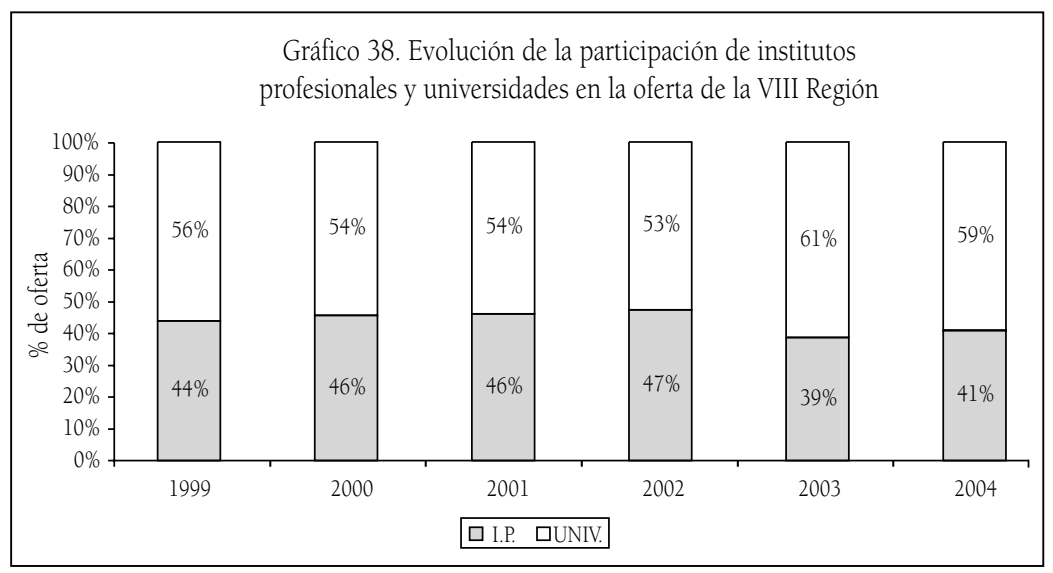

El crecimiento de la matrícula y de las carreras impartidas por el conjunto del sistema se mantiene a lo largo del tiempo, al igual que la participación según tipo de institución. La matrícula parece estancarse sólo entre 2003 y 2004. Cabe hacer notar que la participación de los IP en la oferta es bastante mayor que en la matrícula.

Gráfico 39. Evolución de la matrícula de $1^{\text {er }}$ año y de las carreras impartidas por instituciones de educación superior entre los años 1999 y 2004 en la VIII Región

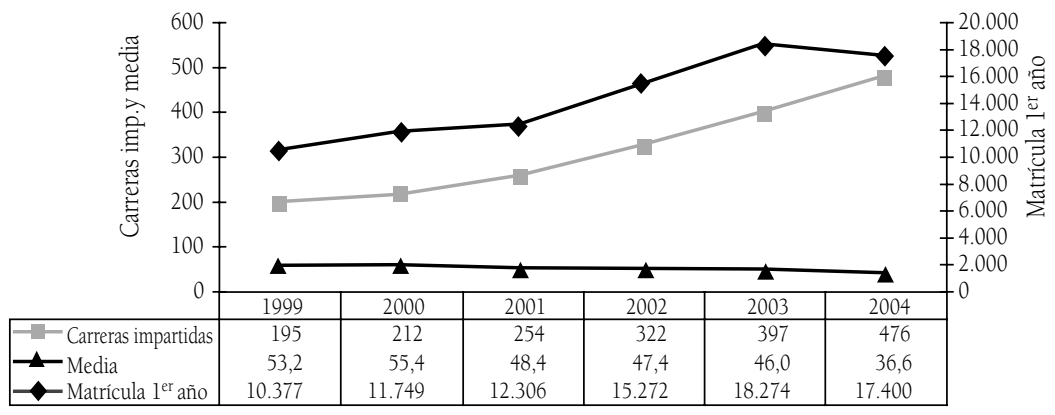


Gráfico 40. Evolución de la participación de los tipos de instituciones en la matrícula de las carreras impartidas en la VIII Región entre los años 1999 y 2004

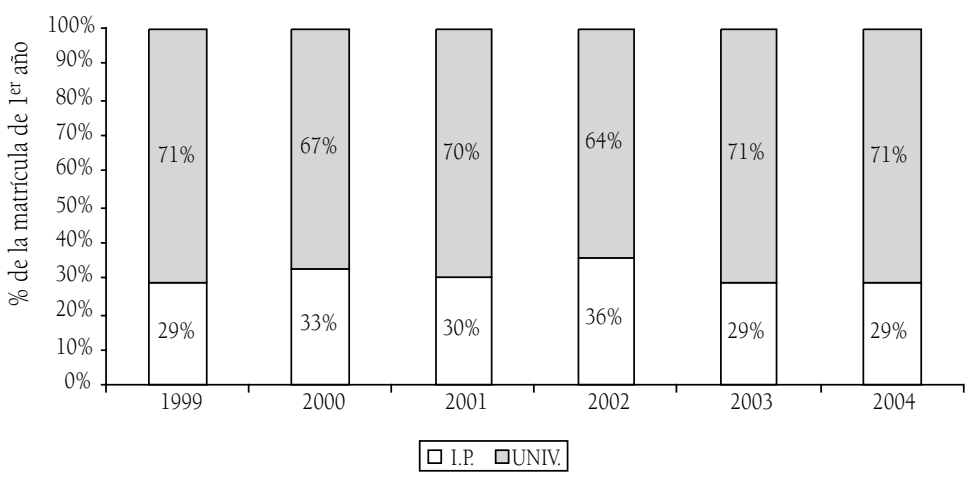

La tasa de crecimiento de la oferta en la IX Región es mayor en el caso de las universidades, hecho que se evidencia en la participación relativa en la oferta de educación superior de la región, donde las universidades han ocupado históricamente entre el 73 y el $77 \%$.

Gráfico 41. Evolución de la oferta de institutos profesionales y universidades de la IX Región

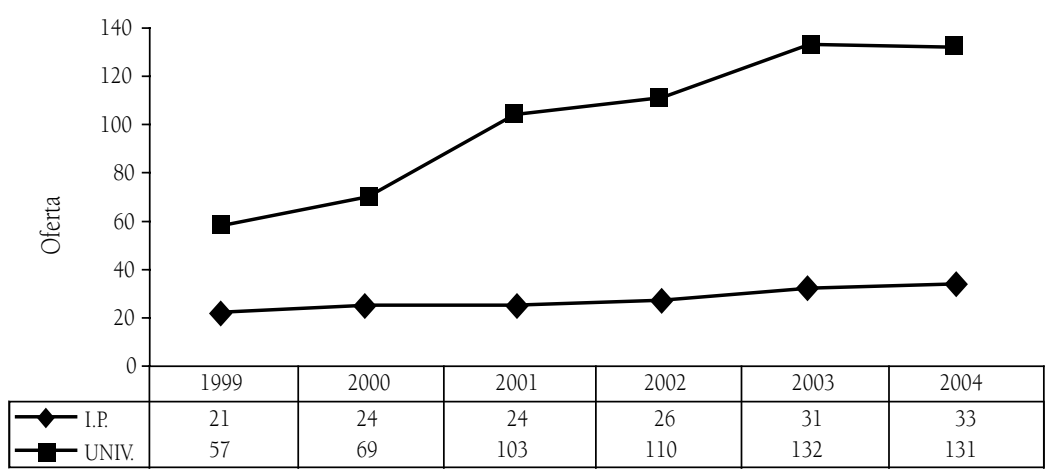




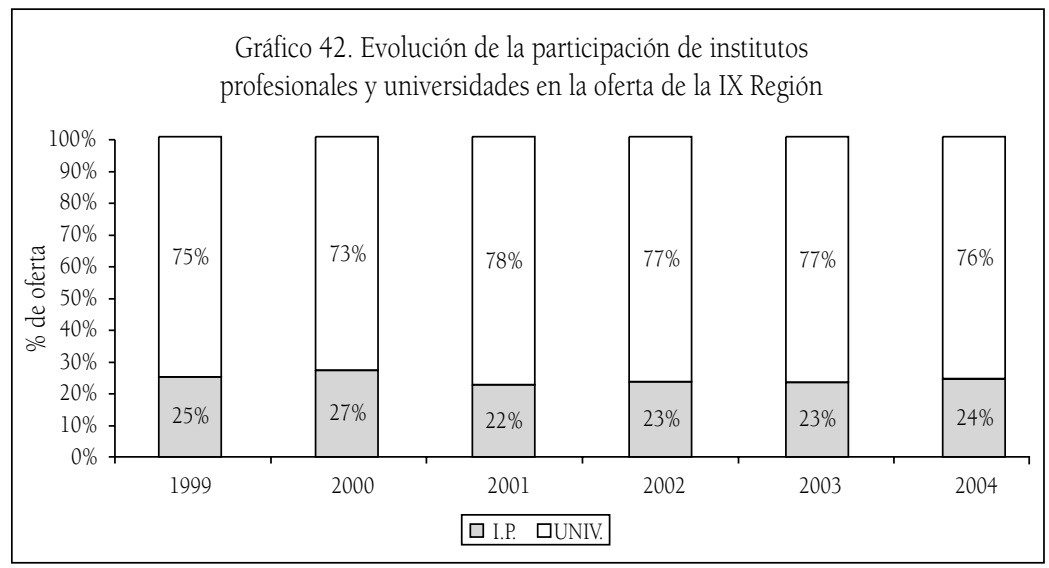

En esta región los indicadores fluctúan en el tiempo. La participación de las universidades en la matrícula de primer año es muy superior a la de los IP (85\% v/s 15\% aproximadamente).

Gráfico 43. Evolución de la matrícula de $1^{\text {er }}$ año y de las carreras impartidas por instituciones de educación superior entre los años 1999 y 2004 en la IX Región

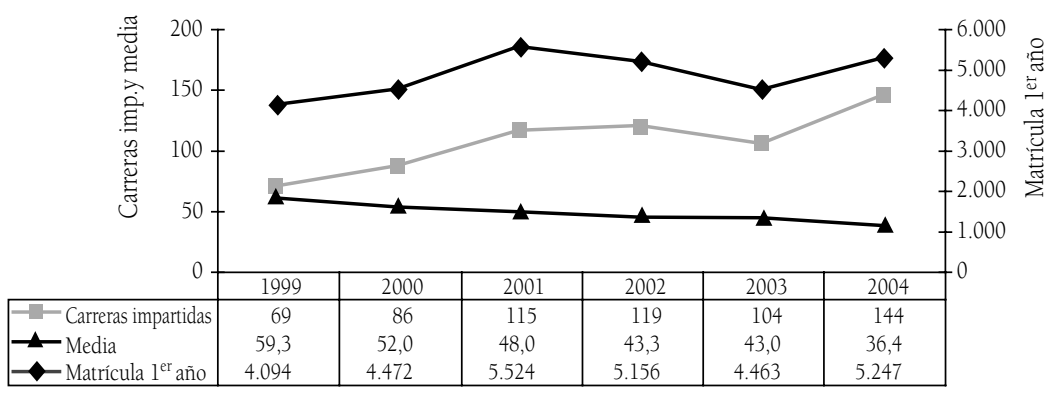


Gráfico 44. Evolución de la participación de los tipos de instituciones en la matrícula de las carreras impartidas en la IX Región entre los años 1999 y 2004

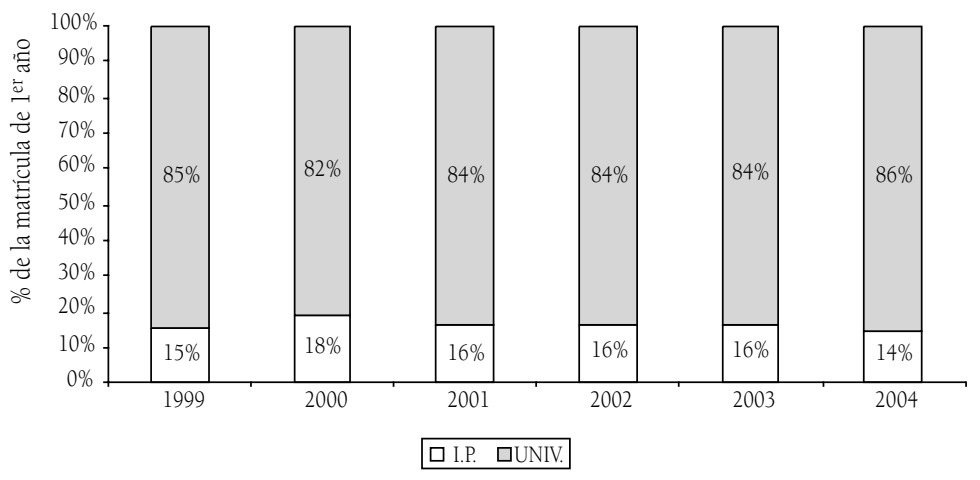

En la X Región la evolución de la oferta es muy similar entre universidades e institutos profesionales, los que además han compartido la participación equitativamente entre 1999 y 2004. Entre 1999 y 2000 se mantuvo relativamente estable la oferta de educación superior, comenzando a expandirse tímidamente en 2001 y con mayor fuerza desde 2002.

Gráfico 45. Evolución de la oferta de institutos profesionales y universidades de la X Región

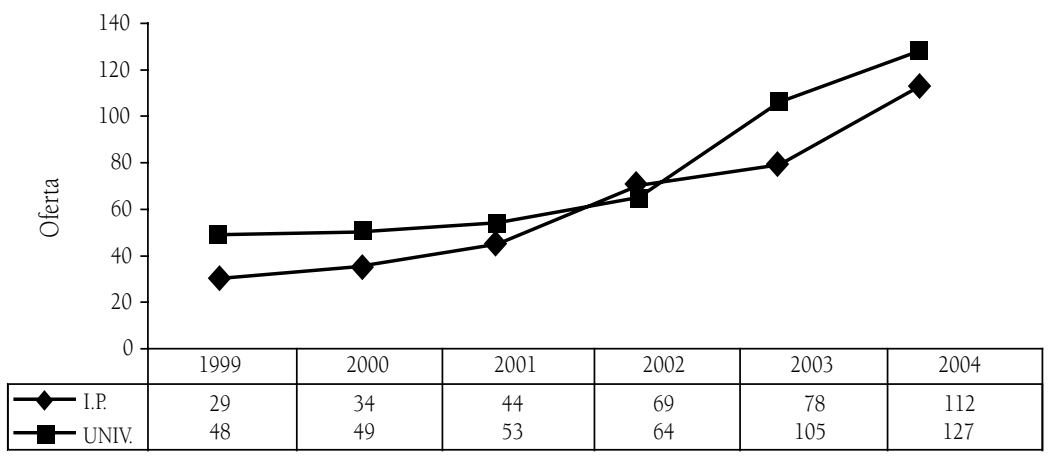




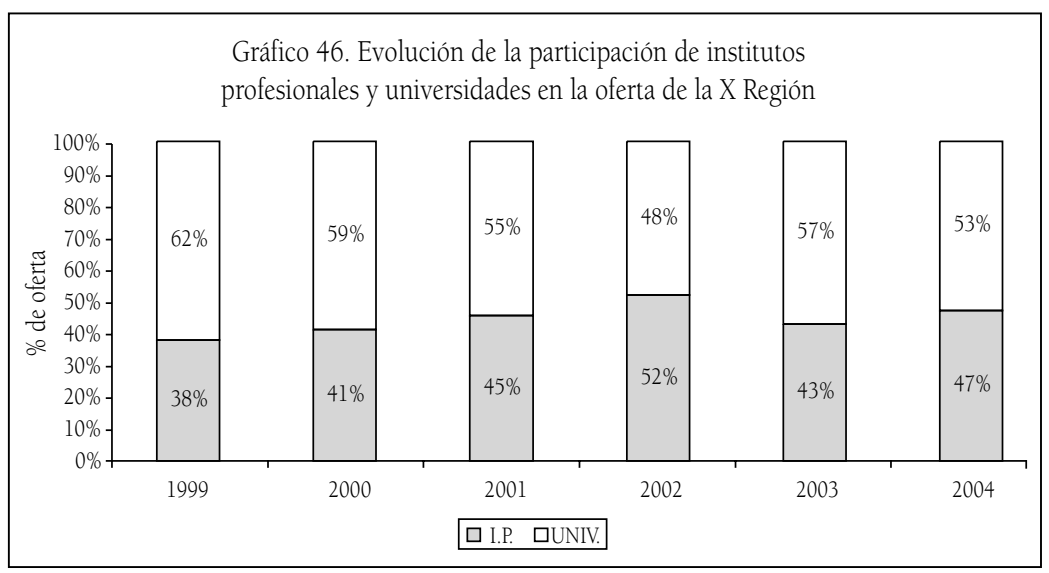

Se observa un aumento en el crecimiento de la matrícula y de las carreras impartidas desde 2002, mientras que, en términos de participación relativa según tipo de institución, el indicador es estable y favorable para las universidades, incluso de manera más acentuada que en el caso de la oferta.

Gráfico 47. Evolución de la matrícula de $1^{\text {er }}$ año y de las carreras impartidas por instituciones de educación superior entre los años 1999 y 2004 en la X Región

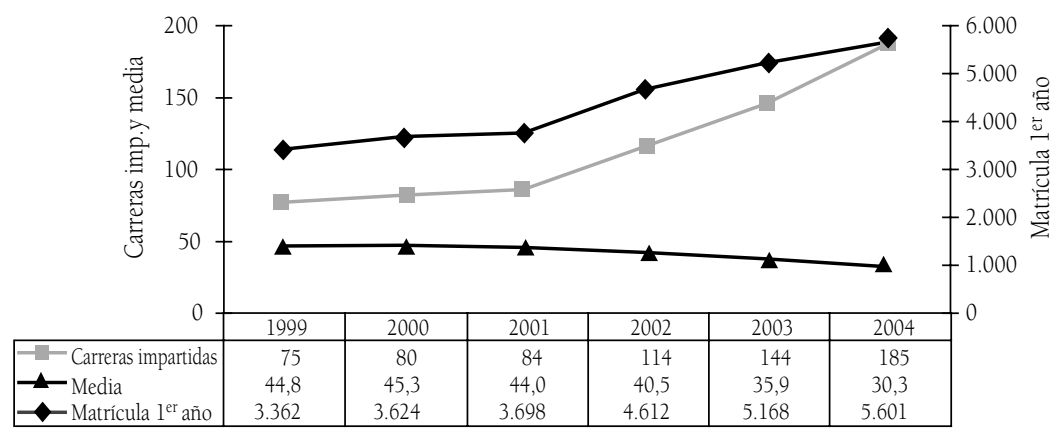


Gráfico 48. Evolución de la participación de los tipos de instituciones en la matrícula de las carreras de pregrado impartidas en la X Región entre los años 1999 y 2004

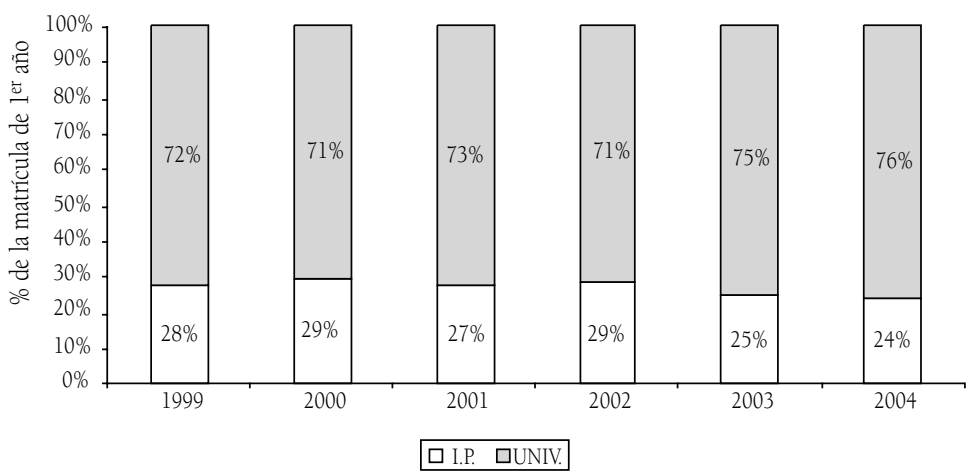

En la XI Región no hay oferta universitaria y la oferta de IP ha ido disminuyendo durante estos seis años, al punto que a 2004 se imparten sólo dos programas.

Gráfico 49. Evolución de la oferta de institutos profesionales de la XI Región

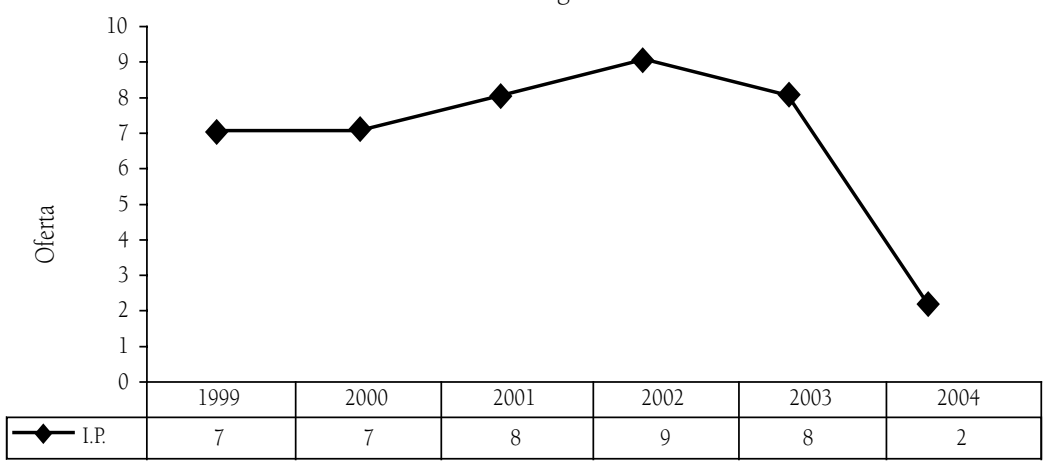

En esta región, que tradicionalmente ha tenido baja matrícula y escasas carreras impartidas, se observa una caída dramática de estudiantes y programas en 2002: lejos de remontar, la situación se agudiza en 2004. 
Gráfico 50. Evolución de la matrícula de $1^{\text {er }}$ año y de las carreras impartidas por instituciones de educación superior entre los años 1999 y 2004 en la XI Región

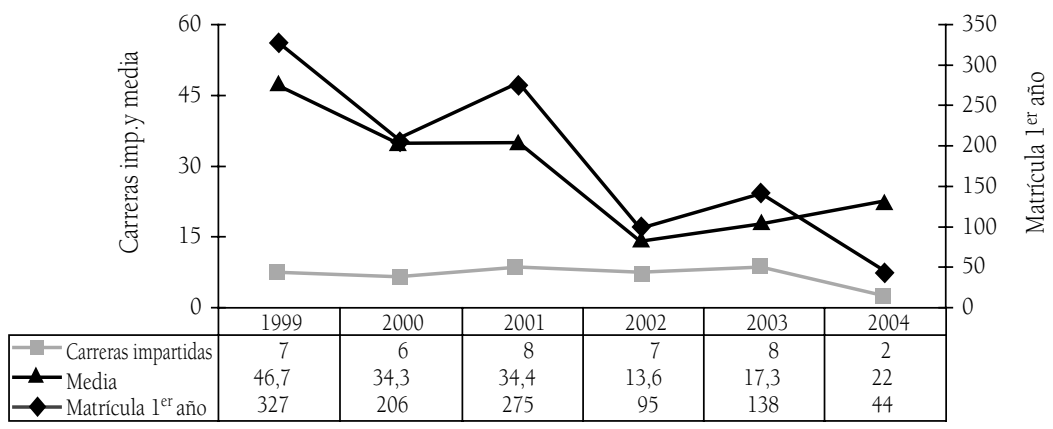

La expansión de la oferta en la XII Región tiene el mismo comportamiento para las universidades y los institutos profesionales, aun cuando es mayor la oferta de las primeras (llegan a ocupar el $73 \%$ del total de la oferta en 2004). Por otro lado, la participación relativa de los institutos profesionales en la oferta de la región aumenta de un 17 a un $27 \%$.

Gráfico 51. Evolución de la oferta de institutos profesionales y universidades de la XII Región

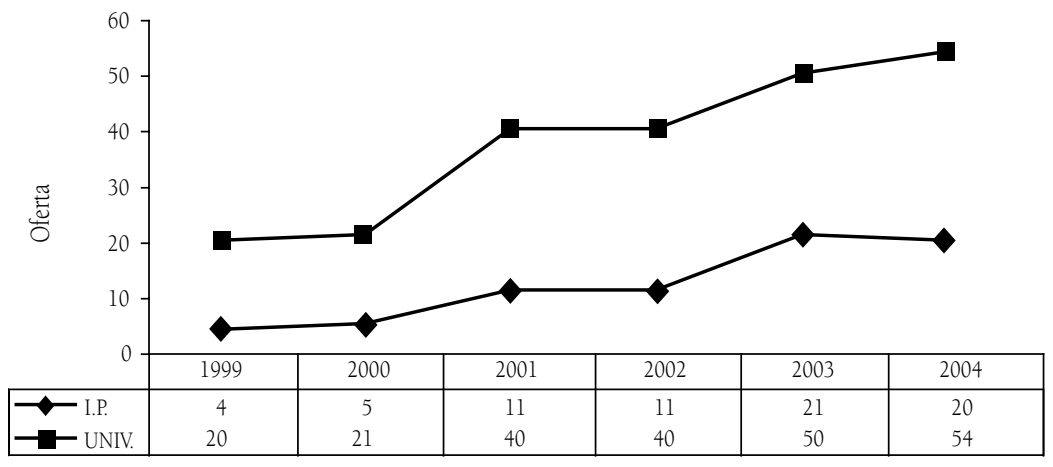




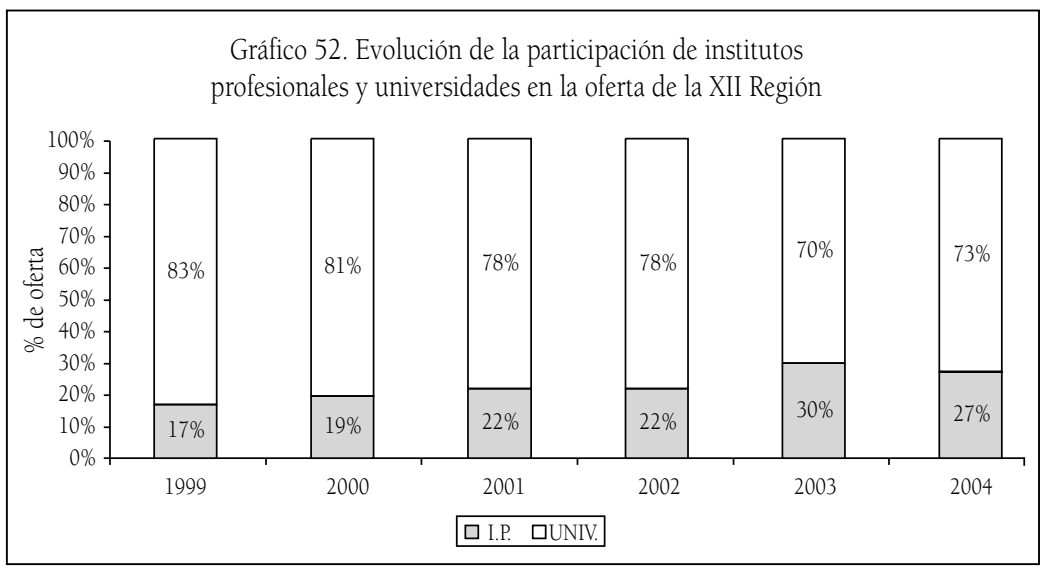

Con fluctuaciones, las universidades captan aproximadamente un $85 \%$ de los estudiantes de la región, porcentaje menor a su participación en la oferta. En lo que se refiere al crecimiento absoluto del sistema en su conjunto (IP y universidades), se aprecia un alza sostenida y sintónica entre el número de carreras y de estudiantes desde 2001 en adelante.

Gráfico 53. Evolución de la matrícula de $1^{\text {er }}$ año y de las carreras impartidas por instituciones de educación superior entre los años 1999 y 2004 en la XII Región

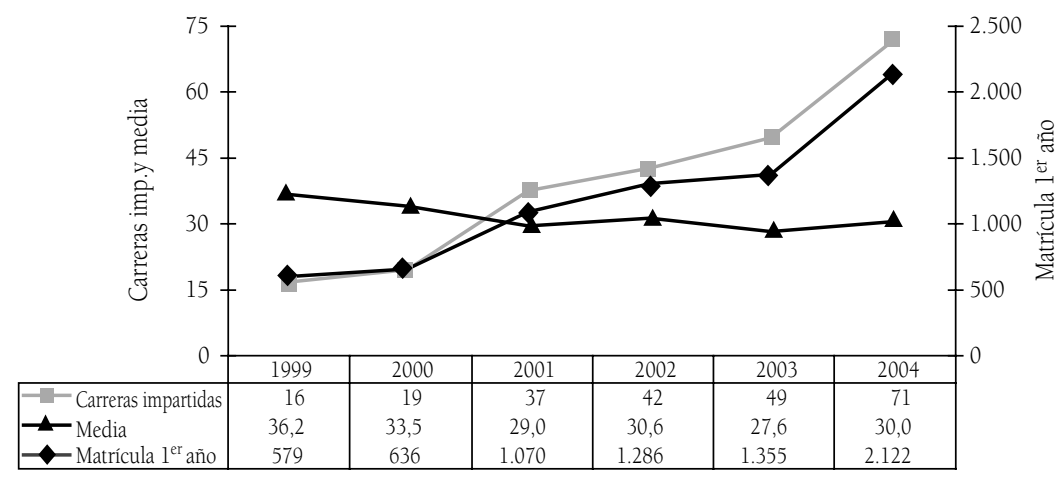


Gráfico 54. Evolución de la participación de los tipos de instituciones en la matrícula de las carreras impartidas en la XII Región entre los años 1999 y 2004

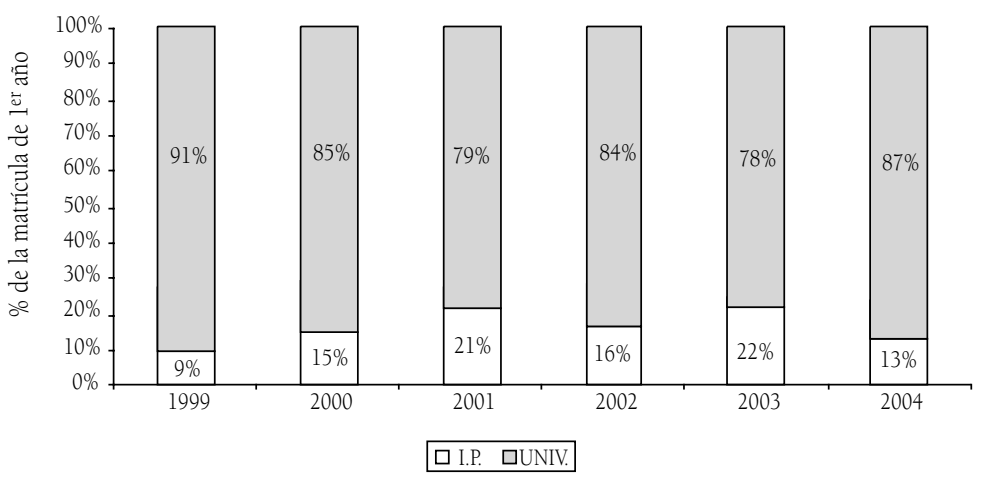

La RM tiene aproximadamente el $40 \%$ de la oferta de educación superior del país, por lo que el comportamiento de sus indicadores es muy parecido al patrón nacional. Entre 1999 y 2000 el crecimiento es muy leve pero gana intensidad desde 2001. La participación relativa de las universidades y de los institutos profesionales en la oferta es similar a los datos que muestra el conjunto del país (65\% v/s 35\%).

Gráfico 55. Evolución de la oferta de institutos profesionales y universidades de la Región Metropolitana

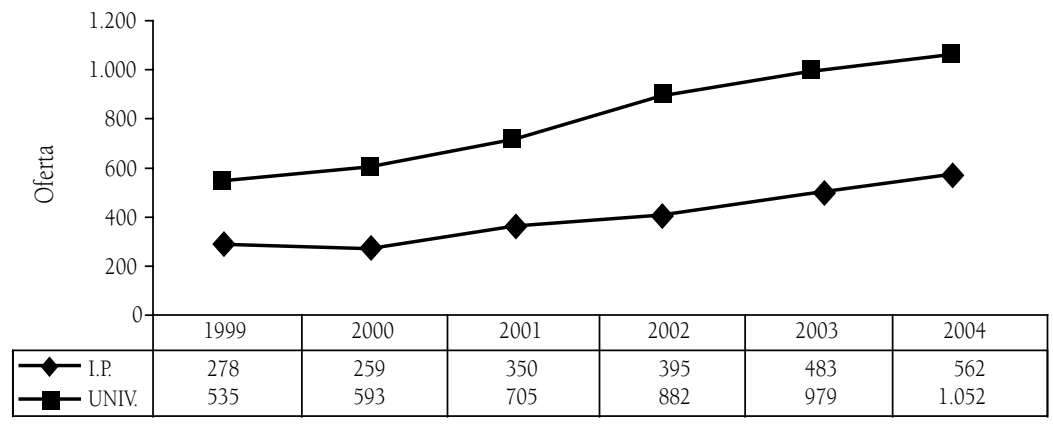




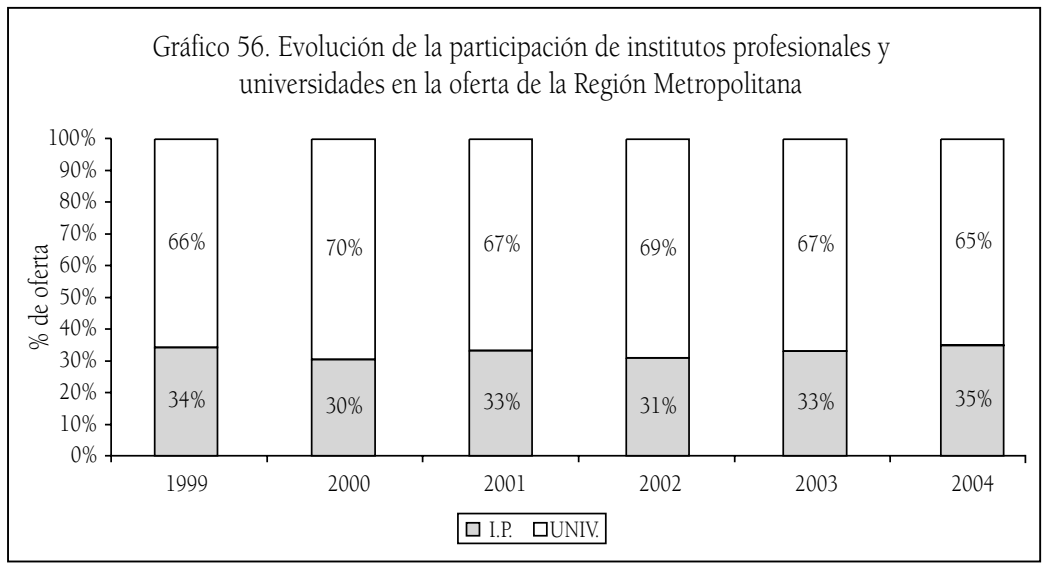

La RM representa el 50\% de los estudiantes y las carreras impartidas en el país, por lo que se replican los patrones de crecimiento ya expuestos en el primer capítulo. Presenta un aumento estable y similar en ambos indicadores. Nuevamente, las universidades tienen un mayor porcentaje de estudiantes en comparación con los institutos profesionales, participación que es incluso superior a la que tienen en la oferta.

Gráfico 57. Evolución de la matrícula de $1^{\text {er }}$ año y de las carreras impartidas por instituciones de educación superior entre los años 1999 y 2004 en la Región Metropolitana

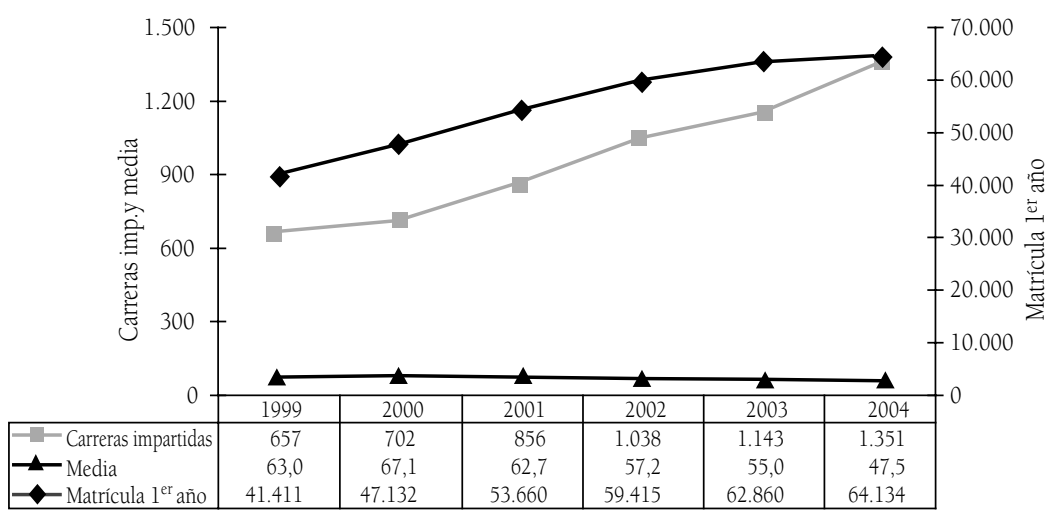




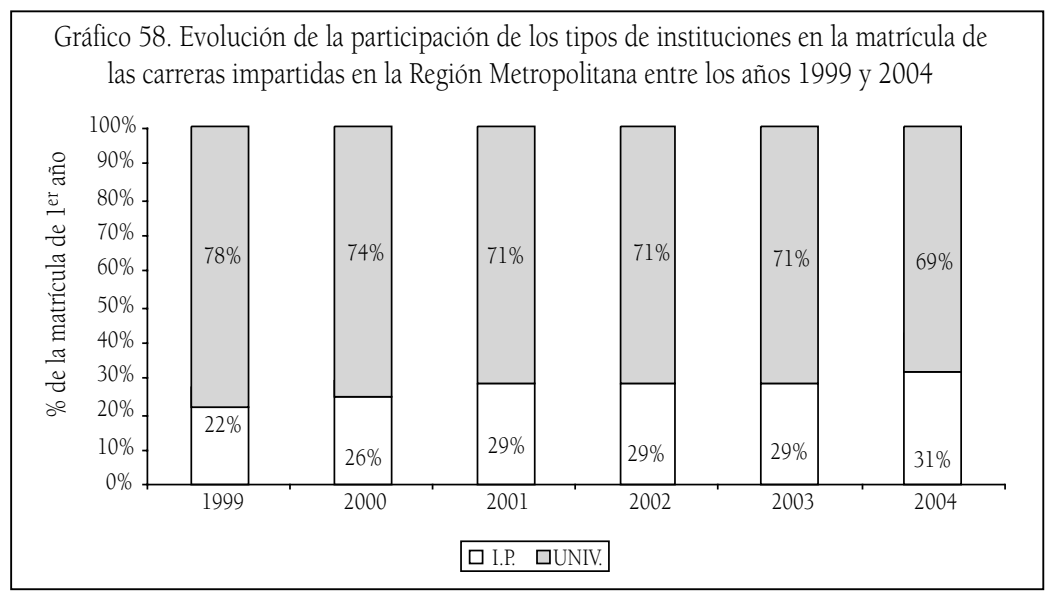

\section{La oferta y la matrícula según áreas del conocimiento}

El análisis de oferta y matrícula según áreas del conocimiento contribuye con información para responder a la pregunta por la diversificación del sistema, admitiendo, claro está, que la diversidad no se limita a un problema de disciplinas del saber sino que abarca dimensiones como los aranceles, la extensión de los programas, su jornada, los tipos de certificación entregados, las orientaciones curriculares y valóricas de cada carrera, entre otras. Siendo así, este apartado se concentra en explorar uno de los aspectos relevantes para entender si y cómo se amplían las alternativas académicas, profesionales y técnicas en las universidades e institutos profesionales del país. 
Gráfico 59. Evolución de la participación de las áreas del conocimiento en la oferta de carreras entre los años 1999 y 2004

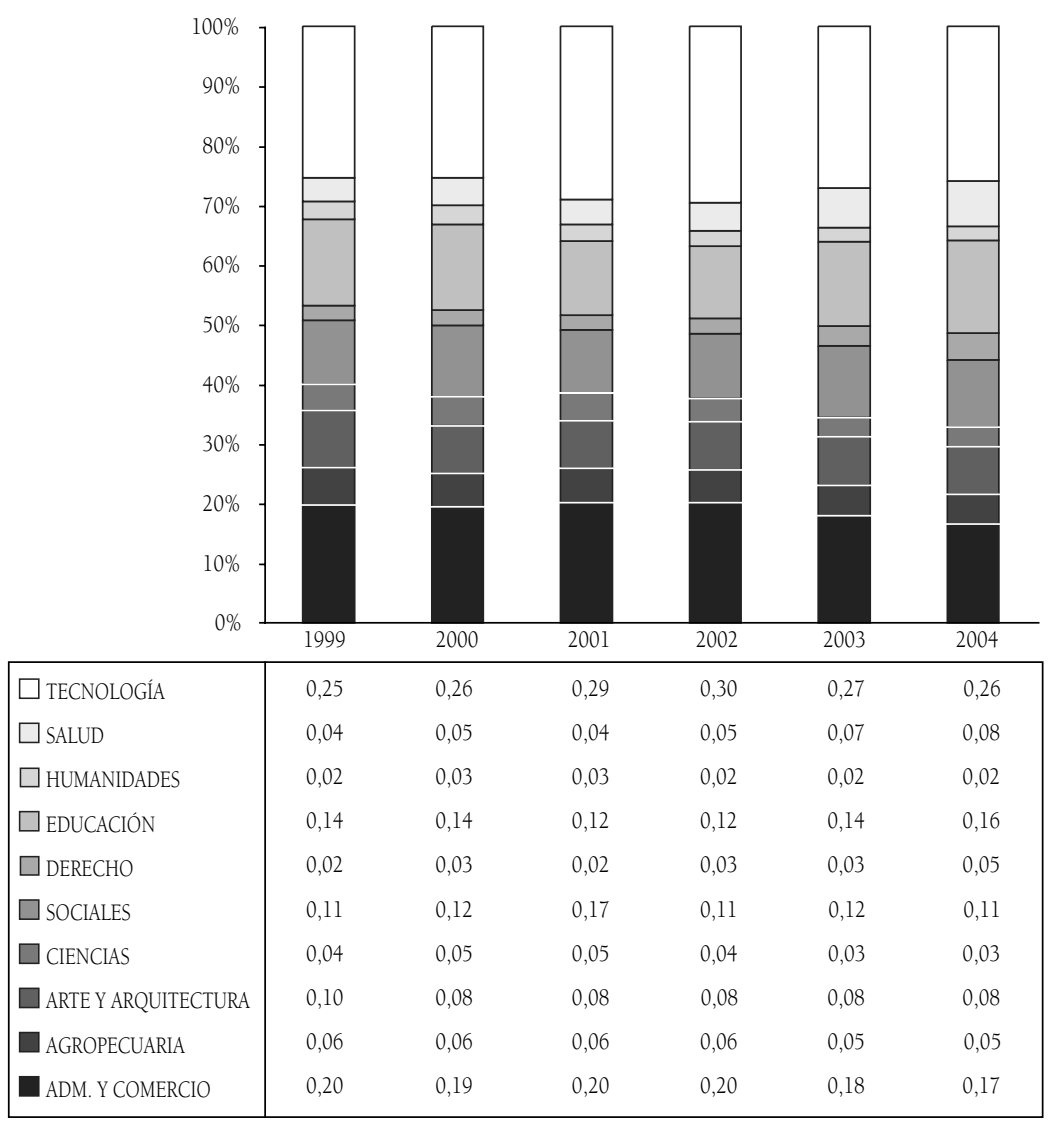

Sumadas, las áreas de Tecnología y Administración y Comercio concentran cerca de la mitad de la oferta de carreras en los últimos seis años. Tecnología exhibe porcentajes que llegan incluso al 30\% en 2002. Aunque con fluctuaciones, las carreras de Educación han llegado a representar un $16 \%$ de la oferta en 2004, lo que eleva su presencia relativa en el mercado. Siguen en importancia las áreas de Ciencias Sociales ( $11 \%$ aproximadamente) y Arte y Arquitectura (8\%). Las demás áreas exhiben porcentajes menores de la oferta total, no obstante, se puede decir que las carreras de Salud y 
Derecho van aumentando su peso relativo hacia 2004, en contraste con Agropecuaria, Ciencias y Humanidades que parecieran ir en la tendencia opuesta los últimos años ( 5,3 y $2 \%$ respectivamente).

Gráfico 60. Evolución de la participación de las áreas del conocimiento en la matrícula de 1er año de carreras impartidas entre los años 1999 y 2004

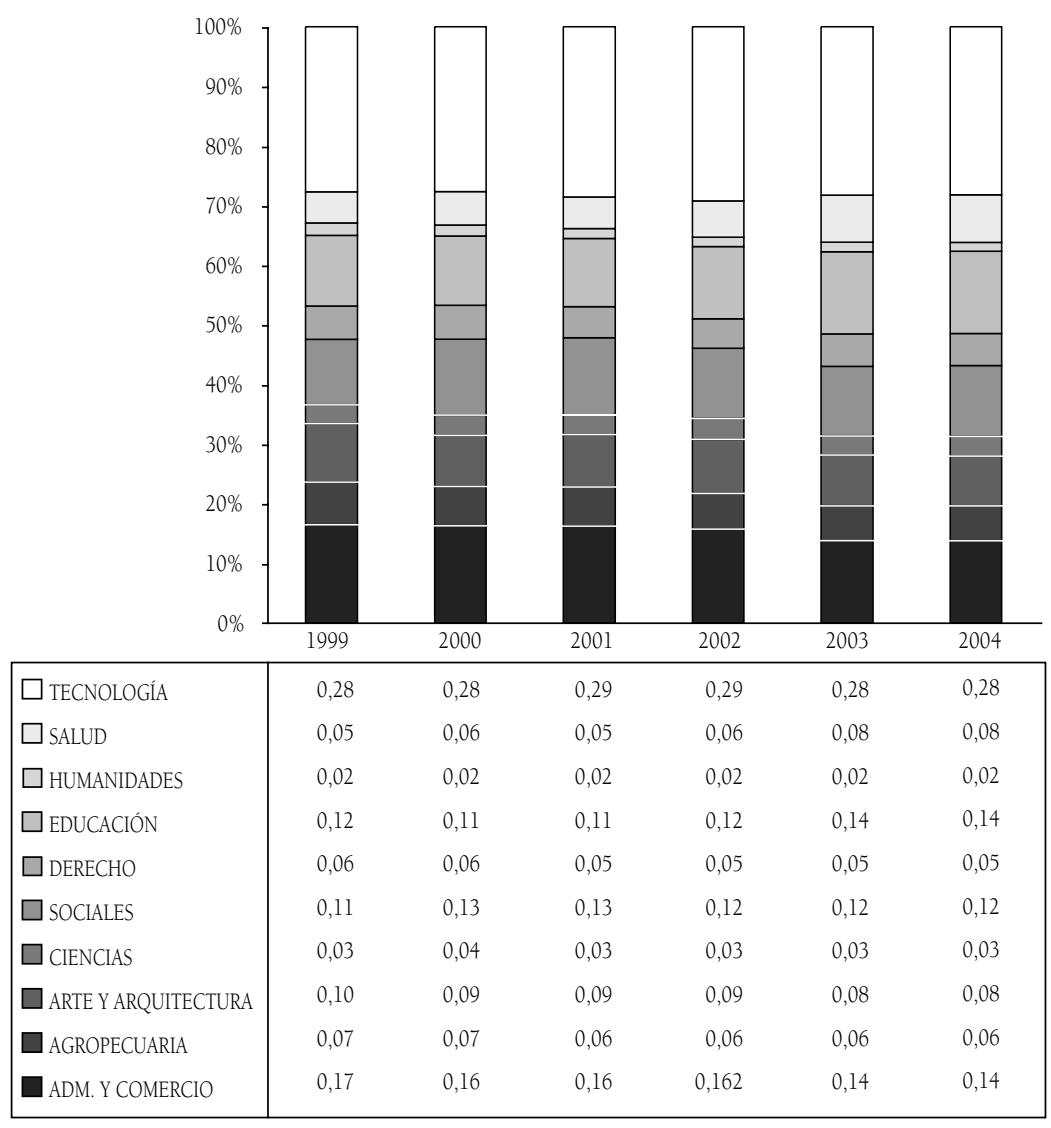

La participación de las áreas del conocimiento en la matrícula de las carreras impartidas por universidades e institutos profesionales es muy similar a su participación en la oferta de carreras. La única diferencia se observa en el área Administración y Comercio, pues posee $5 \%$ menos de participación en la matrícula en comparación con su porcentaje en la oferta de carreras. En 
términos de las tendencias de incremento o descenso, la matrícula refleja mayor estabilidad que la oferta a lo largo del periodo, pero confirma el interés creciente por Educación y Salud.

Esta lectura de la variación en el peso relativo de las áreas del conocimiento no debe hacer olvidar que tanto la oferta como la matrícula han aumentado sostenidamente en todas las áreas, en mayor o menor grado. Por ello, también es importante poner atención a las frecuencias en cada una de las áreas, así como a su distribución regional y por tipo de institución.

\section{Administración y Comercio}

Al analizar la información al interior de cada área del conocimiento vemos que, históricamente, los institutos profesionales y las universidades han compartido muy equitativamente la oferta de carreras del área de Administración y Comercio. La mitad de la oferta se encuentra en la Región Metropolitana, seguida por la V y VIII regiones con un 15\% aproximado cada una.

Gráfico 61. Evolución de la oferta de carreras del área de Administración

y Comercio según tipo de institución

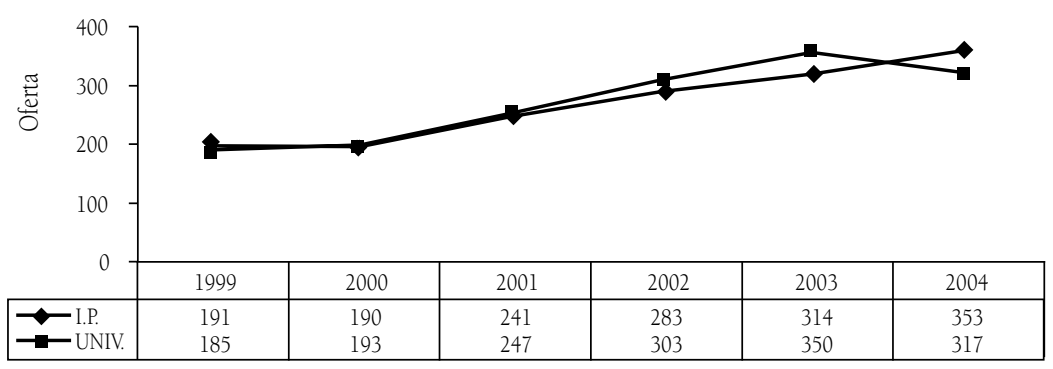




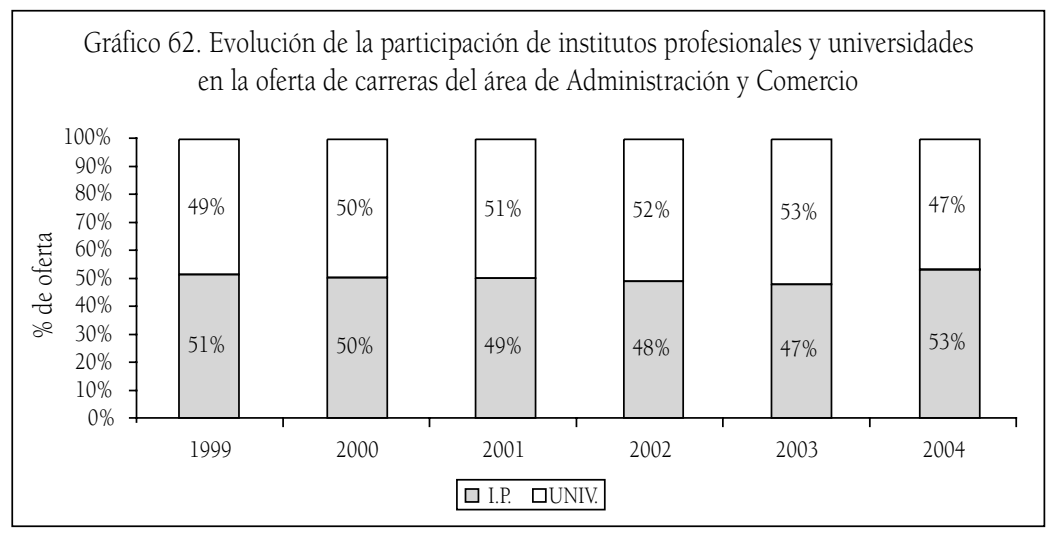

A partir del año 2001 las carreras impartidas presentan un crecimiento sostenido hasta el año 2004, mientras que la matrícula se ha mantenido relativamente estable e incluso baja los últimos dos años. Con variaciones menores, este patrón se repite en las regiones.

A diferencia de la participación equitativa de los tipos de institución de educación superior en la oferta de carreras del área de Administración y Comercio, la participación de las universidades en la captación de estudiantes es superior a la de institutos profesionales, sugiriendo la posibilidad de sobreoferta por parte de éstos, en especial dado que no disminuyen su oferta en 2004 como sí lo hace el sector universitario.

Gráfico 63. Evolución de la matrícula de $\mathrm{l}^{\mathrm{er}}$ año y de las carreras impartidas en el área de Administración y Comercio

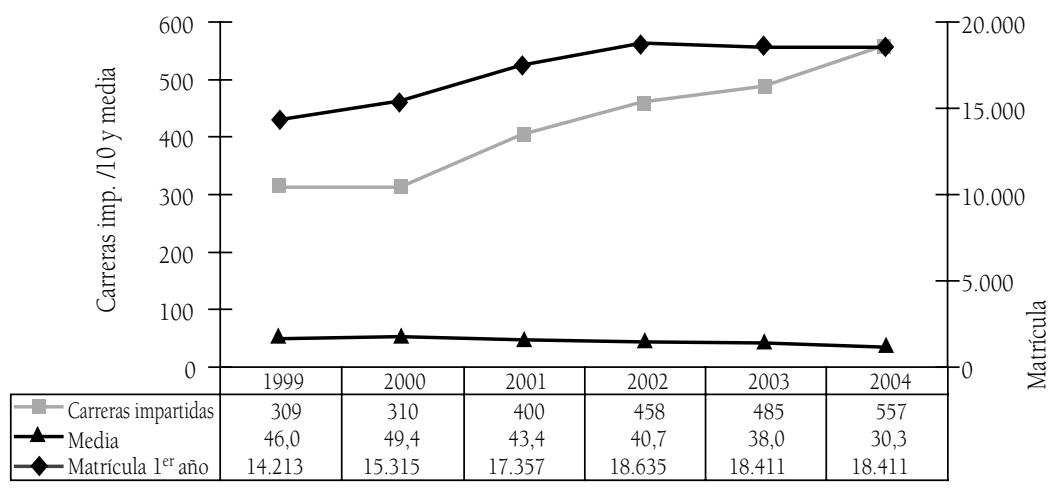




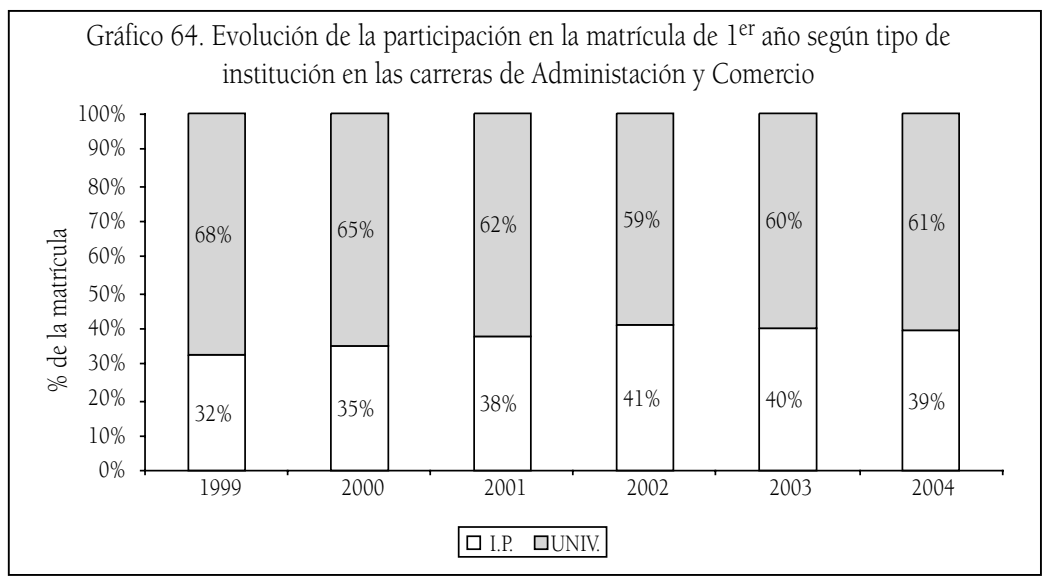

\section{Agropecuaria}

En el área Agropecuaria las universidades son las que ocupan un mayor porcentaje de la oferta, dejando un $20 \%$ para los institutos profesionales. La distribución regional de la oferta de carreras muestra que las regiones VIII y X le quitan peso relativo a la oferta de carreras de la RM, donde la VIII llega a igualarla en participación (20\% aproximadamente), mientras que la X y la V alcanzan $15 \%$ cada una. Otro dato relevante es que en las regiones III y XI no existe oferta de carreras del área Agropecuaria.

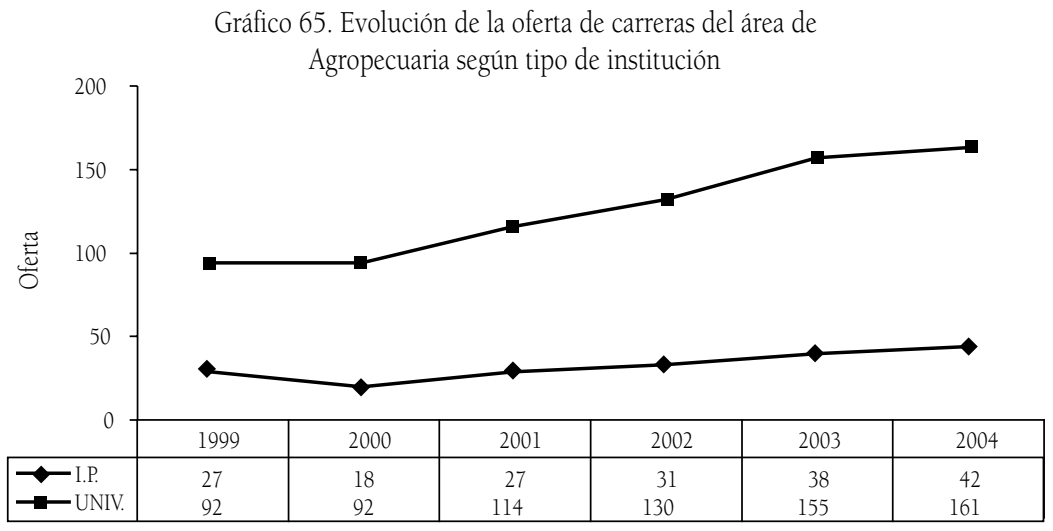




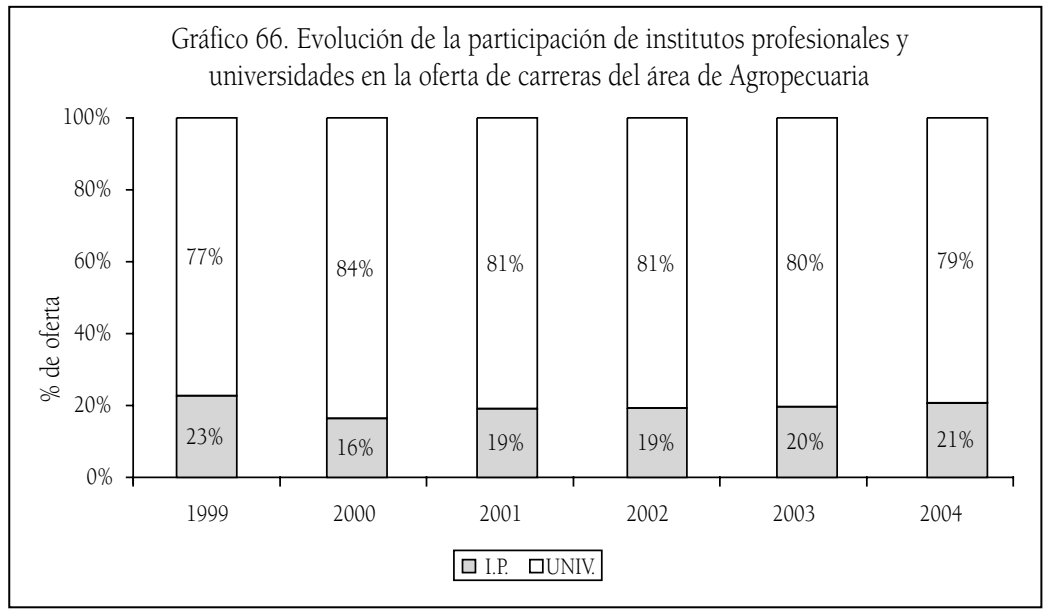

En el área Agropecuaria los indicadores nacionales de matrícula suben con moderación hasta 2003 y se mantienen en 2004, al tiempo que el número de carreras impartidas sigue aumentando. En las regiones la matrícula se mantiene o incluso baja en los últimos años, siendo la IX Región la única que, en consecuencia, disminuye levemente su oferta.

Las universidades captan la mayoría de los estudiantes, mientras que los IP, como se veía anteriormente, tienen aproximadamente el $20 \%$ de la oferta de carreras y un porcentaje de la matrícula que sólo en los últimos tres años se eleva por sobre el $10 \%$.

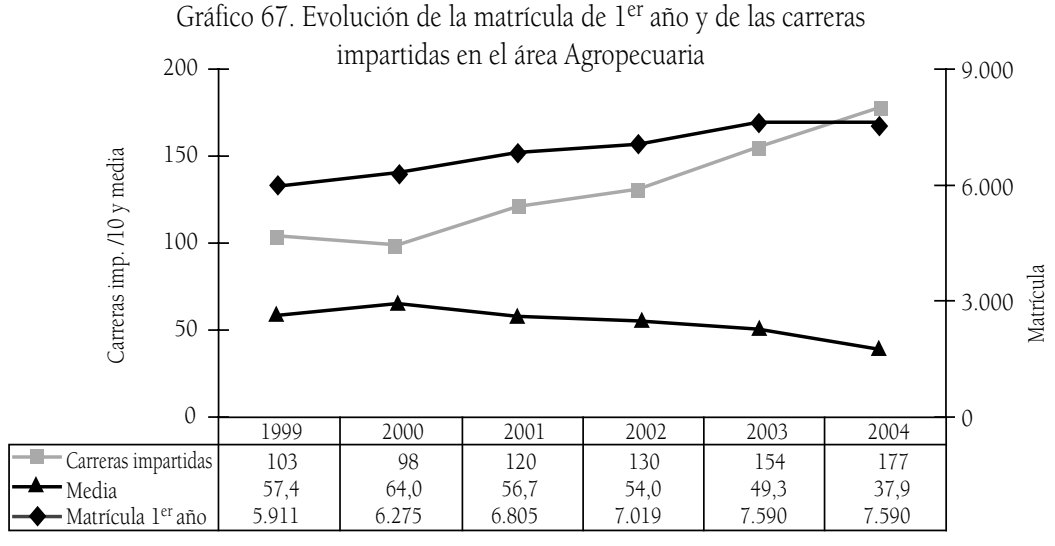




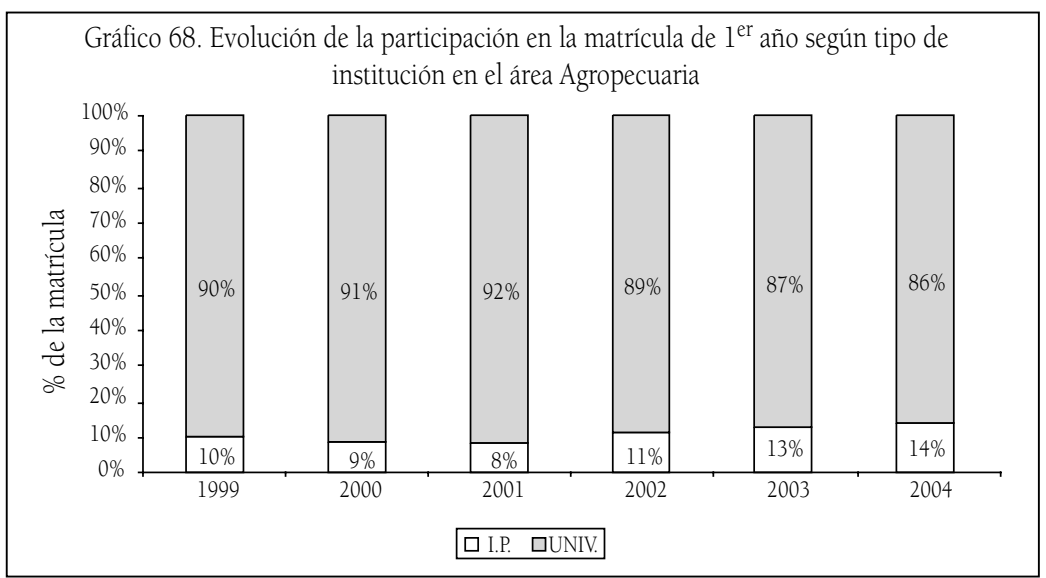

\section{Arte y Arquitectura}

Interesante es el caso de Arte y Arquitectura, pues la RM concentra aproximadamente un $60 \%$ de la oferta, seguido por la V Región, con un $20 \%$, y por la VIII que no alcanza el $10 \%$. Del mismo modo que en el área Agropecuaria, las regiones III y XI tampoco tienen oferta de carreras del área Arte y Arquitectura. La participación de las universidades en la oferta de carreras ha ido aumentando lentamente a lo largo de los años, variando desde un 52 a un $62 \%$.

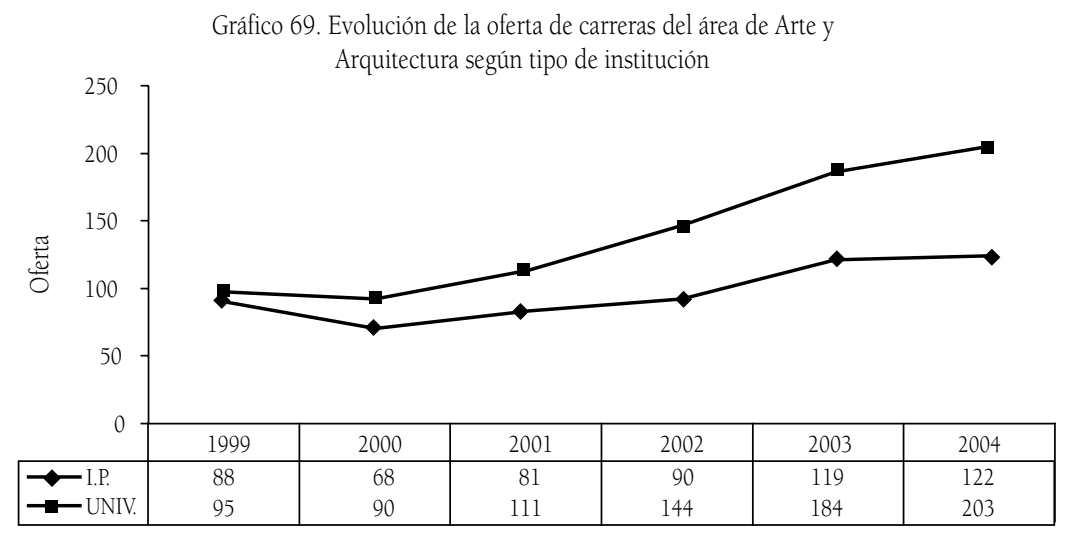




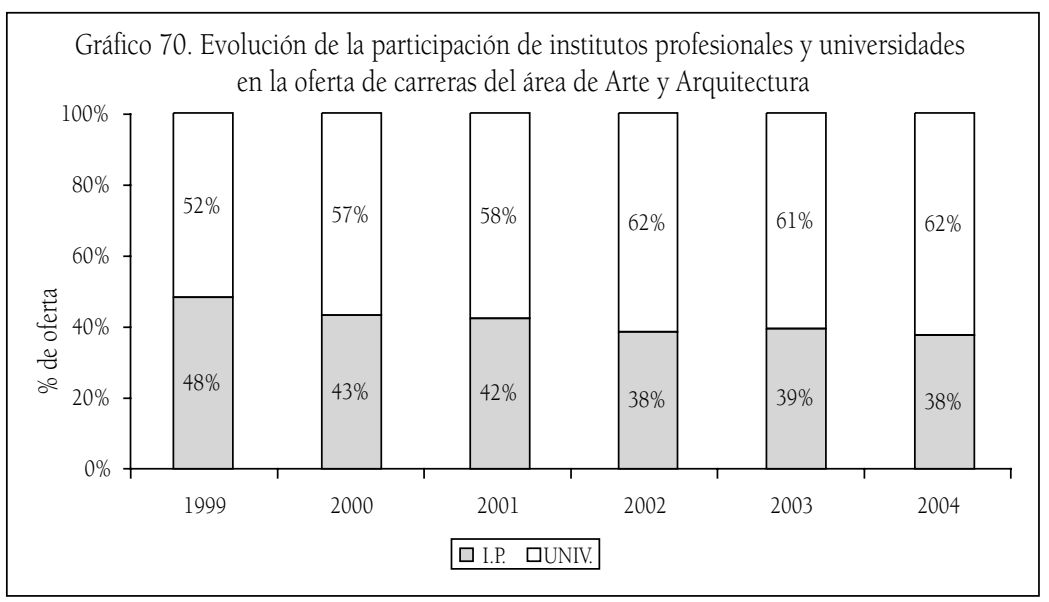

La matrícula de primer año en las carreras impartidas en Arte y Arquitectura crece entre 2000 y 2002, frenando el alza los últimos años, a diferencia del número de carreras, que aumenta sostenidamente desde el 2000. Este patrón se aprecia también en la VIII Región. La cantidad de carreras y de estudiantes se mantiene estable en la X, y en la IX fluctúa la matrícula y aumentan sostenidamente las carreras. La II es la única región donde el crecimiento de matrícula es notorio y destaca por sobre las carreras impartidas, por lo que habrá que esperar cómo reacciona la oferta. Las demás regiones aumentan sus matriculados pero éstos se reparten en un número de carreras también creciente, por lo que cabe preguntarse si estamos ante una sobreoferta que demandará ajustes posteriores.

Nuevamente, las universidades tienen mayor proporción de estudiantes de carreras de esta área (más del 60\%); sin embargo, en comparación con otras áreas ya analizadas, esta participación es muy similar a la captada en la oferta de carreras. 
Gráfico 71. Evolución de la matrícula de $\mathrm{l}^{\mathrm{er}}$ año y de las carreras impartidas en el área de Arte y Arquitectura
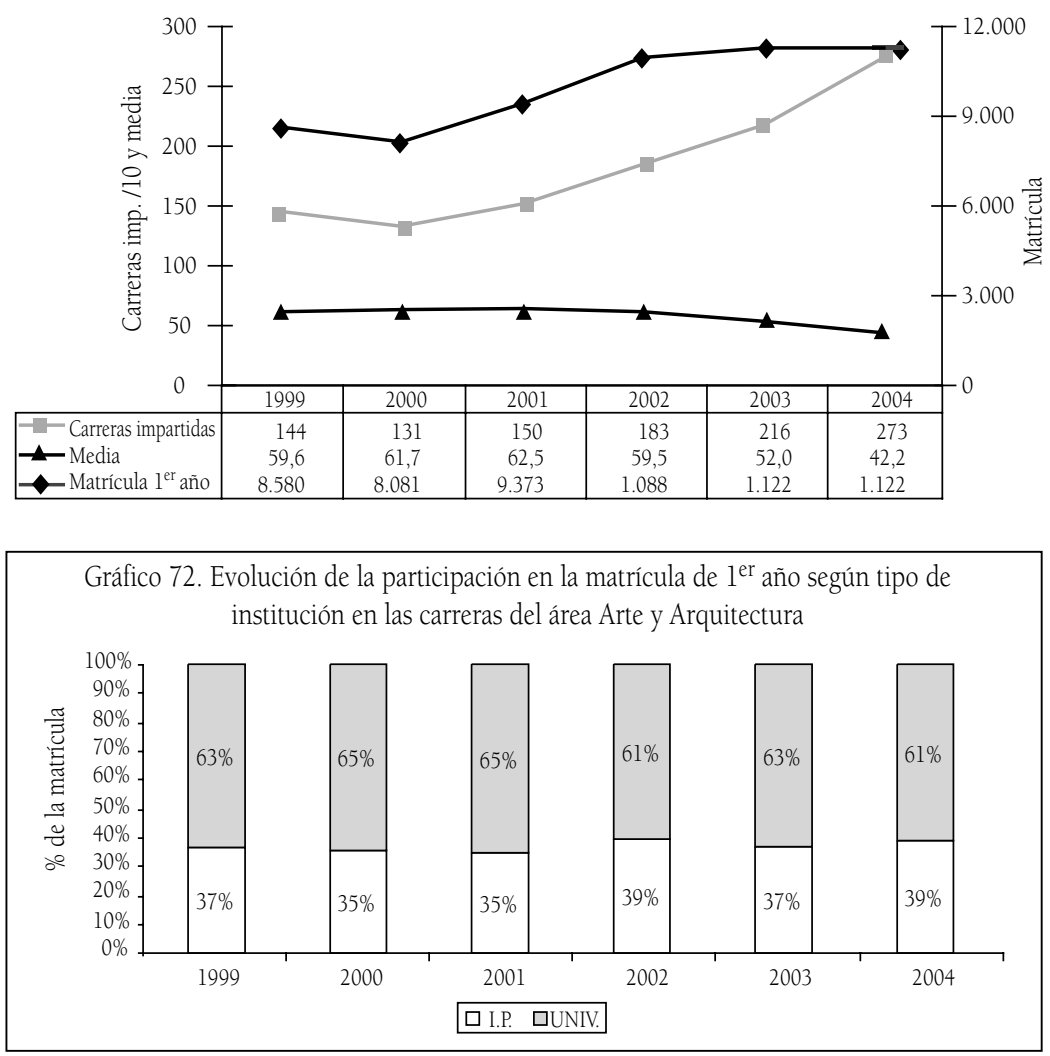

\section{Ciencias}

La oferta de carreras del área de Ciencias tiene una distribución limitada, ya que en las regiones III, VI, VII y XI no existe oferta de carreras científicas; sin embargo, existen más regiones con presencia importante en términos de carreras ofrecidas; además de la RM (34\%), seguida por la V (24\%) y VIII (14\%), la II Región también posee una participación mayor al 10\%. En relación con la participación de los tipos de institución en la oferta de carreras, las universidades han llegado a cubrir casi el $100 \%$ de la oferta total de carreras científicas. 
Gráfico 73. Evolución de la oferta de carreras del área de

Ciencias según tipo de institución
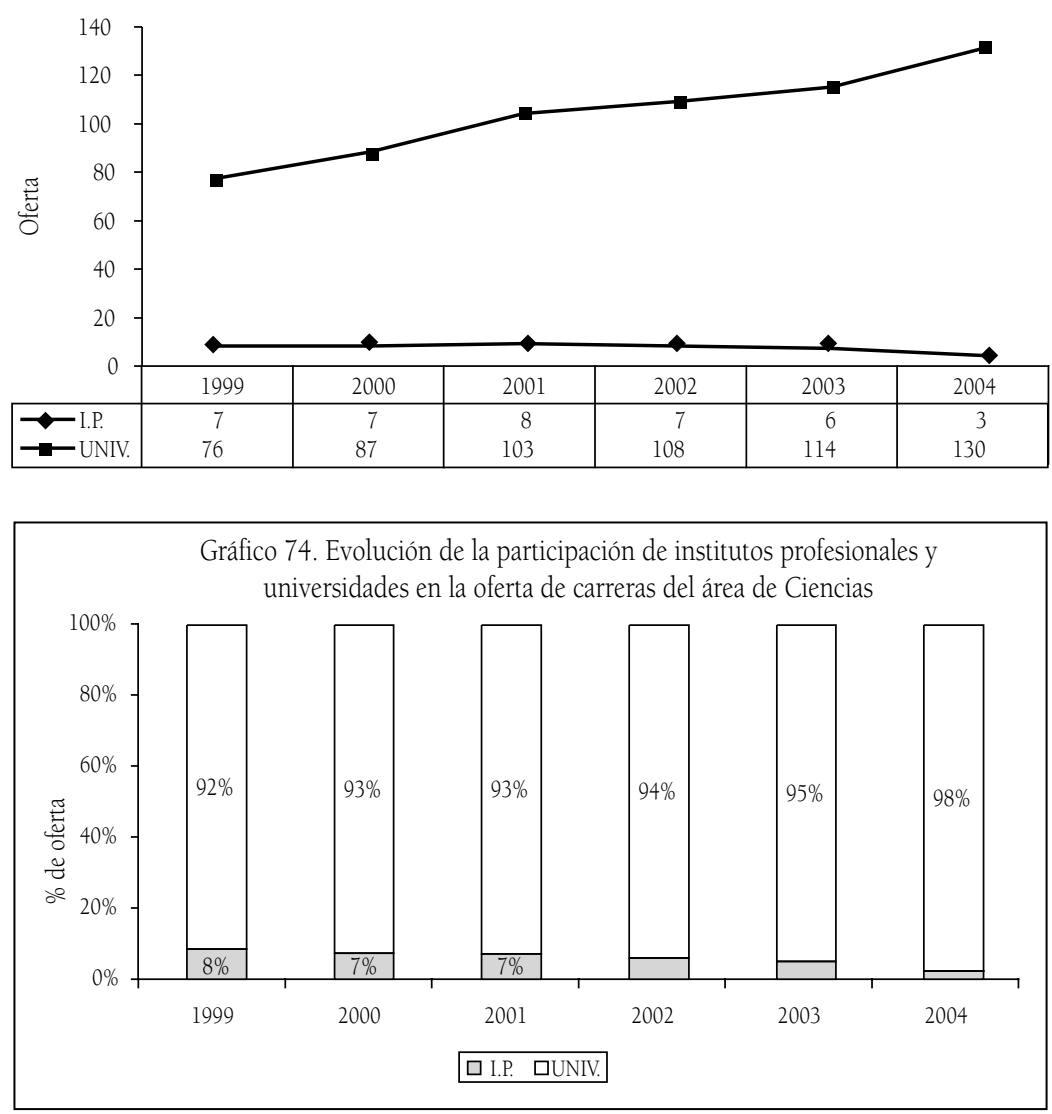

La matrícula de primer año y las carreras impartidas del área de Ciencias han presentado un leve, similar y estable crecimiento a lo largo del tiempo. En la I Región, se produce en 2004 un incremento notable tanto de matrícula como en el número de carreras impartidas, en contraste con la RM donde ambas bajan.

En términos de participación de los tipos de institución en la matrícula total, y del mismo modo que la participación en la oferta de carreras, las universidades tienen casi el 100\% de los estudiantes de carreras científicas. 
Gráfico 75. Evolución de la matrícula de $1^{\text {er }}$ año y de las carreras impartidas del área de Ciencias

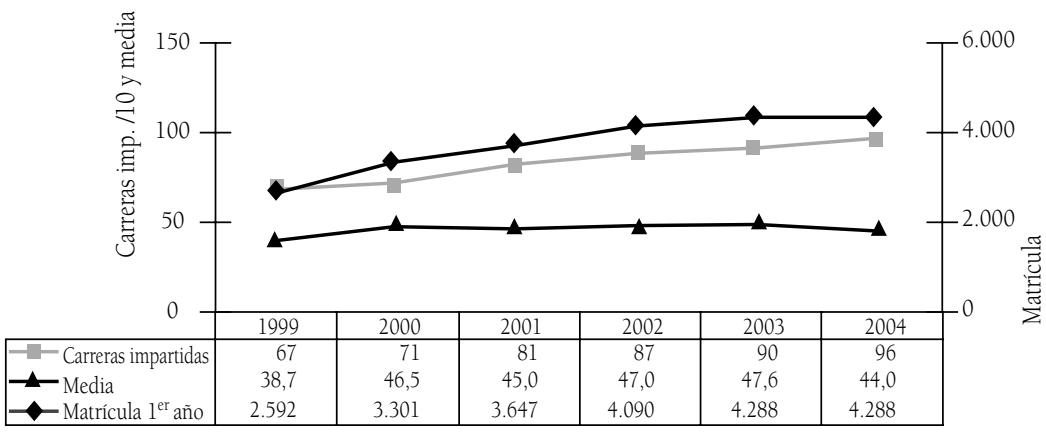

\section{Ciencias Sociales}

El área de Ciencias Sociales tiene un comportamiento muy parecido al área de Administración y Comercio, con presencia en todas las regiones del país pero concentrando casi la mitad de la oferta en la RM, seguida de la V y VIII regiones. La diferencia se observa en las instituciones que ofrecen dichas carreras, ya que, a lo largo del tiempo, la participación de las universidades en la oferta ha ido aumentando desde un 65 a un 74\%.

Gráfico 76. Evolución de la oferta de carreras del área de

Ciencias Sociales según tipo de institución

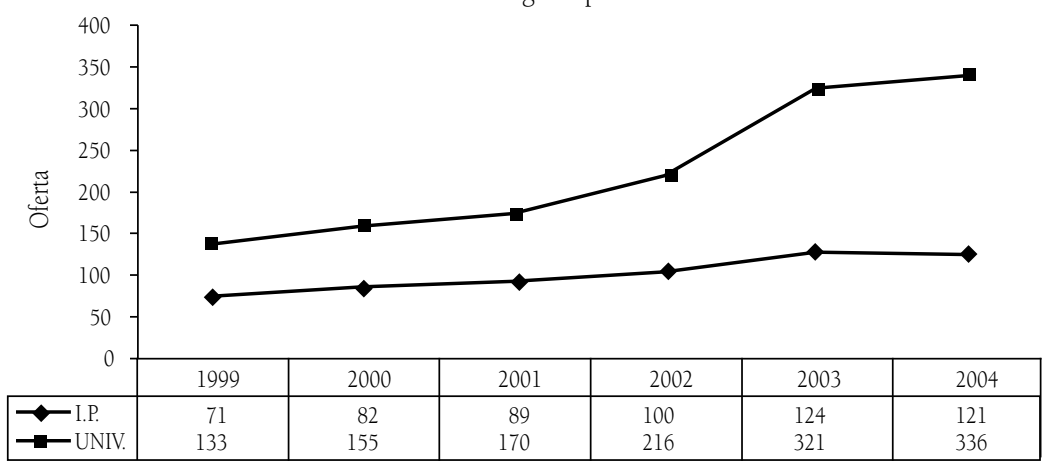




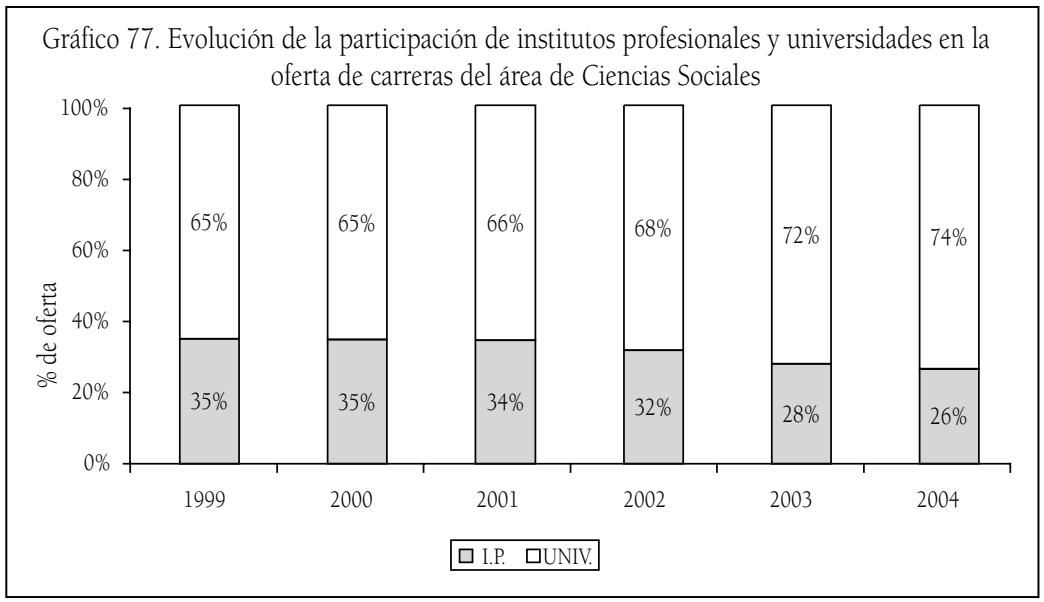

El área de Ciencias Sociales presenta un pronunciado y estable crecimiento de la matrícula y de las carreras impartidas en el país. De todos modos, la leve baja en la media de estudiantes por carrera hace pensar que el crecimiento de la inscripción en los programas es de menor intensidad a partir de 2002. En la regiones Metropolitana, II, IV, IX y X tienden a observarse oscilaciones de matrícula junto a un aumento sostenido en el número de carreras impartidas. La I Región llama la atención por el fuerte aumento de programas y de estudiantes matriculados entre el 2003 y el 2004, lo que hace preguntarse respecto de cuándo alcanzará su "techo" de crecimiento. De modo menos agudo, esto también se aplica a la V, VII y VIII regiones.

En términos generales, la supremacía creciente de las universidades en la captación de matrícula es más marcada que en el caso de la oferta. 
Gráfico 78. Evolución de la matrícula de $1^{\text {er }}$ año y de las carreras impartidas en el área de Ciencias Sociales

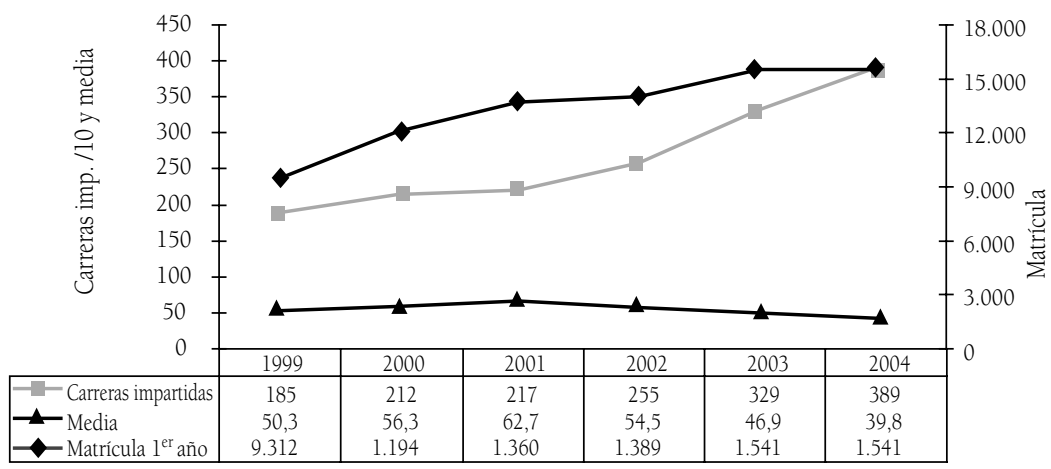

Gráfico 79. Evolución de la participación de los tipos de instituciones en la matrícula de $1^{\text {er }}$ año de las carreras impartidas en el área de Ciencias Sociales

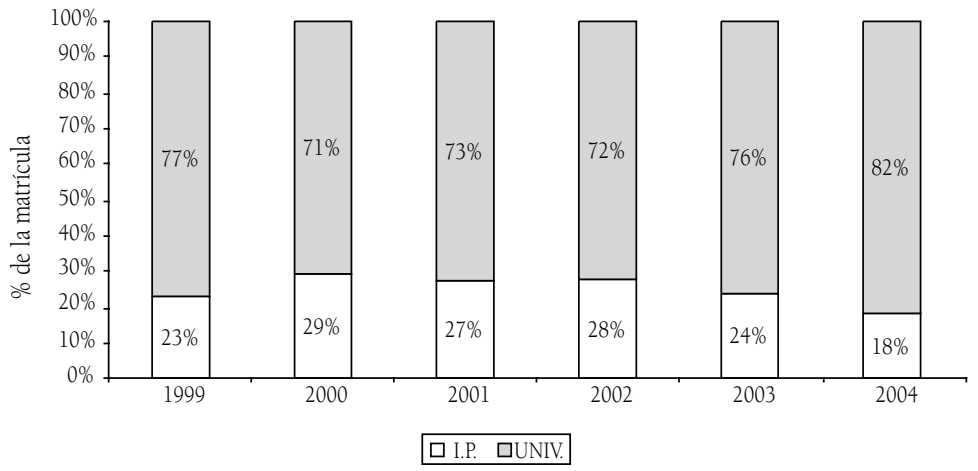

\section{Derecho}

Hasta 2002, el área de Derecho se comporta de modo muy parecido a las áreas Administración y Comercio y Ciencias Sociales, en lo que a distribución regional de oferta se refiere; no obstante, durante 2003 y 2004 se observa un quiebre, debido a que el aumento en la oferta de carreras de derecho en la VIII Región le quitó aproximadamente un $10 \%$ de participación a la RM, con lo que la distribución quedó en cerca de un 20\% de oferta para la VIII Región, casi un 30\% la RM y aproximadamente un 10\% la V Región. Este quiebre afecta 
de manera positiva a la participación de los institutos profesionales en la oferta total de carreras de Derecho en el país, por lo que se deduce que esta explosión de la oferta en la VIII Región fue realizada principalmente por IP, disminuyendo en 30\% la participación de las universidades que, en 1999, eran las únicas que ofrecían carreras en esta área. Aquí es relevante consignar que las carreras nuevas corresponden mayoritariamente a Criminalística.

Gráfico 80. Evolución de la oferta de carreras del área de Derecho según tipo de institución

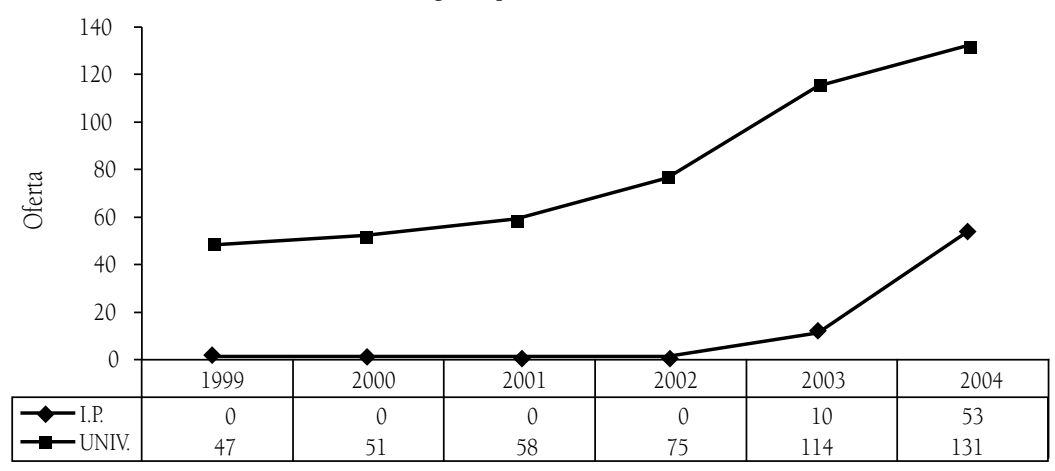

Gráfico 81. Evolución de la participación de institutos profesionales y universidades en la oferta de carreras del área de Derecho

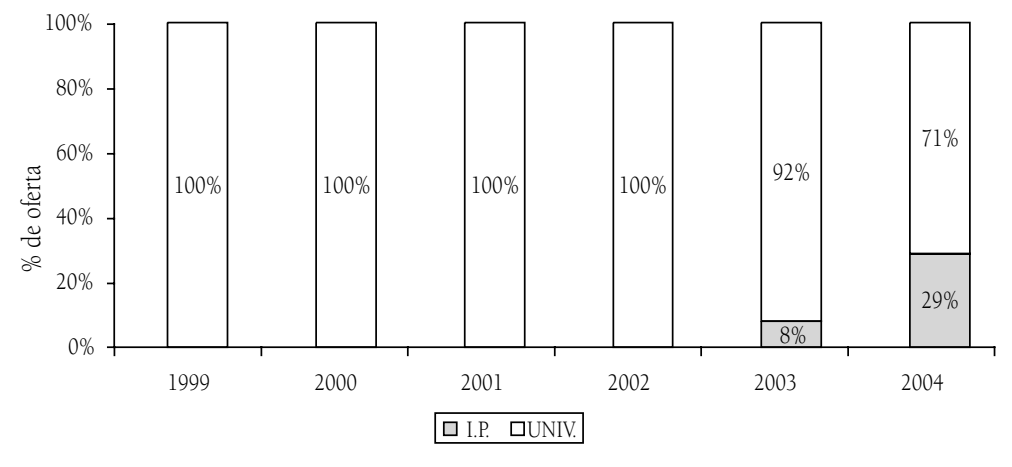

El incremento de las carreras del área Derecho impartidas en el país ha sido de un 54\% entre 2003 y 2004, mientras que el 
crecimiento de la matrícula de primer año se estanca en el mismo periodo, provocando una gran baja en el promedio de estudiantes por carrera. Este patrón se corresponde con la situación de las regiones II, IV, VI, XII, pero en las demás sí se observa un aumento de matrícula, por lo que la pregunta debe centrarse en la explosión de carreras que la acompaña y en las proyecciones de la oferta.

En términos de participación, según tipo de instituciones, casi la totalidad de la matrícula corresponde a estudiantes de universidades, a pesar de la explosión de la oferta de carreras de IP que lleva a los institutos a tener una participación de un 30\%, evidenciando nuevamente una probable sobreoferta de carreras del área de Derecho por parte de los IP, puesto que su participación en la matrícula es de sólo $15 \%$.

Gráfico 82. Evolución de la matrícula de $1^{\text {er }}$ año y

de las carreras impartidas del área de Derecho

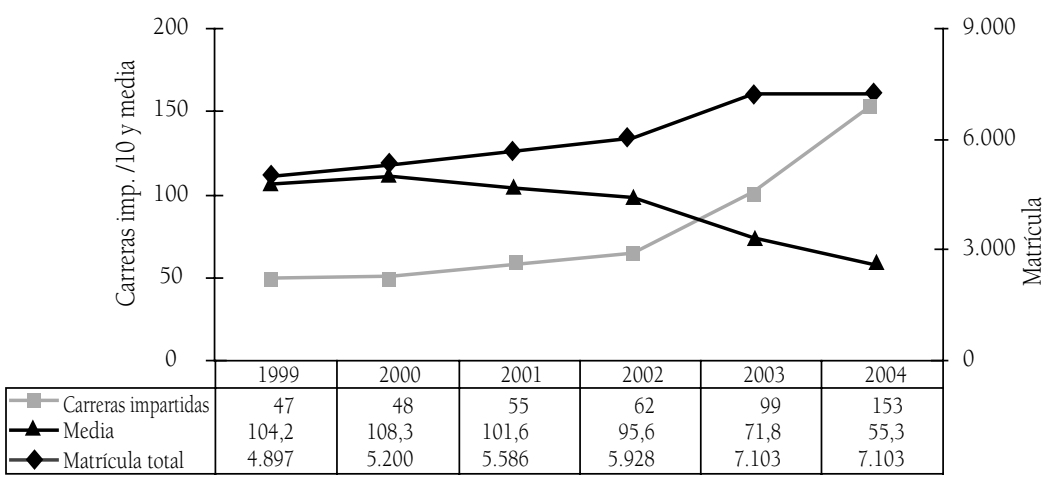

\section{Educación}

La oferta de carreras del área de Educación se concentra en la RM (aproximadamente un 36\%), seguida por la VIII Región (cerca de un $16 \%$ ) y la V (en torno a un 13\%). Esta última ha experimentado una baja de $7 \%$ en su participación en la oferta del área. En cuanto al tipo de institución, un $80 \%$ de la oferta de carreras de Educación la tienen las universidades y un 20\% los institutos profesionales. 

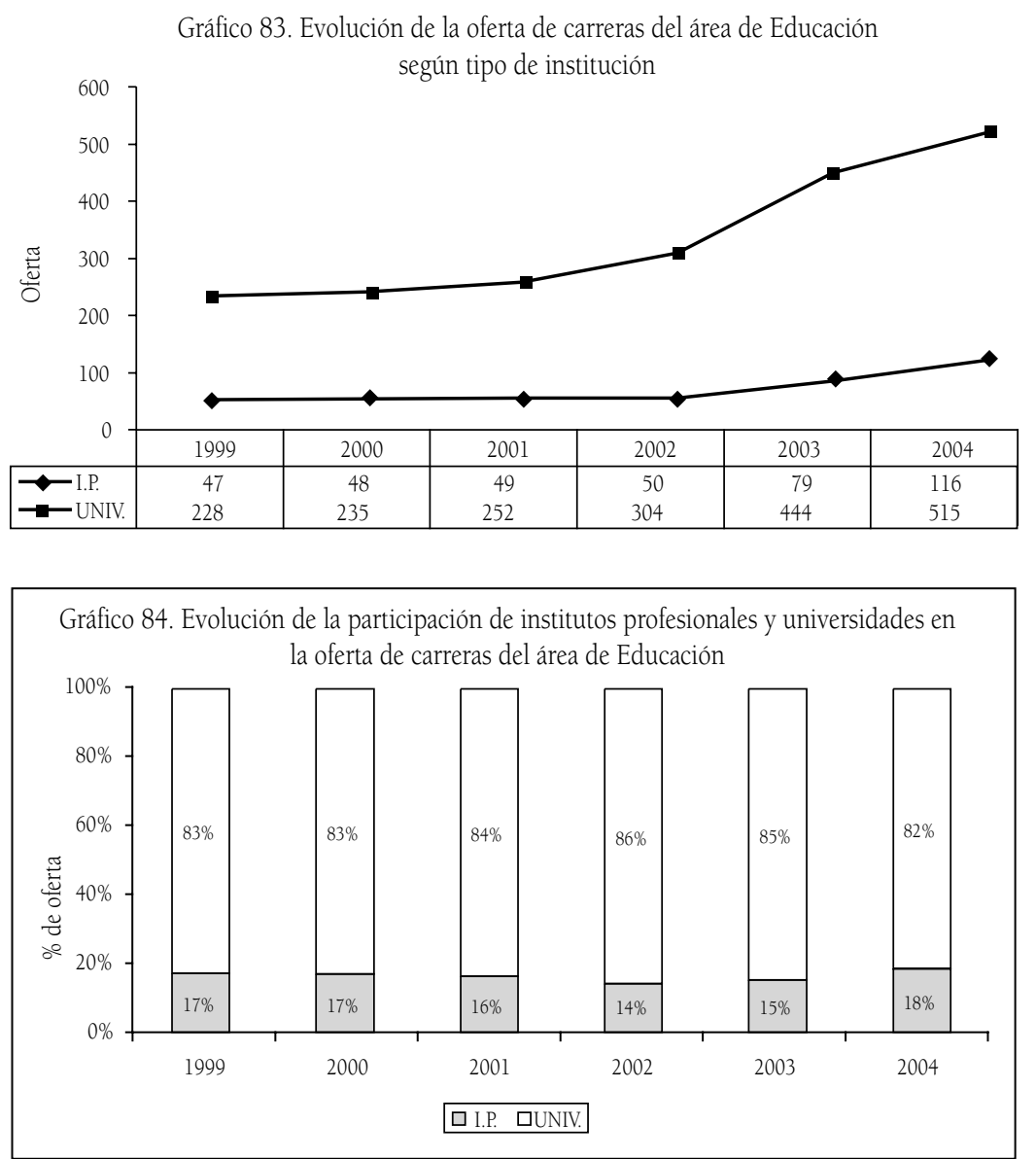

Del mismo modo que en el área de Ciencias Sociales, en Educación también se observa un pronunciado y estable crecimiento de la matrícula y de las carreras impartidas en el país, sobre todo desde 2002, con un $87 \%$ de la participación de las universidades en la captación de estudiantes. Las regiones I y V destacan por un crecimiento abrupto de las carreras impartidas en 2003 y 2004 que no se condice con el aumento moderado de la matrícula. En menor medida, las demás regiones también están haciendo una apuesta fuerte en ese sentido, abriendo interrogantes en relación con la evolución futura de la oferta y la captación de matrícula en el área. 
Gráfico 85. Evolución de la matrícula de $1^{\text {er }}$ año y

de las carreras impartidas en el área de Educación
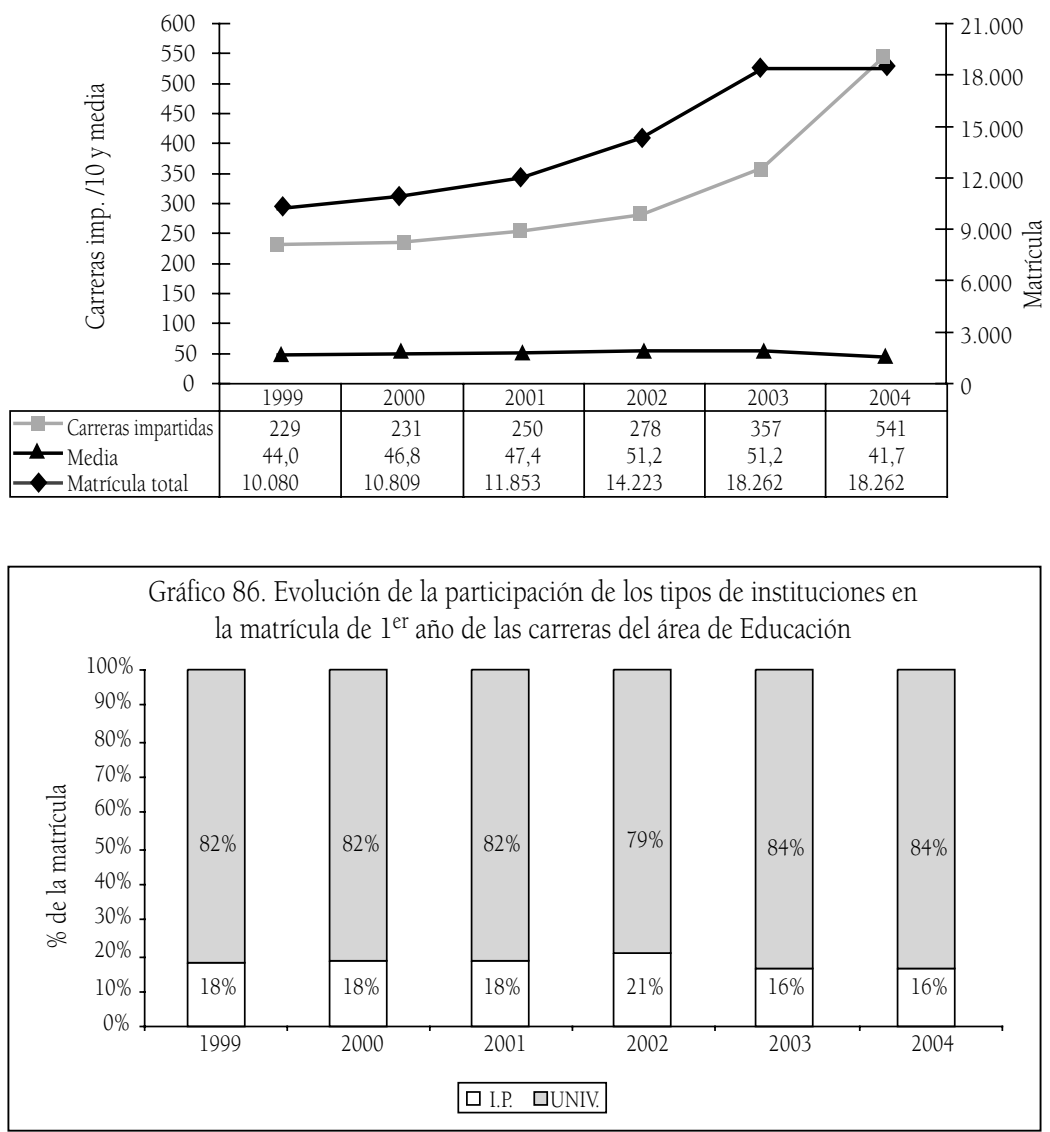

\section{Humanidades}

El área de Humanidades tiene una participación regional muy parecida a Arte y Arquitectura, con una aportación en la oferta de cerca de un $60 \%$ en la RM y un $20 \%$ en la V Región. Las regiones VI, VII y XI son las que no tienen oferta de carreras de Humanidades, y las universidades tienen una participación de aproximadamente un $90 \%$ de la oferta de carreras de esta área en el país. 
Gráfico 87. Evolución de la oferta de carreras del área de Humanidades según tipo de institución
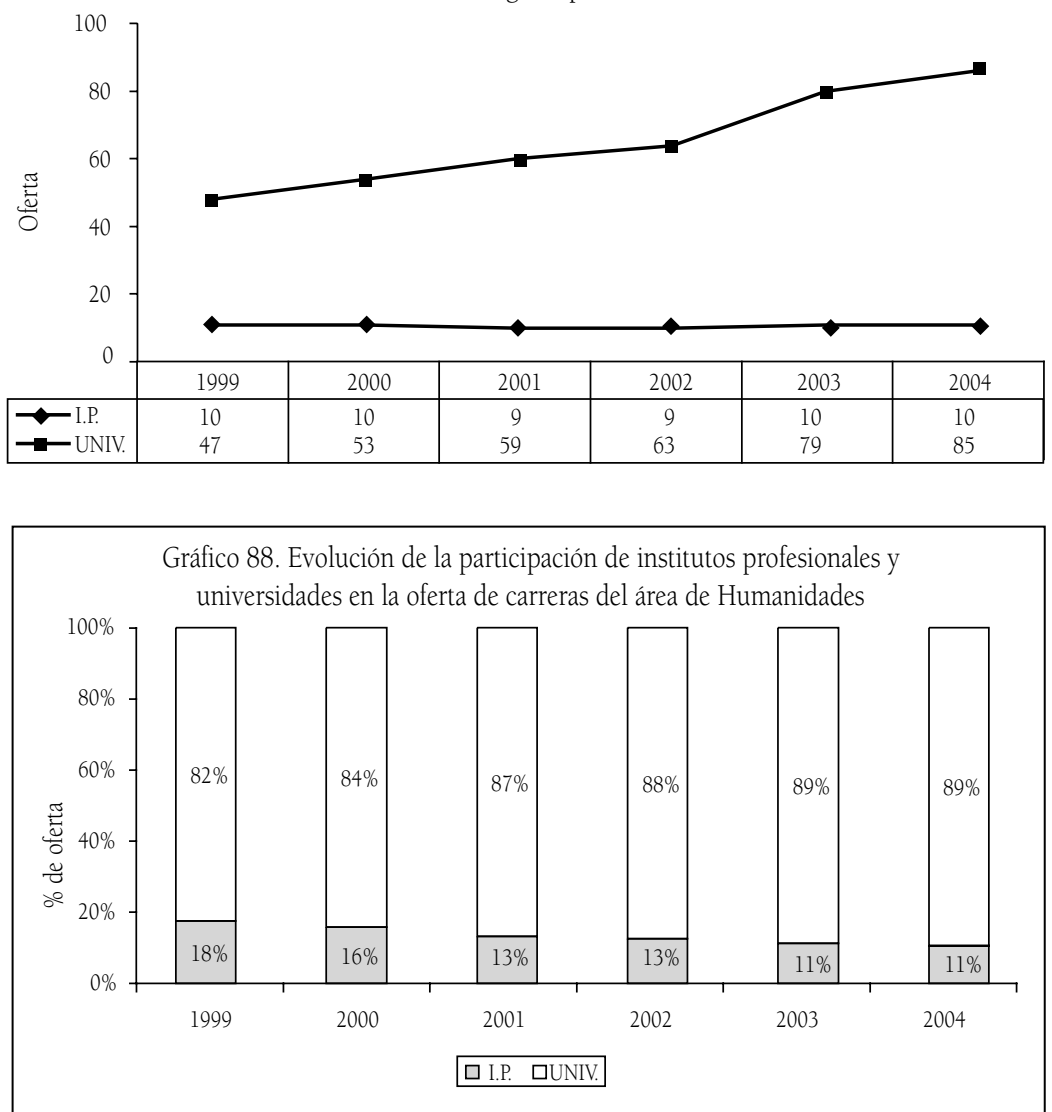

En el área de Humanidades, los indicadores de matrícula muestran una leve baja en la media de alumnos por carrera impartida, producto del crecimiento en el número de carreras, siendo la V Región el ejemplo más claro de ello. Las universidades tienen a casi la totalidad de los estudiantes de carreras del área de Humanidades en 2004 (90\%), lo que, de todos modos, representa un retroceso relativo, puesto que antes captaban incluso una mayor proporción de alumnos. 
Gráfico 89. Evolución de la matrícula de $1^{\text {er }}$ año y carreras impartidas del área de Humanidades

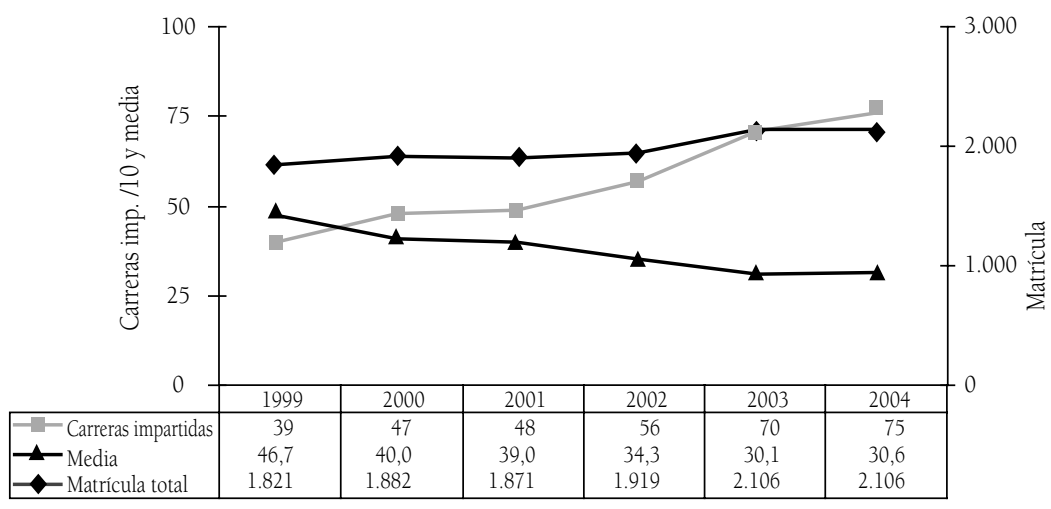

\section{Salud}

En 2002 se produce un alza en la oferta de carreras del área de Salud. Al año siguiente, los IP inician su participación en el mercado, disminuyendo el peso relativo de las universidades al 80\% en 2004. La RM tiene cerca de un 30\% de la oferta de carreras del área Salud, mientras que la VIII Región aproximadamente un 16\% y la V Región se acerca a un $12 \%$.

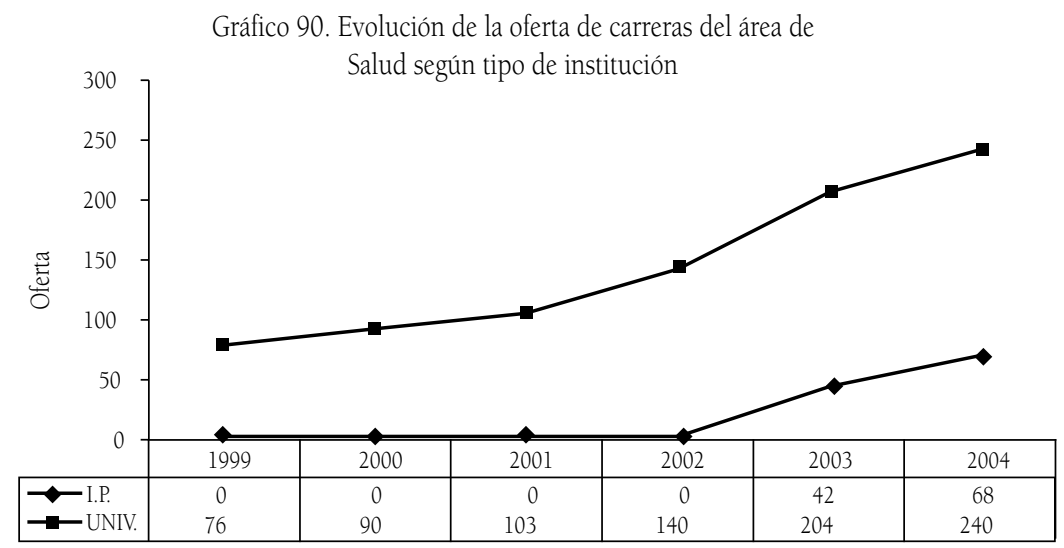




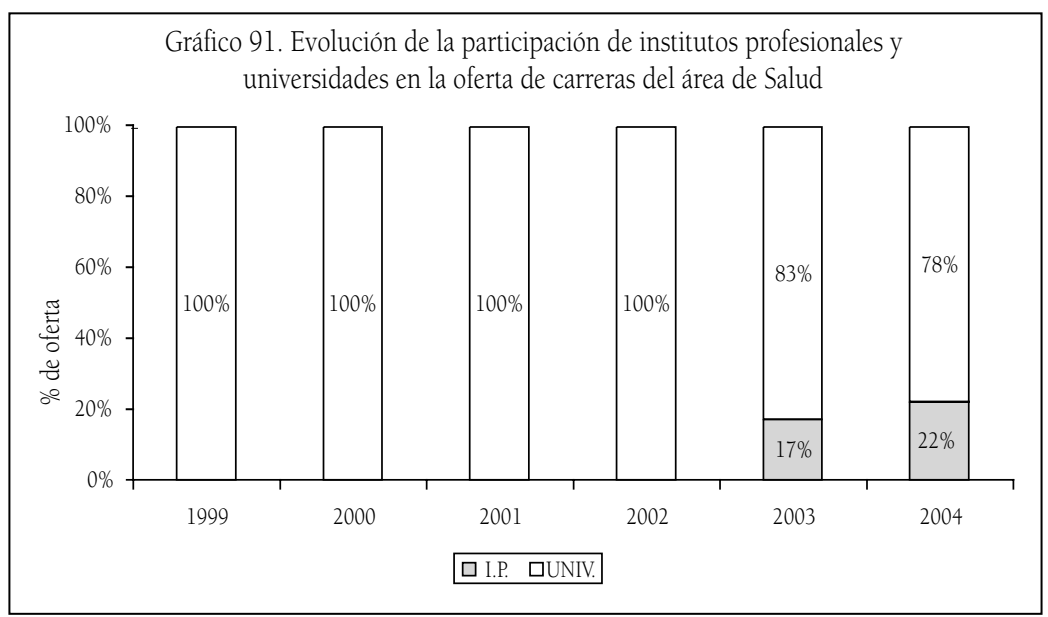

El área de Salud presenta un pronunciado y estable crecimiento del número de carreras impartidas y de matrícula desde 2002, el cual se frena dos años después. A decir verdad, la mayoría de las regiones crece en número de estudiantes hasta 2004 inclusive, sólo las regiones II, VI y VIII corresponden relativamente al patrón general descrito. Nuevamente, las dudas conciernen a las proyecciones de oferta y de matrícula.

A partir de 2003, los IP comienzan a captar una parte mínima de la matrícula que en 2003 llega al 5\% y en 2004 al 11\%. Ello, a pesar de que su participación en la oferta alcanza un $20 \%$ aproximadamente.

Gráfico 92. Evolución de la matrícula de $1^{\text {er }}$ año y de las carreras impartidas del área de Salud

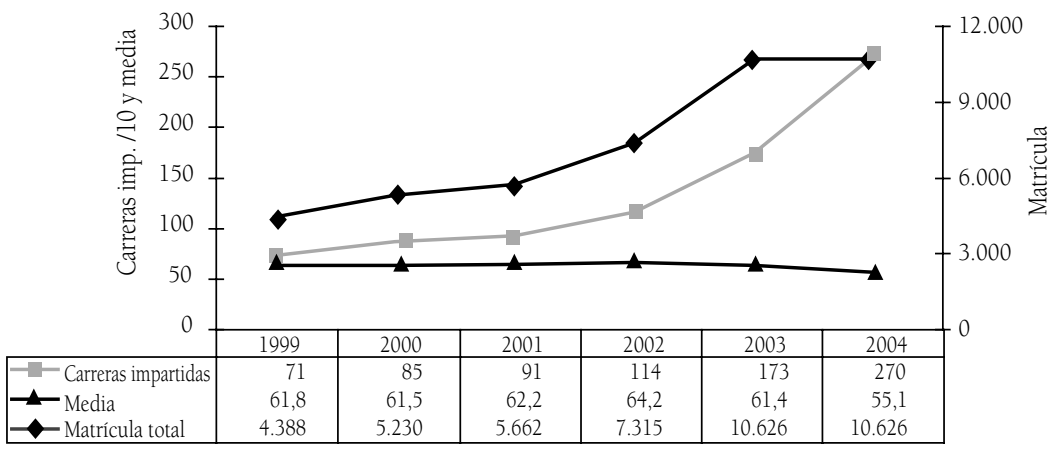




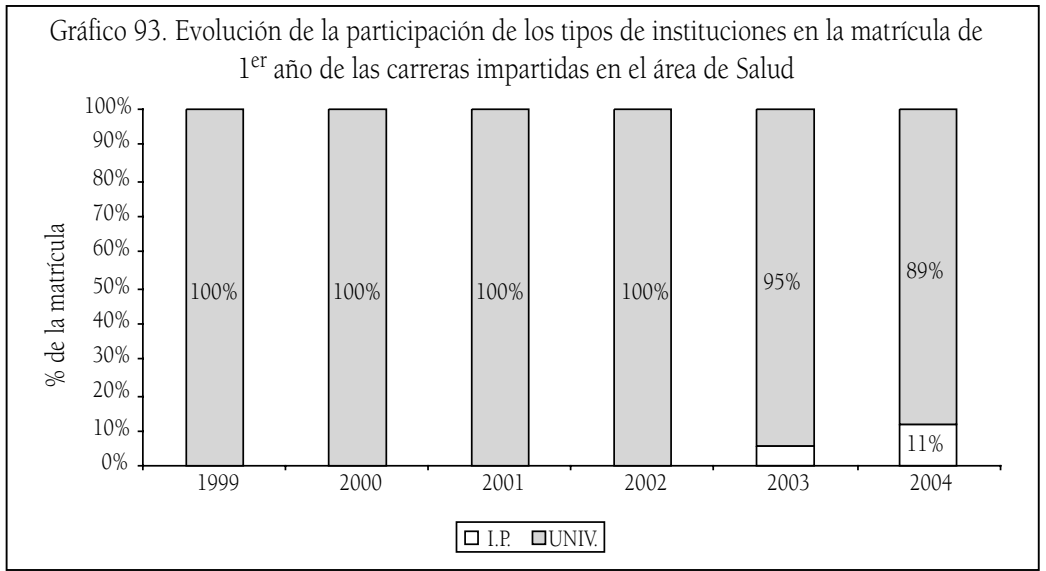

\section{Tecnología}

El Área de Tecnología se comporta de manera muy parecida al área de Administración y Comercio, respecto de la participación casi equitativa entre IP y universidades en la oferta de sus carreras, además de la concentración de cerca de un $40 \%$ en la RM, seguida por las regiones V y VIII con un 15\% aprox. En 2001 se inicia un alza sostenida de oferta que se detiene en 2004.

Gráfico 94. Evolución de la oferta de carreras del área de Tecnología según tipo de institución

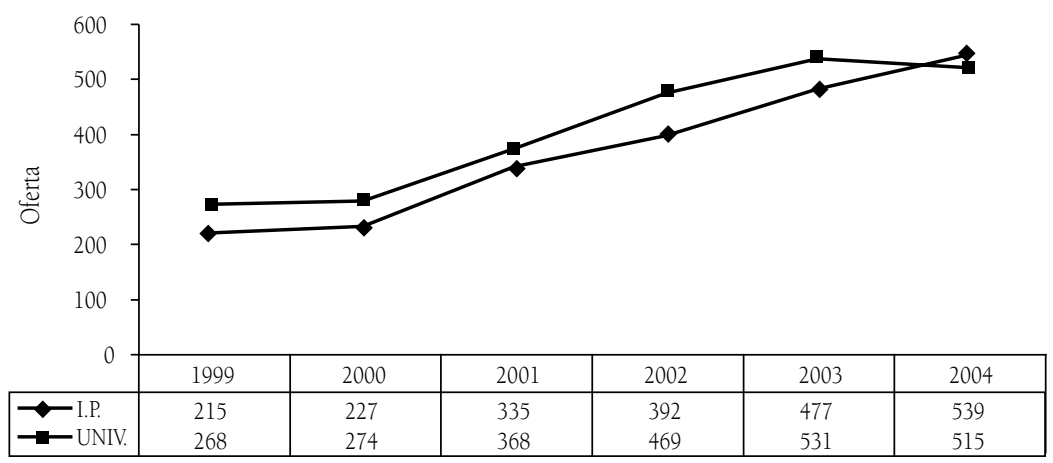




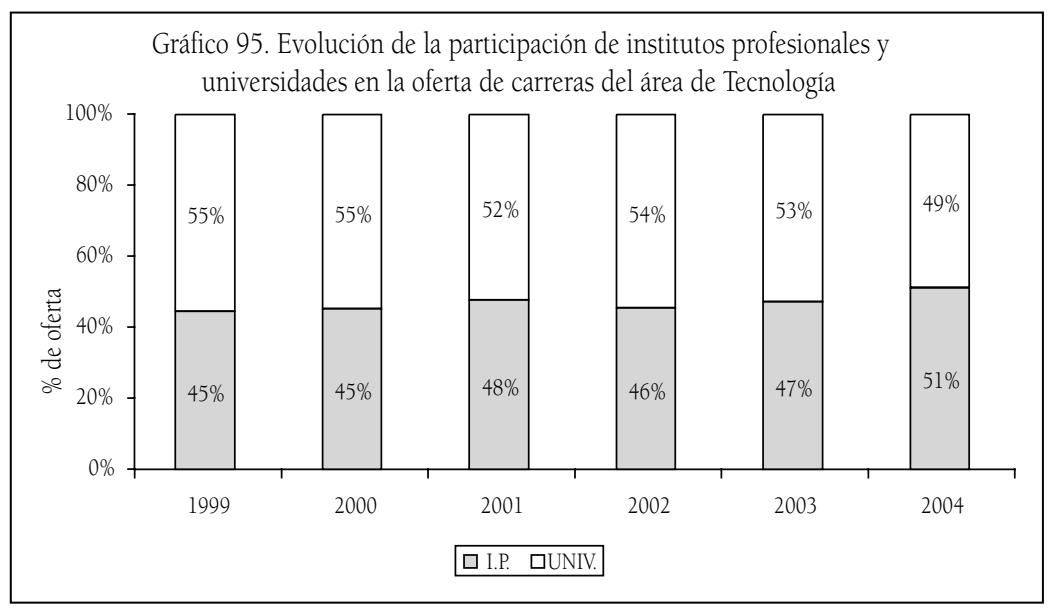

El área de Tecnología también presenta un pronunciado y estable crecimiento de las carreras impartidas y de la matrícula. Pese a ello, el incremento de esta última se detiene en 2004. La mayoría de las regiones coincide con este patrón, excepto la III y VI que ganan terreno, en lo que a captación de alumnos se refiere, hasta 2004 inclusive.

Aproximadamente un 56\% de estudiantes matriculados se incorporan al sector universitario: una proporción no tan lejana a la distribución de oferta por tipo de institución.

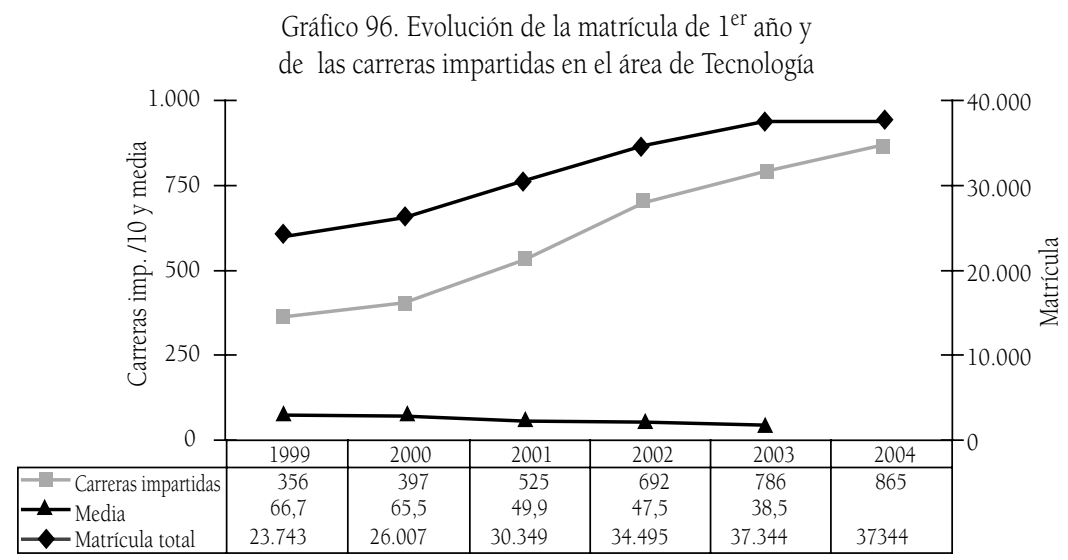


Gráfico 97. Evolución de la participación de los tipos de instituciones en la matrícula de $1^{\text {er }}$ año de las carreras del área de Tecnología

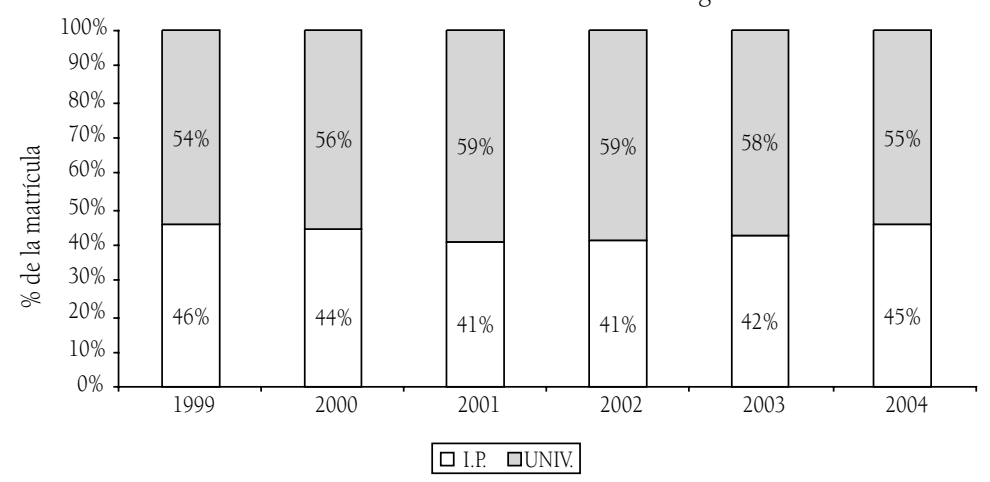

\section{Comentarios conclusivos sobre la tercera sección}

La distribución de la oferta y la matrícula entre las distintas áreas del conocimiento se ha mantenido relativamente estable en todo el país, aunque se observa que áreas como Educación y, en menor proporción, Salud, han elevado su presencia en comparación con áreas tradicionalmente fuertes como Tecnología y Administración y Comercio. Si se habla de diversificación, probablemente estos sean los únicos signos visibles de transformación en lo que a áreas del conocimiento se refiere.

La distribución de oferta por área del conocimiento en las regiones presenta variaciones en cuanto a concentración geográfica. Arte y Arquitectura junto con Humanidades son las más concentradas en la RM (60\%), mientras que en esta misma región se ofrece la mitad de las carreras de las áreas Administración y Comercio, Ciencias Sociales y un $40 \%$ de los programas de Tecnología. Se puede aseverar que el resto de las áreas se distribuye de manera más equitativa, geográficamente hablando, salvo en las regiones III, VI y XI, donde la variedad de áreas de conocimiento en el mercado es limitada.

De la revisión del comportamiento de la matrícula al interior de cada área, su relación con las carreras impartidas y la participación 
diferencial por tipo de institución, emergen algunas tendencias que vale la pena examinar, con miras a identificar futuros objetos de investigación y seguimiento. Se pueden resumir los hallazgos en dos afirmaciones que, a su vez, deben ser matizadas exponiendo las particularidades que escapan al diagnóstico grueso.

1. Aunque ya en 1999 llevaban la delantera, las universidades han ido ganando terreno en lo concerniente a su participación en la oferta de carreras, lo que se acentúa en el caso de la matrícula. Tecnología, dada la importante atracción que ejerce en los alumnos, constituye una excepción no menor a esta tendencia, porque los institutos profesionales captan un porcentaje similar de estudiantes en comparación con las universidades.

2. La matrícula de las carreras crece hasta 2002, pero tiende a desacelerar o estancar su aumento durante los últimos dos años, mientras que el número de carreras no detiene su incremento salvo en casos muy puntuales.

La segunda afirmación sugiere que se asiste a un punto de inflexión muy interesante, cuyas consecuencias todavía están por verse. Ciertamente, los vínculos dinámicos entre oferta y matrícula son difíciles de capturar con una síntesis de esta naturaleza, pero pareciera que las instituciones de educación superior reaccionan ante cualquier alza de matrícula, instalando en el mercado más carreras que no siempre encuentran recepción de público. En este sentido, la fluctuación en la matrícula y la oferta de las áreas de Ciencias Sociales y Arte y Arquitectura serían útiles de observar con detención.

En la otra dirección, también puede que las instituciones de algunas regiones perciban que el interés potencial por un área de conocimiento no se actualiza en matrícula, justamente debido a la falta de alternativas de programas, y deciden apostar por que la oferta potencie la matrícula; este podría ser el caso del aumento de oferta en la I Región para las áreas de Ciencias, Ciencias Sociales y Educación. 
En cualquier caso, es preciso insistir en el punto de inflexión que pareciera vivir el mercado de la educación superior en Chile y en la necesidad de monitorear sus transformaciones de aquí en adelante.

\section{Análisis de las subáreas del conocimiento con mayor presencia en la oferta y la matrícula del país}

La observación de las áreas del conocimiento motiva, lógicamente, la exploración de dichas categorías en mayor detalle. Puntualmente, abre interrogantes sobre cuál es la situación específica de aquellas subáreas que, intuitivamente, percibimos ejerciendo mayor atracción de estudiantes y de oferta. Esta sección presenta una caracterización de aquellas subáreas o grupos de carreras ${ }^{7}$ que acaparan mayor número de alumnos y de programas en el país.

Para decidir cuántas subáreas seleccionar entre las que más atraen estudiantes hasta 2004, éstas se ordenan de mayor a menor hasta alcanzar el $60 \%$ de la matrícula anual. Así, se intenta asegurar el análisis de una proporción relevante cuantitativamente hablando. Por ese motivo se toma la decisión de seguir la evolución de los 14 grupos de carreras que, sumadas, también representan el $60 \%$ de la oferta total. La caracterización de cada subárea informa sobre los tipos de carreras que comprende, de acuerdo con la clasificación utilizada por el CSE para efectos de sistematización e investigación; entrega datos sobre el peso relativo de cada subárea en la oferta y matrícula nacionales; ilustra los porcentajes de participación según tipo de institución, tanto en la oferta como en la matrícula de primer año; presenta un gráfico que expone la evolución, en cifras absolutas, del número de carreras impartidas, la matrícula y el promedio de alumnos por carrera en todo el país y, finalmente, comenta sobre algunos patrones observados en regiones.

7 Algunas subáreas contienen gran variedad de carreras, mientras que otras están compuestas por una carrera. 


\section{Computación e Informática}

La subárea incluye las carreras de Ingeniería en Computación e Informática, Ingeniería Civil en Computación e Informática, Ingeniería de Ejecución en Computación e Informática y carreras técnicas. Computación e Informática llega a representar el 9,3\% de la oferta país en 2002 pero en 2004 retrocede a 8,3\%, rebaja porcentual aún más manifiesta en el caso de la matrícula, pues un $8,5 \%$ de estudiantes optaban por la subárea hasta hace dos años y, hoy, éstos constituyen el 6,9\% de los alumnos de primer año. La participación en la oferta y matrícula por tipo de institución favorece a los IP que, incluso, acrecientan levemente su participación en la oferta (de 55 a 63\%) y captan cerca del 58\% de la matrícula.
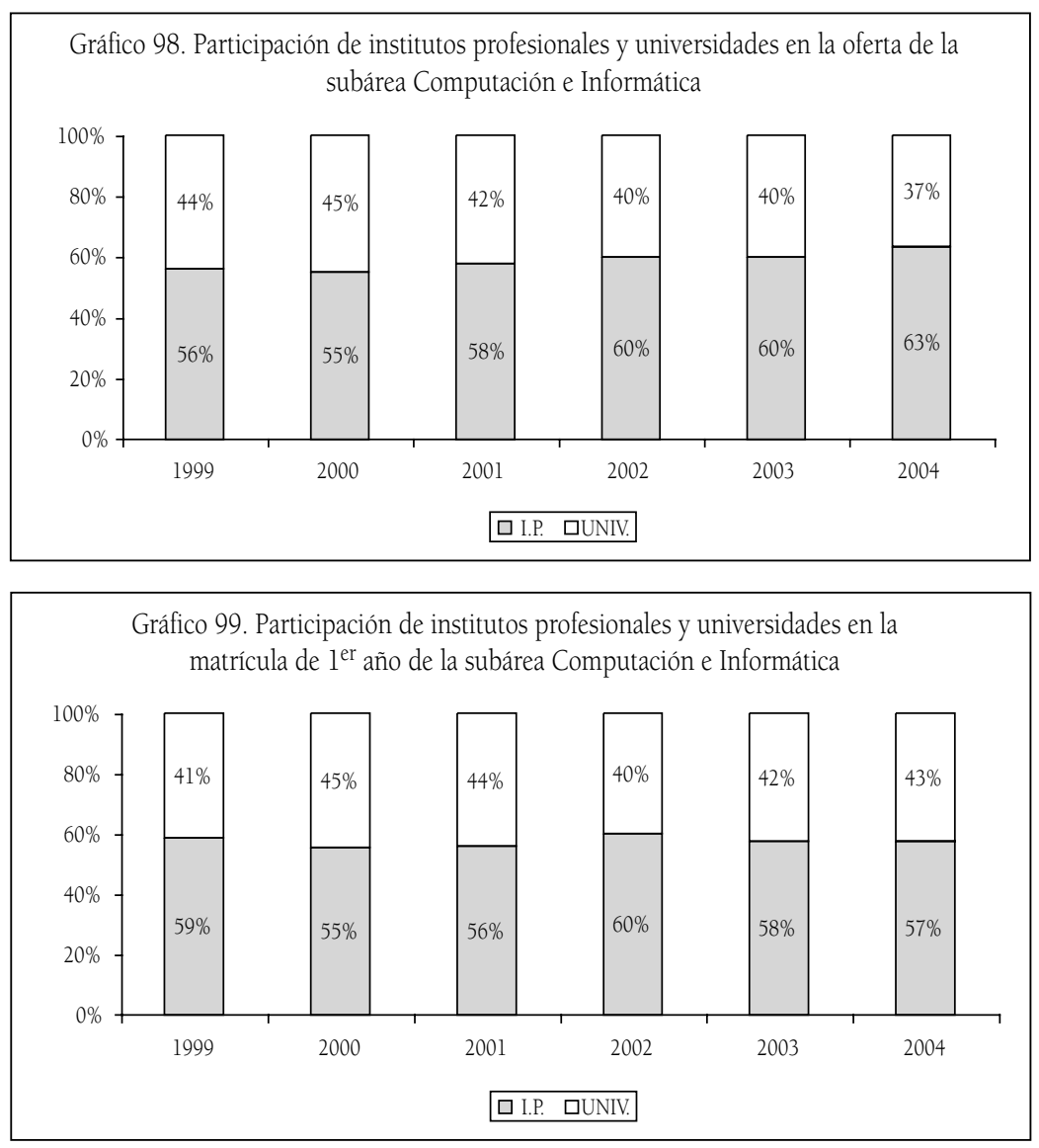
Las cifras absolutas, graficadas más abajo, muestran que hay un aumento explosivo de los programas entre 2000 y 2003, que parece desacelerar en 2004. La matrícula, por su parte, replica este movimiento pero con una intensidad del alza menor, lo que deriva en la disminución del promedio de alumnos por carrera. Las instituciones en regiones parecen ajustar la oferta de los últimos dos años atendiendo al nulo o bajo crecimiento de estudiantes inscritos, excepto las regiones II, VIII y Metropolitana donde, debido a las alzas de 2003, las carreras impartidas aumentaron en 2004 sin que ello tuviera eco en la matrícula.

Gráfico 100. Evolución de la matrícula de $1^{\text {er }}$ año en el conjunto de carreras de la subárea Computación e Informática

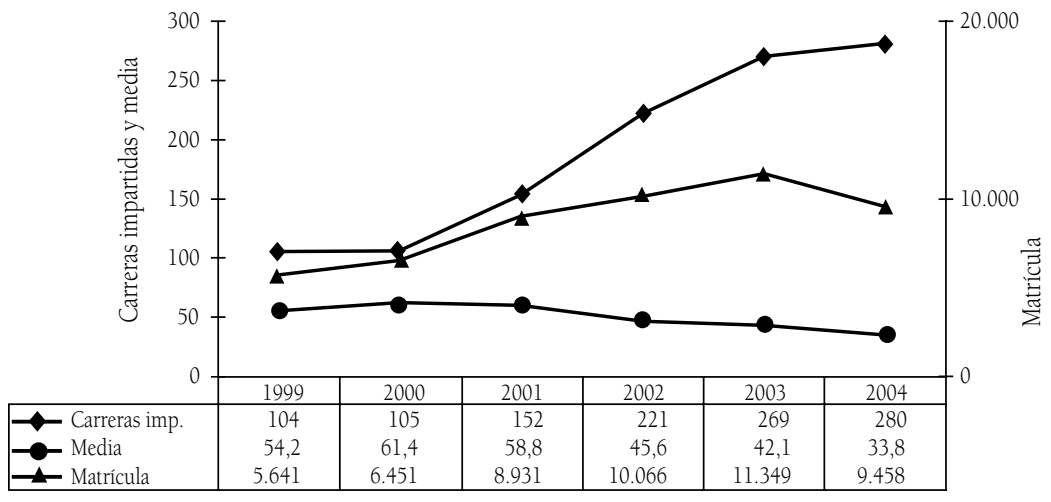

\section{Administración}

Esta subárea comprende cinco tipos de carreras, a saber: Administración de Empresas, Administración y Gestión Pública, Ingeniería Comercial, Recursos Humanos y carreras técnicas. Las carreras de administración llegaron a representar el 10\% del total nacional de carreras impartidas en 2001; hoy equivalen al $8 \%$ y acaparan al 6,7\% de los estudiantes de primer año del país. Durante el periodo estudiado, los IP proveen alrededor del $40 \%$ de la oferta y se quedan con aproximadamente el 26\% de la matrícula. 


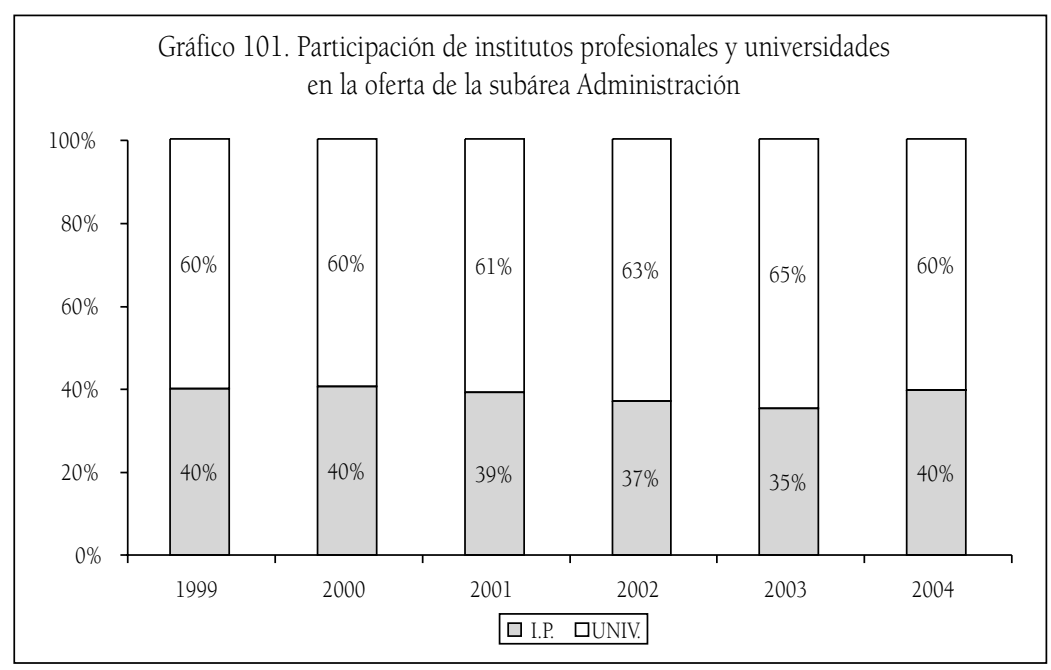

Gráfico 102. Participación de institutos profesionales y universidades en la matrícula de $1^{\mathrm{er}}$ año de la subárea Administración

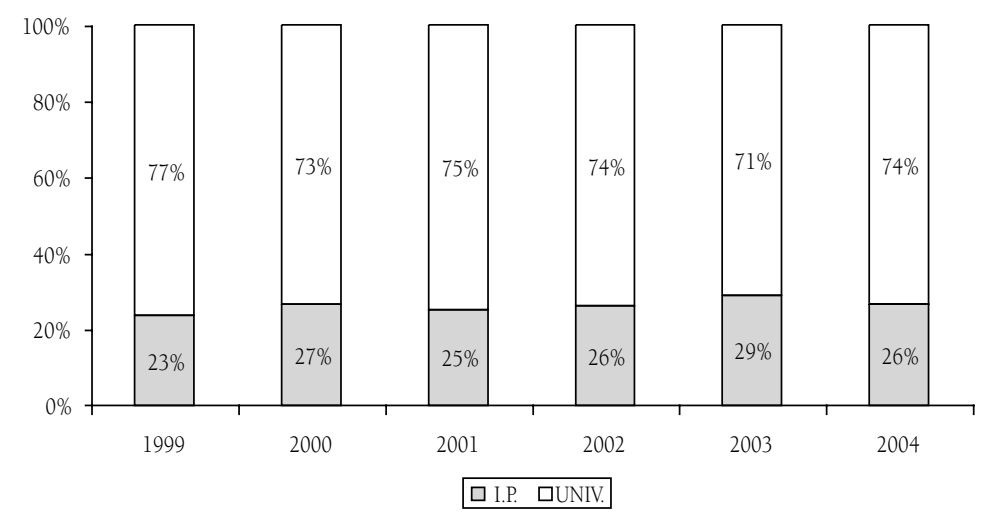

En términos de crecimiento absoluto nacional, los programas de la subárea experimentan un alza a partir del año 2000, mientras que la matrícula se mantiene estable, haciendo que el promedio de alumnos por programa decrezca levemente. Durante los últimos dos años, la mayoría de las regiones presenta incrementos bastante armónicos entre la matrícula y la cantidad de carreras impartidas, en contraste con la RM donde la matrícula decae en 2004, a pesar de que se imparten ocho nuevos programas. 
Gráfico 103. Evolución de la matrícula de $1^{\text {er }}$ año en el conjunto de carreras de la subárea Administración

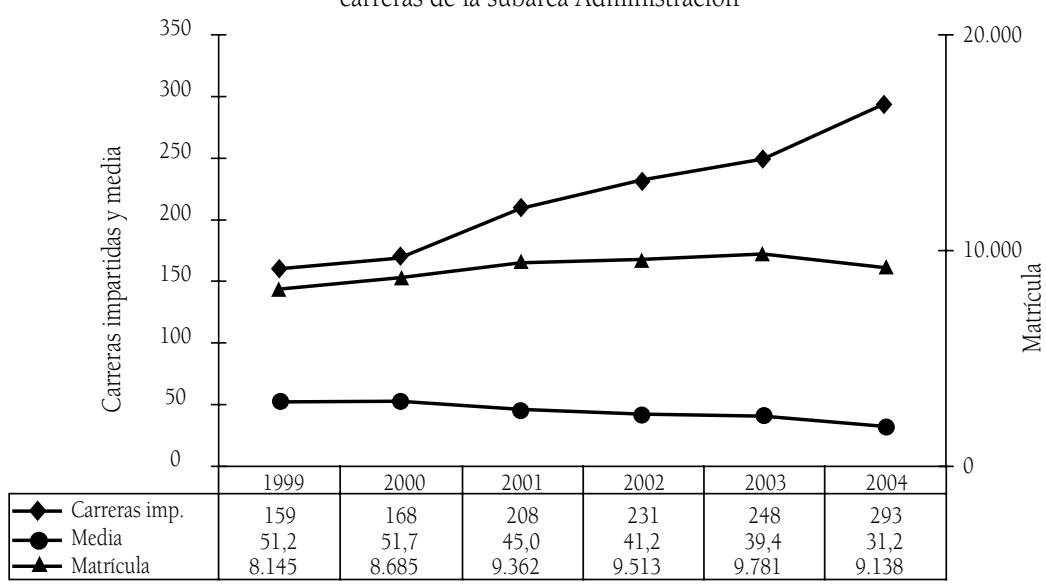

\section{Industrial}

La categoría abarca a carreras como Control de Calidad, Ingeniería Civil Industrial, Prevención de Riesgos, Procesos Industriales y carreras técnicas relacionadas. En términos de oferta, la representación de la subárea Industrial se mueve entre el 6 y el 7\% del total nacional, pero su peso relativo en matrícula disminuye desde un 6,5 a menos del 5\%. De ese porcentaje, los IP retroceden, en cuanto a participación en la matrícula, de un 57\% en 2000 al $40 \%$ en 2003, muy en consonancia con la oferta.

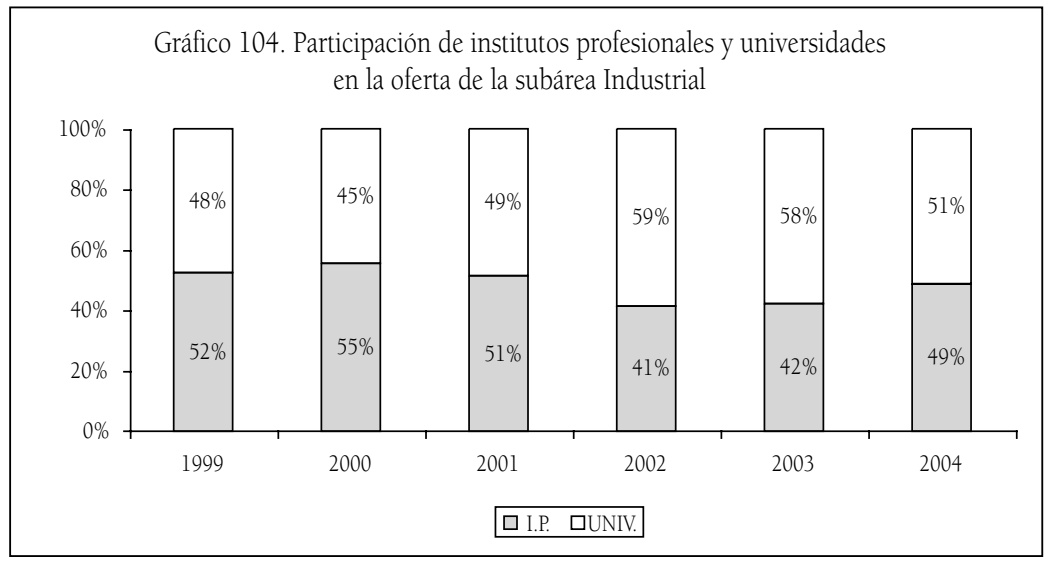




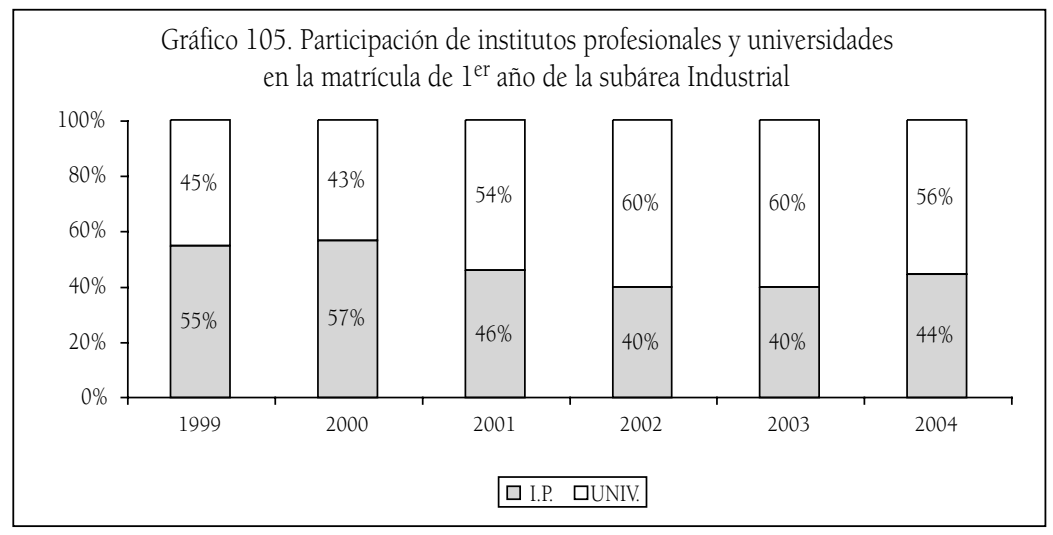

En cuanto a lo que nos pueden informar las cifras nacionales agregadas, y sumando los dos tipos de instituciones, se observa que, después de una caída en 2001, las carreras impartidas repuntan de modo claro y regular. El incremento en la matrícula también es visible pero retrocede en 2004 derivando en el descenso del promedio de estudiantes por carrera. Las regiones que coinciden más o menos con esta descripción son la IV y V; en cambio, en las regiones I, VII y IX la tendencia gruesa es a la baja de matriculados y de programas en 2004. Finalmente, las regiones VIII y Metropolitana coinciden en el aumento sostenido de estudiantes (salvo en 2003), así como en el de carreras en el mercado.

Gráfico 106. Evolución de la matrícula de $1^{\mathrm{er}}$ año en el conjunto de carreras de la subárea Industrial

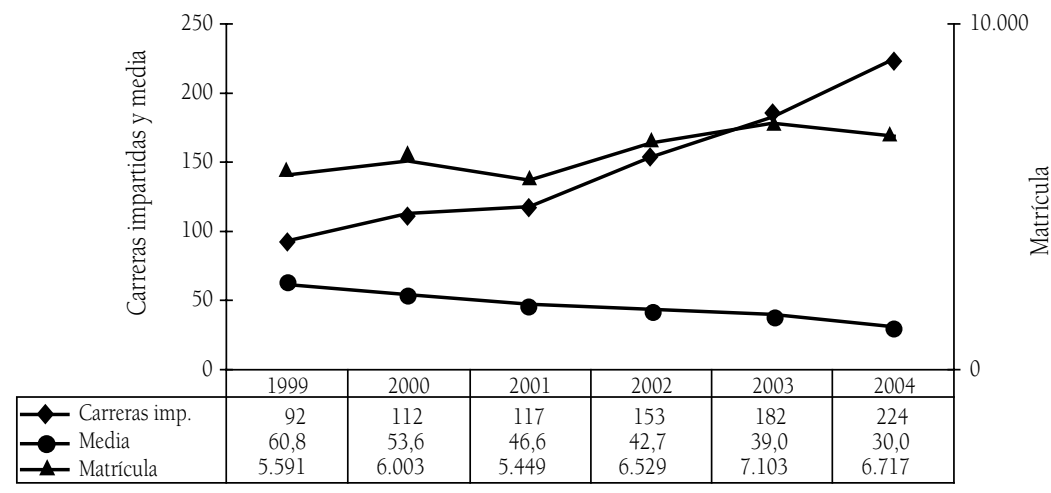




\section{Contabilidad}

La subárea que se examina a continuación está formada por dos tipos de carreras: Contador Público-Auditor y carreras técnicas. Su participación relativa en la oferta nacional durante estos seis años sufre una merma notoria (6,4\% en 1999 a 3,7\% en los últimos años). La oferta de los IP se mantiene estable alrededor del 50\%, mientras que la participación en la matrícula de este tipo de instituciones es de aproximadamente un $41 \%$ para los últimos tres años.
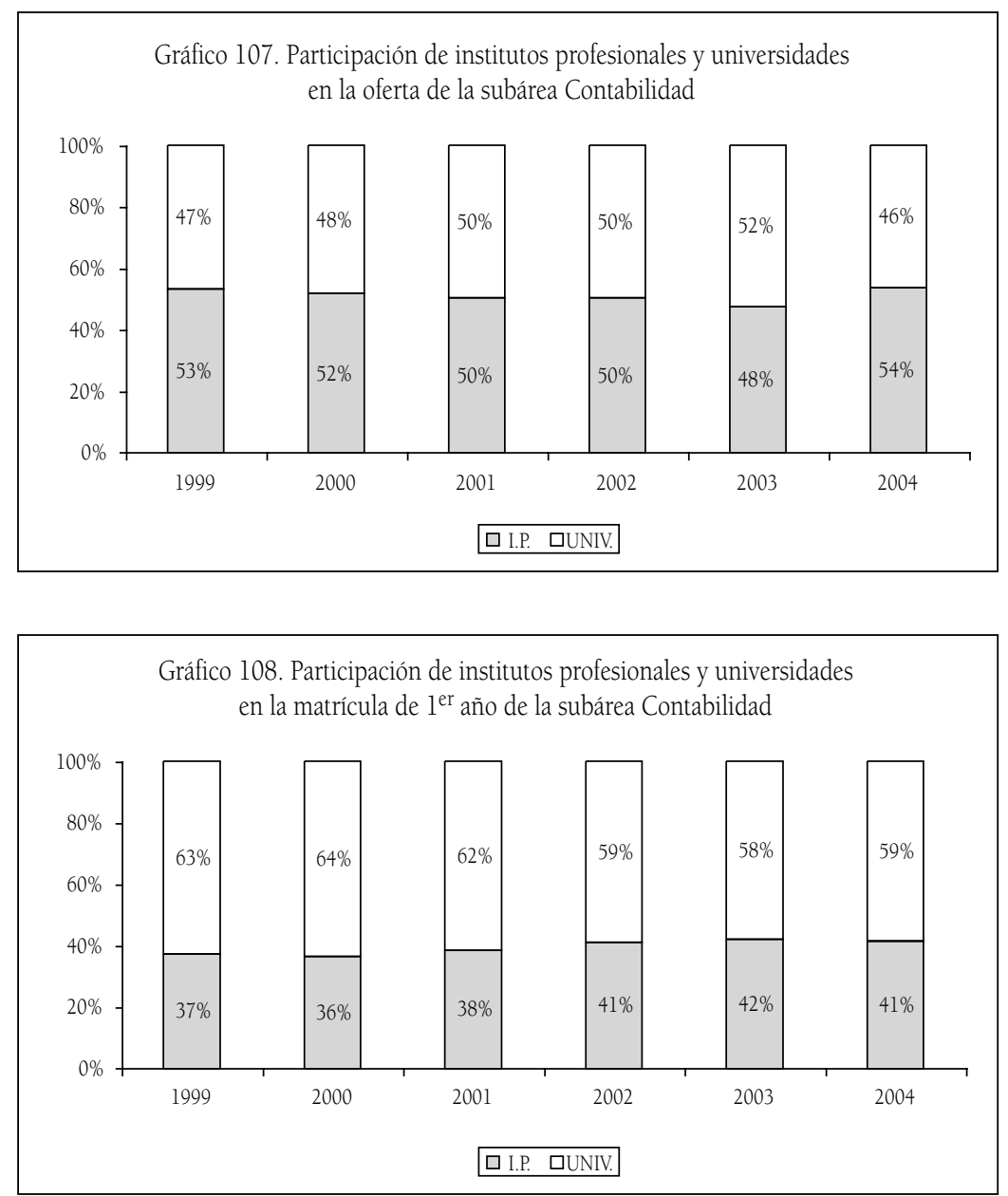
En términos de crecimiento absoluto, las carreras impartidas en el país aumentan desde 2000, mientras que la matrícula se mantiene relativamente estable hasta 2003, tras lo cual disminuye. La revisión más exhaustiva de las regiones revela, en gran parte de los casos, una matrícula oscilante, que alcanza un peak en 2002 o 2003. La excepción es la VI Región que gana estudiantes sostenidamente, en 2004 inclusive. Las regiones de mayor concentración de población (Metropolitana, V, VIII y X) son precisamente aquellas donde las instituciones parecen "confiar" en la bonanza de matrícula de años anteriores, apostando por sostener o incluso añadir programas a la oferta, sin que ello atraiga más alumnado. En el resto de las regiones, en cambio, la disminución de carreras impartidas en 2004 sugiere un ajuste de la oferta.

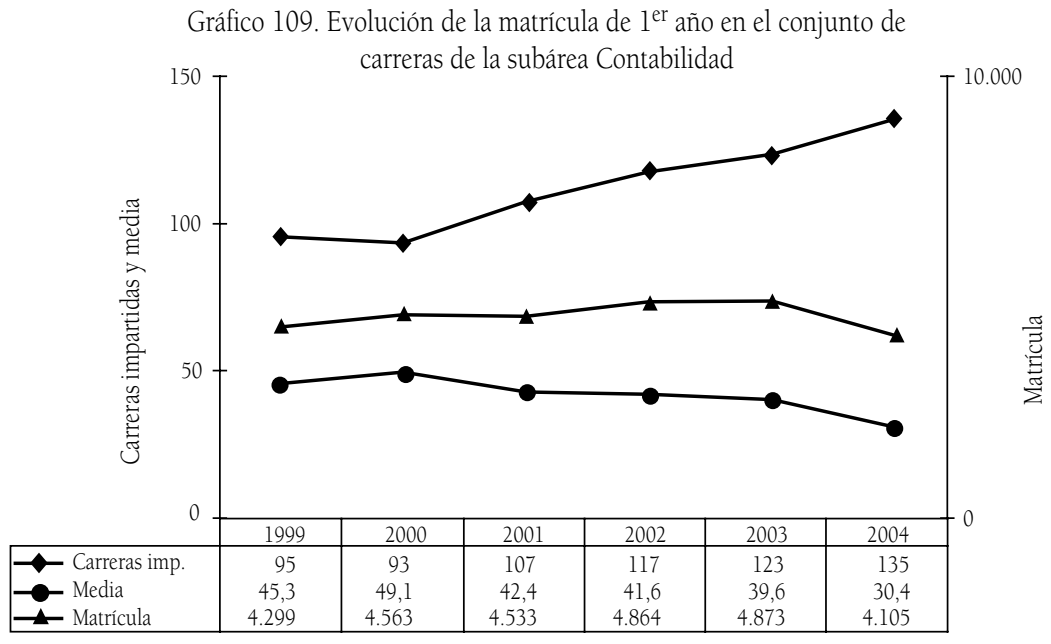

\section{Diseño}

Esta subárea comprende gran variedad de carreras, como Diseño, Diseño de Ambientes y Mobiliario, Diseño de Áreas Verdes, Diseño Gráfico, Diseño Industrial y Diseño de Vestuario. Su porcentaje en la oferta total del país no varía sustantivamente (de un $4 \%$ a un 3,3\%), tampoco el de matrícula (3,5\%). Durante los últimos seis años, los IP acaparan cerca del 50\% de inscritos pero, sorprendentemente, 
disminuyen su oferta de un 59\% a un $46 \%$, lo que lleva a pensar en que los alumnos se están concentrando en menos programas y, eventualmente, en menos instituciones que antaño.
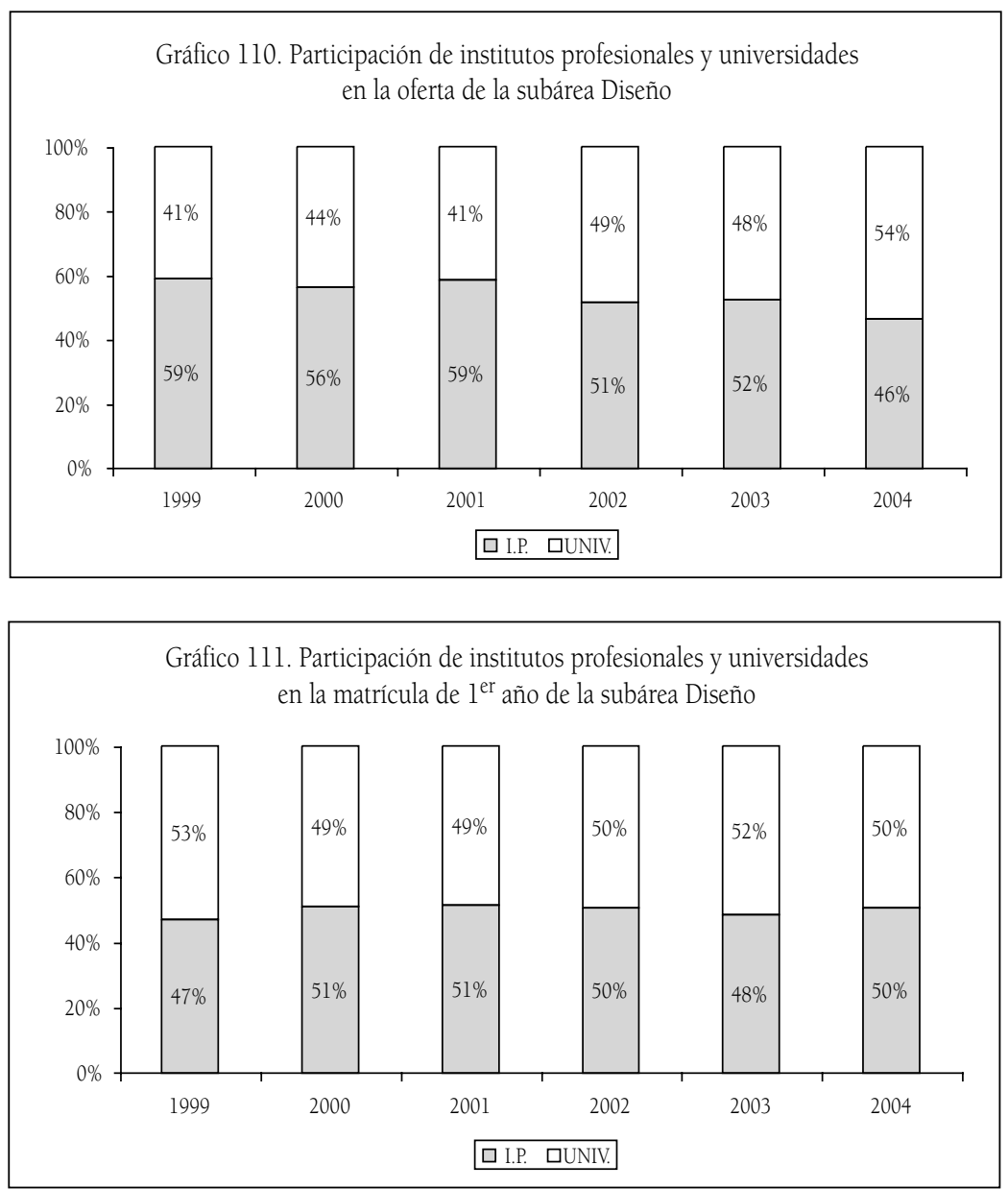

Desde 2003 hay una tendencia creciente en el país en el número de carreras impartidas, que va acompañada del crecimiento de matrícula; no obstante, en 2004 la matrícula se estanca, produciendo una baja en el número promedio de estudiantes por carrera. En efecto, la única región donde la matrícula retrocede en 2004 es la Metropolitana, pero, 
en virtud de la gran concentración de programas en la capital, esta variación tiene impacto en las cifras nacionales agregadas.

Gráfico 112. Evolución de la matrícula de $1^{\text {er }}$ año en el conjunto de carreras de la subárea Diseño

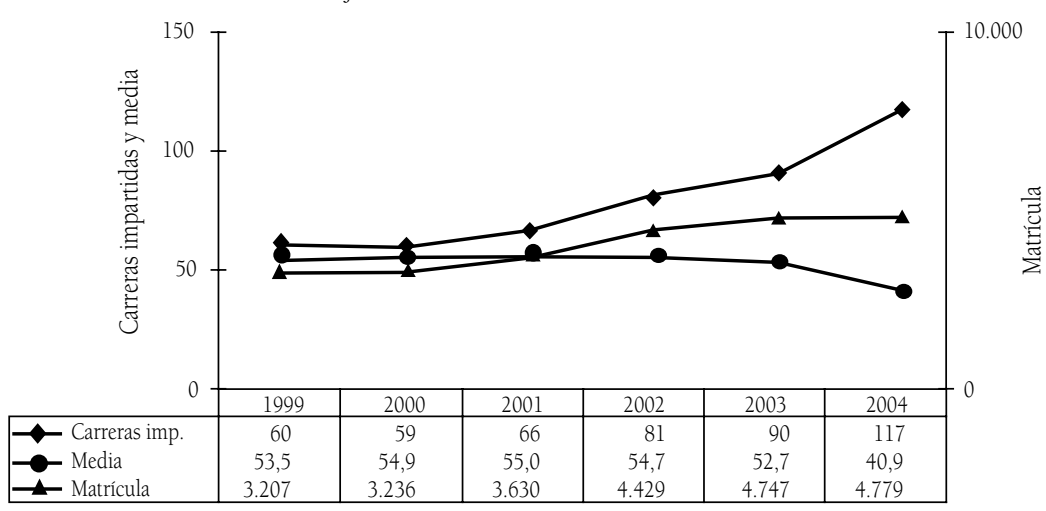

\section{Derecho}

La subárea Derecho consta de la carrera de Derecho y de carreras técnicas (que no incluyen programas de criminalística). Es una de las pocas subáreas cubiertas en este apartado que gana peso relativo; de representar un 2,5\% de la oferta nacional, hoy cuenta con el $3,7 \%$ (y $5,5 \%$ de la matrícula). La participación de los IP, tanto en oferta como en matrícula, es marginal y se limita a las carreras de asistente jurídico.

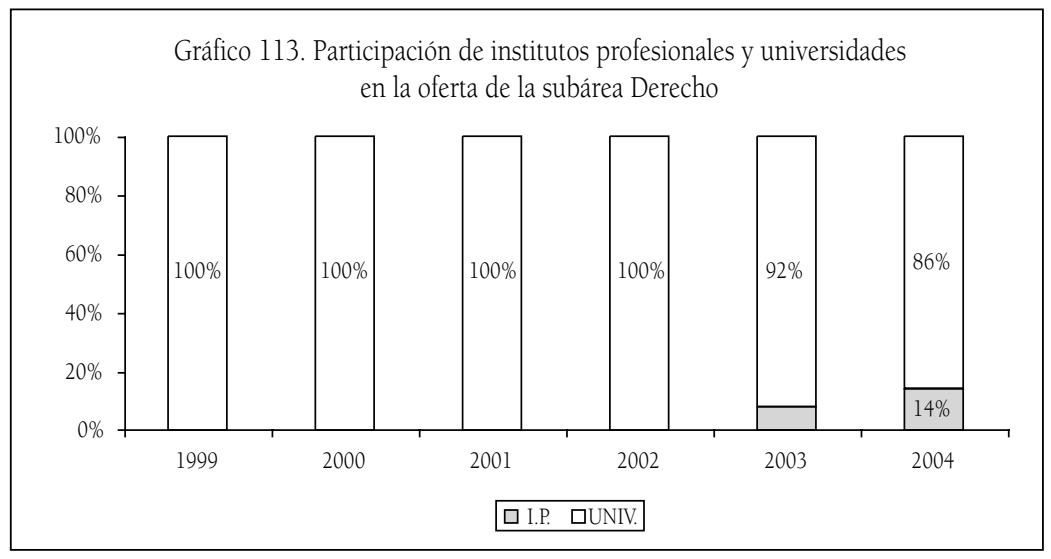




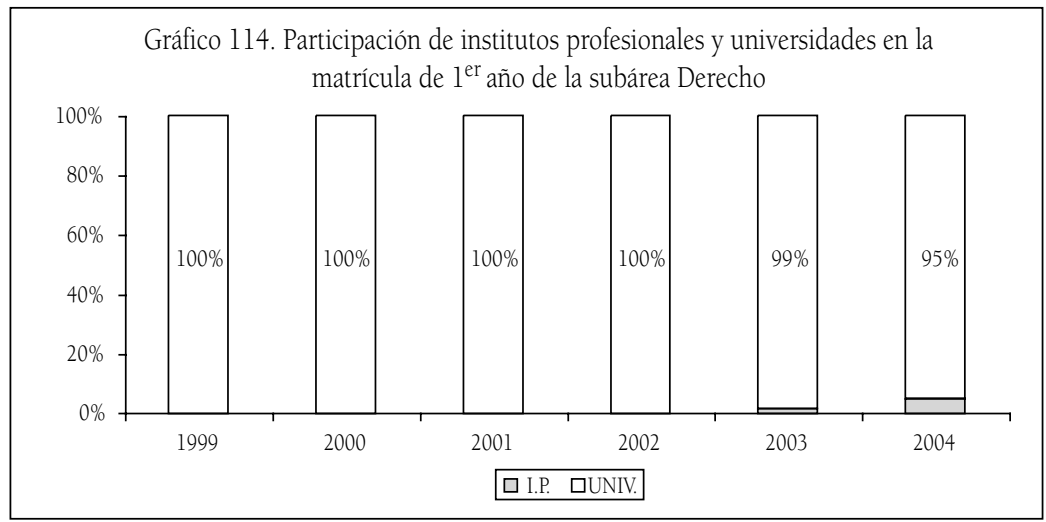

En 2002 se observa una fuerte alza del número total de programas de la subárea que, si bien va acompañada de un aumento de matrícula, de todas formas conduce a la baja ostensible del promedio de estudiantes por carrera. Casi todas las regiones han experimentado un aumento sostenido de matrícula entre 1999 y 2004. En rigor, la IV Región es la única donde se comprueba una disminución clara de matrícula el último año, mientras que en las regiones $\mathrm{V}$ y VIII se constata un crecimiento irregular, pero crecimiento al fin, durante estos seis años. Tal situación obliga a atender en cómo se proyecta el interés por ofrecer e inscribirse en Derecho, y en los riesgos y ventajas que supone esta expansión sostenida para los actores involucrados.

Gráfico 115. Evolución de la matrícula de $1^{\text {er }}$ año en el conjunto de carreras de la subárea Derecho

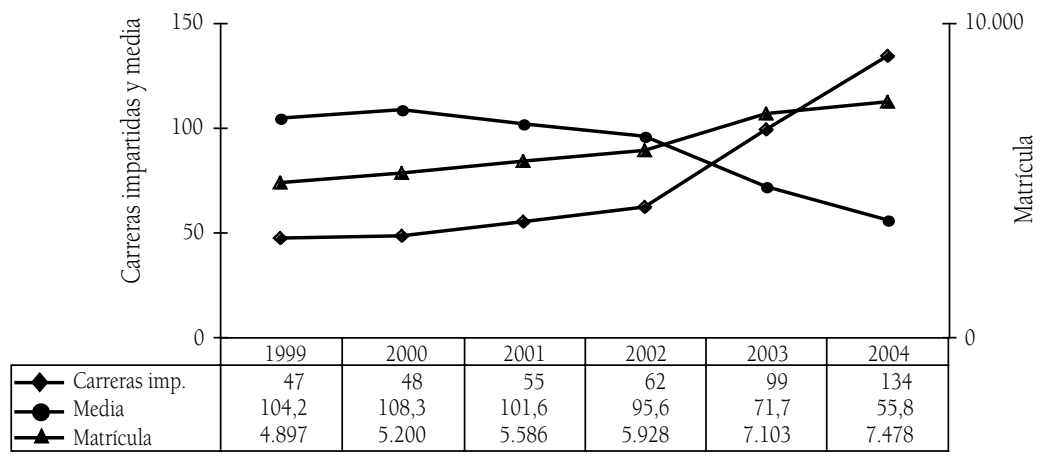




\section{Educación Básica}

Bajo esta categoría hay un solo tipo de carrera: Educación General Básica. Ésta es de las pocas subáreas estudiadas que eleva su participación en la oferta y matrícula nacional de un 2,5 a un 3,3\%. La presencia relativa de los IP muestra una tendencia a la baja especialmente notoria desde 2002, seguramente como resultado de las restricciones para la formación de pedagogías en instituciones no universitarias.
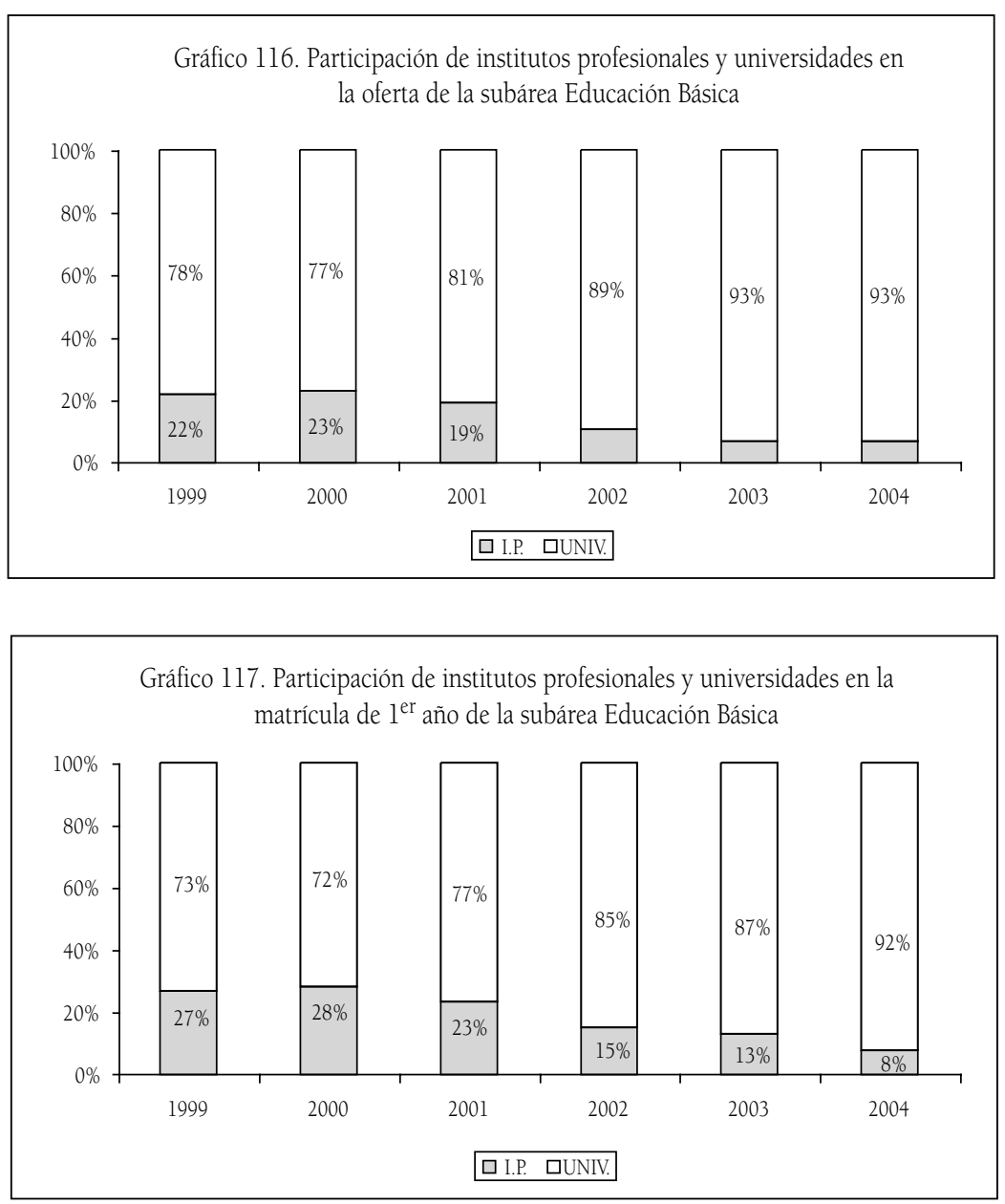
El gráfico de líneas ilustra cómo, a partir de 2002, se incrementa el número total de carreras de Educación Básica en sintonía con el alza de matrícula, al punto que no se observan mermas significativas en el promedio de alumnos por carrera sino hasta 2004. Sin embargo, el panorama regional es más variado; mientras las regiones Metropolitana, II, V y X muestran un alza sostenida en el número de estudiantes inscritos y de carreras, las regiones I, IV, VII, VIII y IX alcanzan el máximo de matrícula y oferta en 2003, tras lo cual, a pesar de mantener o añadir programas al mercado, disminuye su captación de alumnos.

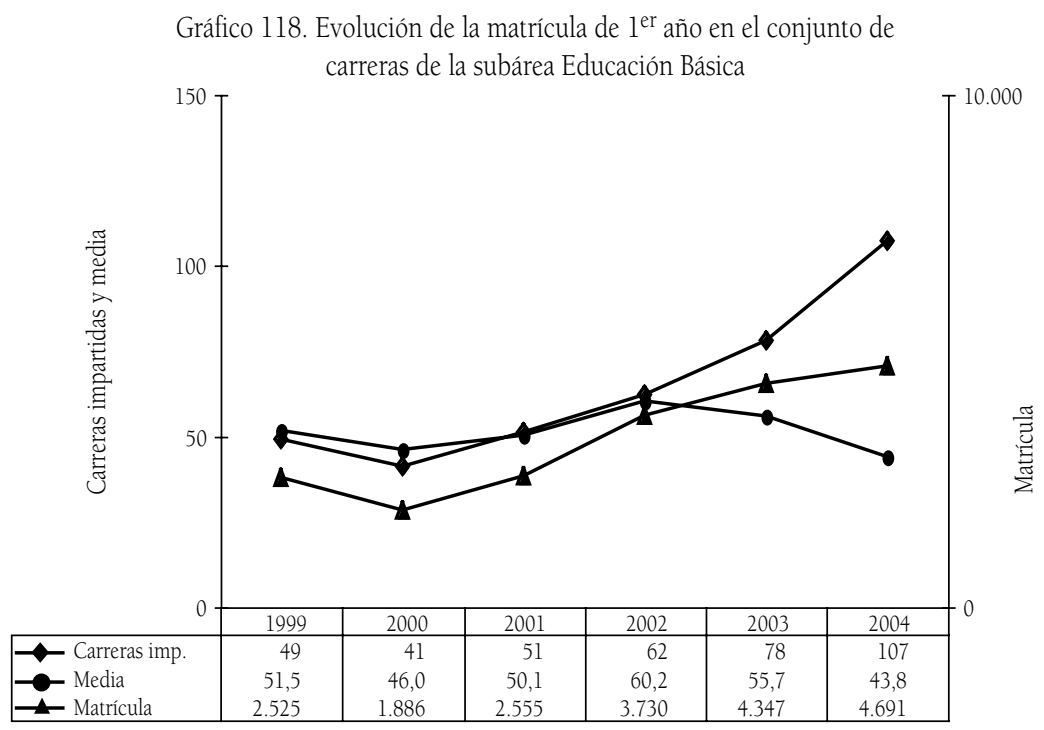

\section{Educación Media}

La subárea comprende las carreras que preparan a los profesores de las distintas asignaturas escolares. Exceptuando en 2002, cuando llegó a representar el 5\% de la oferta y matrícula del país, Educación Media se ha mantenido alrededor del 7\%. De ese porcentaje, los IP captan un $7 \%$ de estudiantes y participan de un 13\% de la oferta en 2004. 

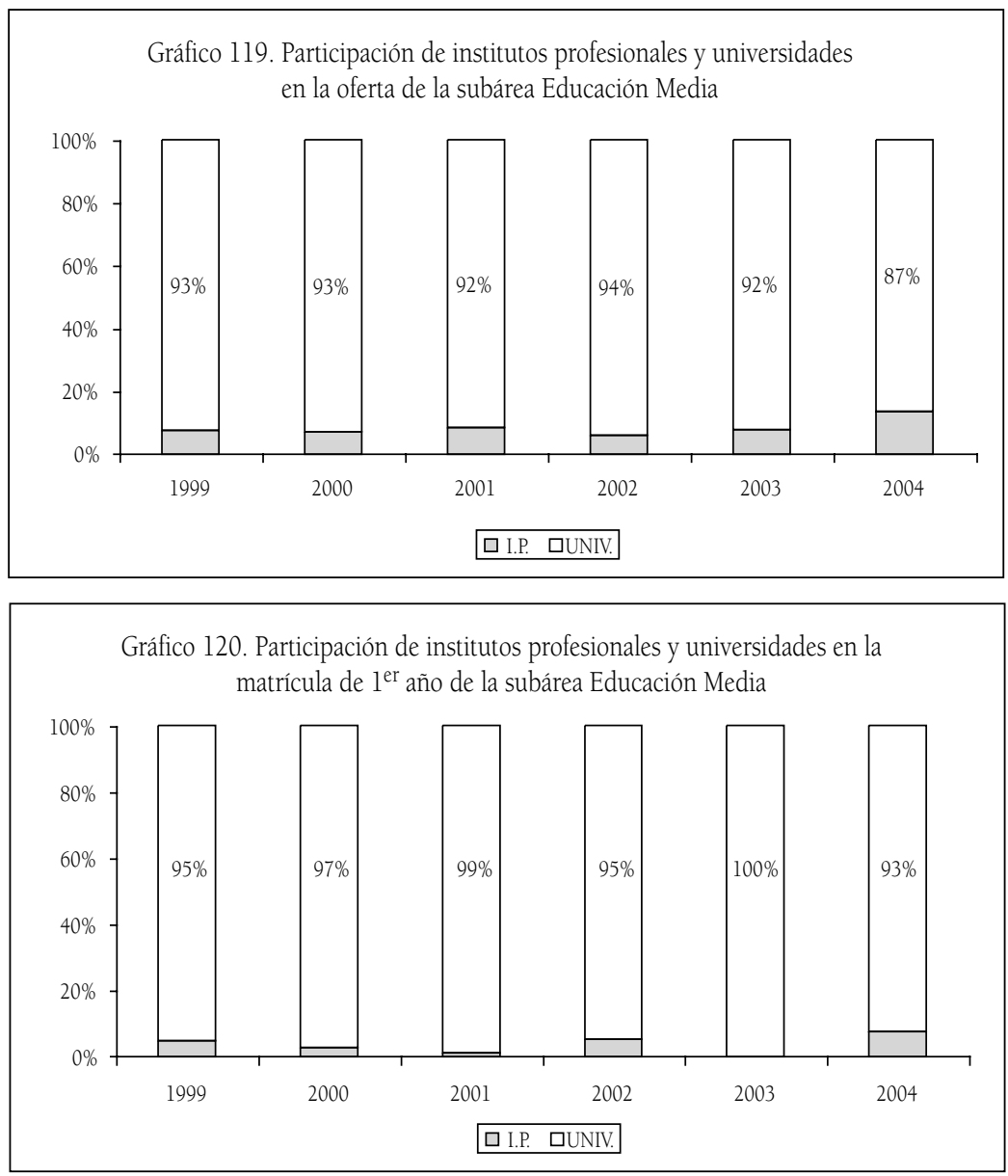

En 2002 se eleva sintónicamente el número de carreras impartidas y la matrícula (el promedio de estudiantes por programa no varía sustantivamente). A juzgar por el panorama regional de la matrícula, el interés por Educación Media avanza en prácticamente todo el territorio y, en algunos casos, de modo explosivo en 2004 (por ejemplo, en las regiones VII y Metropolitana). Por un lado, esta constatación invita a un estudio que explore, al interior de la subárea, qué pedagogías crecen más. Lo reciente del fenómeno hace que sea difícil prever cuál será el comportamiento de la oferta de carreras y el entusiasmo con el que será recibida por parte de 
los postulantes; sin embargo, es obvio que se asiste a un punto de inflexión que sólo puede comprenderse a la luz de antecedentes del contexto social y de política pública que afectan la formación y ejercicio profesional de la pedagogía en Chile.

Gráfico 121. Evolución de la matrícula de $1^{\mathrm{er}}$ año en el conjunto de carreras de la subárea Educación Media

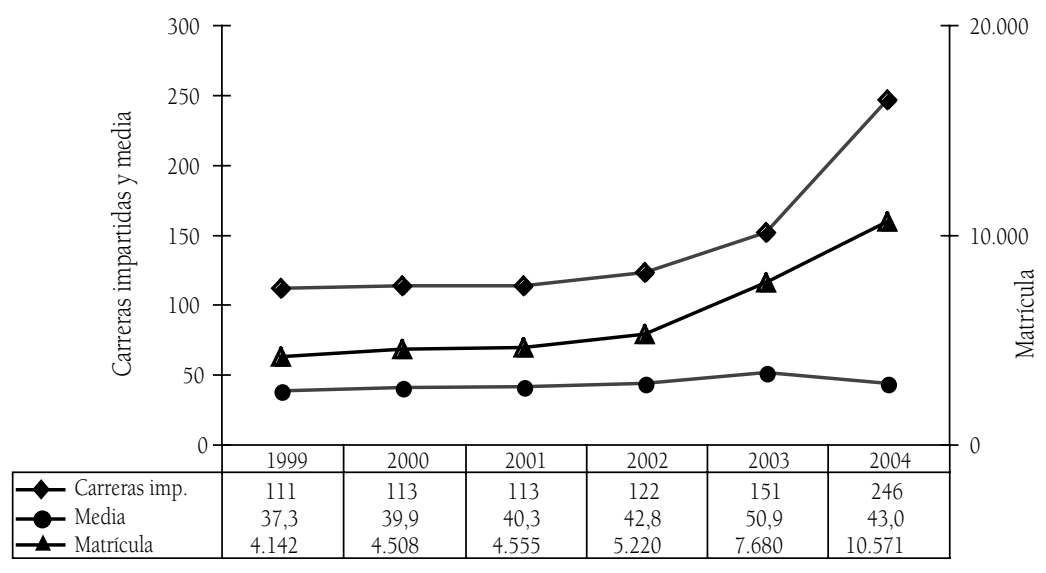

\section{Educación Parvularia}

Comprendidas en esta subárea están Educación Parvularia y las carreras técnicas asociadas que, en conjunto, representan el 2,7\% de la oferta nacional. Con fluctuaciones menores, la oferta de los IP se mueve alrededor del 25\%, mientras que la proporción de matrícula con que se quedan es un poco mayor en promedio e, incluso, llega al 34\% en 2002. 

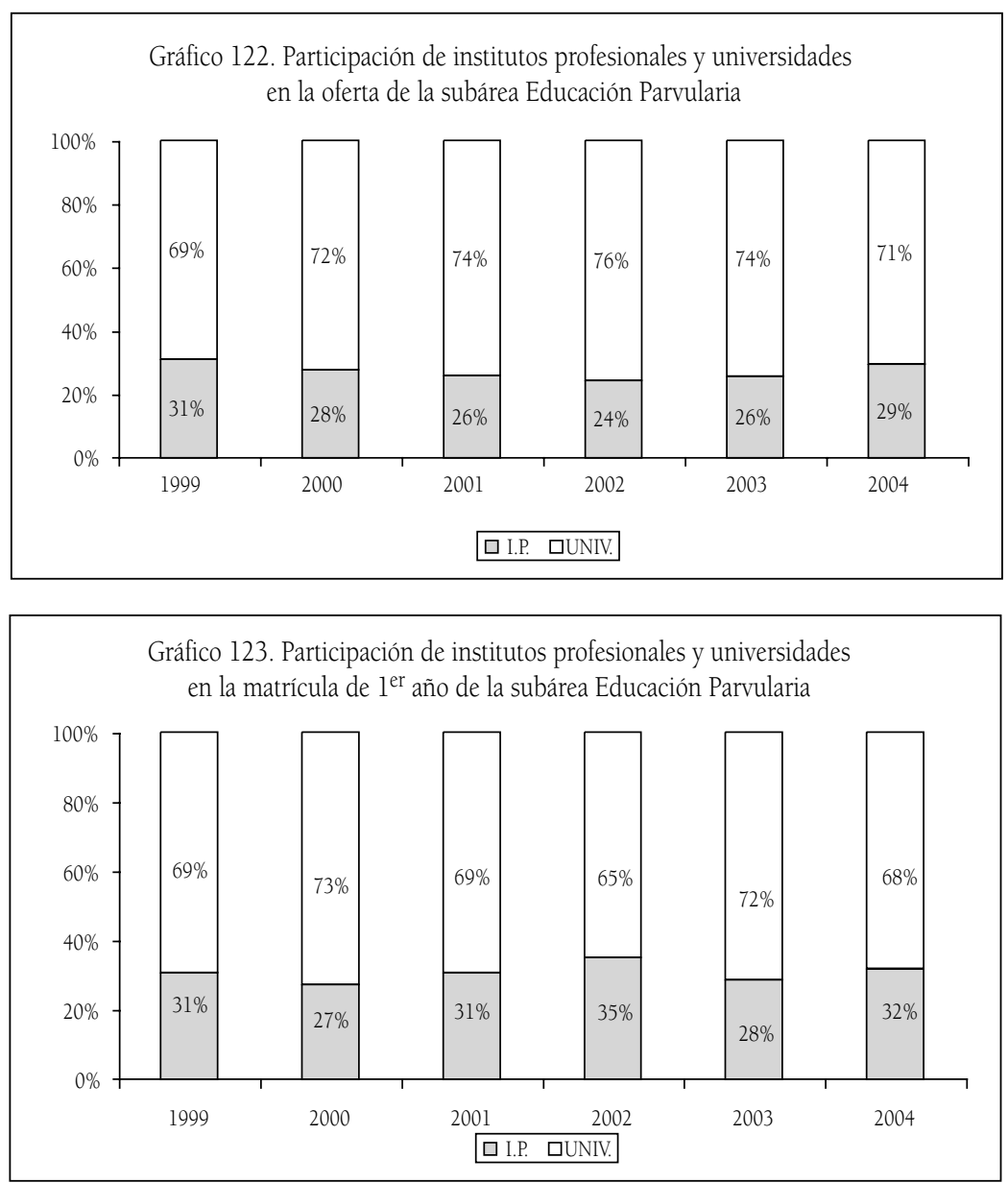

La cantidad de carreras impartidas se eleva desde 2002 de modo sostenido, mientras que la matrícula lo hace con menor intensidad, razón que explica la disminución de promedio de alumnos por programa. Al consultar las cifras regionales, aparecen comportamientos de matrícula oscilantes en regiones como la II, IV, VII y VIII, que en 2003 captan un máximo de estudiantes y sufren una merma de inscritos al año siguiente. Llama la atención que en la VIII Región, a diferencia de las otras, el número de carreras para 2004 aumenta en lugar de disminuir. Las regiones V, X y Metropolitana ganan sostenidamente matriculados e incrementan el número de carreras. 
Gráfico 124. Evolución de la matrícula de $1^{\mathrm{er}}$ año en el conjunto de carreras de la subárea Educación Parvularia

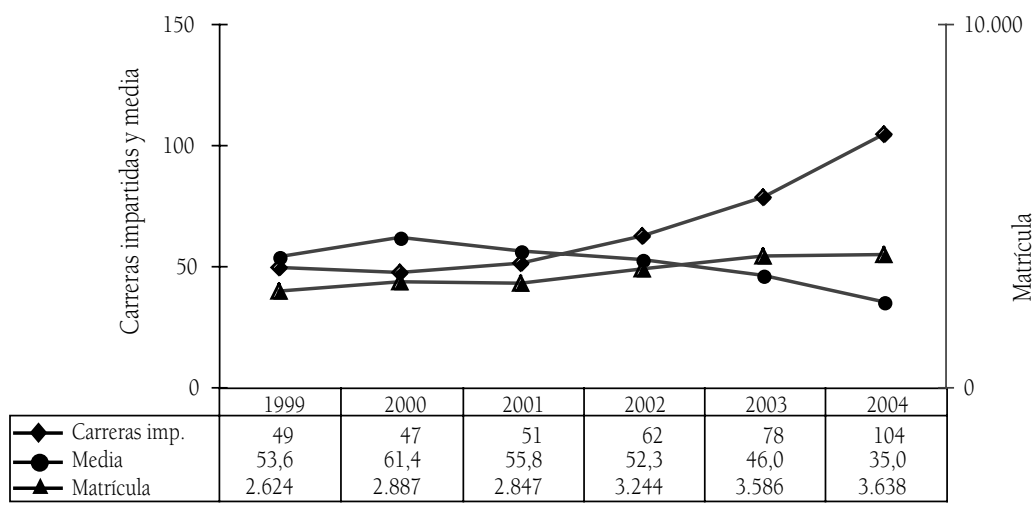

Psicología

Compuesta por una sola carrera, que se imparte exclusivamente en universidades y capta un poco más de 3,5\% de la matrícula de primer año del país (2,5\% de la oferta).

Los últimos dos años aumenta el número de ofertas de la carrera y de matriculados aunque no en igual proporción, produciendo una disminución del número promedio de alumnos por programa. En algunas regiones la matrícula muestra una curva creciente que alcanza un máximo entre 2001 y 2003, para después frenar su crecimiento o caer (regiones IV, VIII y Metropolitana). Distinto es el caso de las regiones I, II, V, VII y X donde los incrementos de matrícula se acentúan los últimos dos años, al igual que el aumento en el número de programas impartidos. Llama la atención la marcada caída de estudiantes que experimenta la IX Región en 2003, ya que la recuperación al año siguiente también es muy clara.

La carrera de Psicología continúa atrayendo estudiantes, especialmente en regiones. No obstante, la merma de alumnos que se observa en la RM y la VIII Región podría ser el antecedente de un fenómeno que se reprodujese en otros lugares. De cualquier forma, habrá que estar atentos a si, en el corto plazo, las instituciones de las 
regiones que crecen en matrícula se arriesgan a instalar más programas en el mercado, en qué medida lo hacen y qué recepción obtienen.

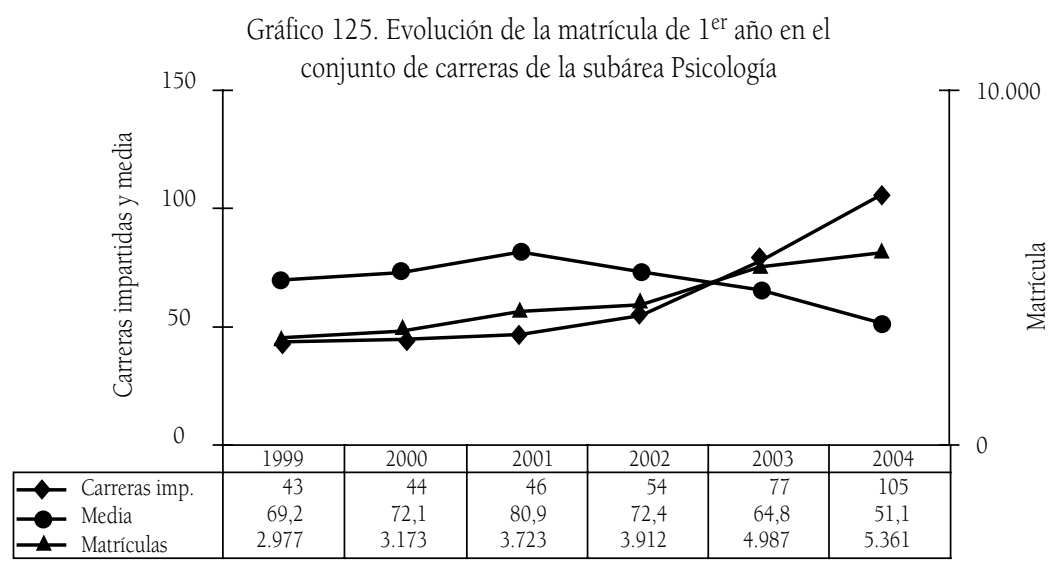

\section{Obras Civiles}

La denominación agrupa a Construcción Civil, Ingeniería en Obras Civiles, Ingeniería Civil en Obras Civiles, Ingeniería de Ejecución en Obras Civiles y a carreras técnicas. Con fluctuaciones, capta entre el 3 y el $4 \%$ de la matrícula de primer año del país y representa un porcentaje similar de la oferta. La participación diferencial según tipo de institución indica que, de tener un 34\% de la matrícula, los IP llegan gradualmente a un $46 \%$. De igual manera, en 2001, la participación de IP en la oferta llega al 50\% aproximado, situación que se mantiene hasta 2004.

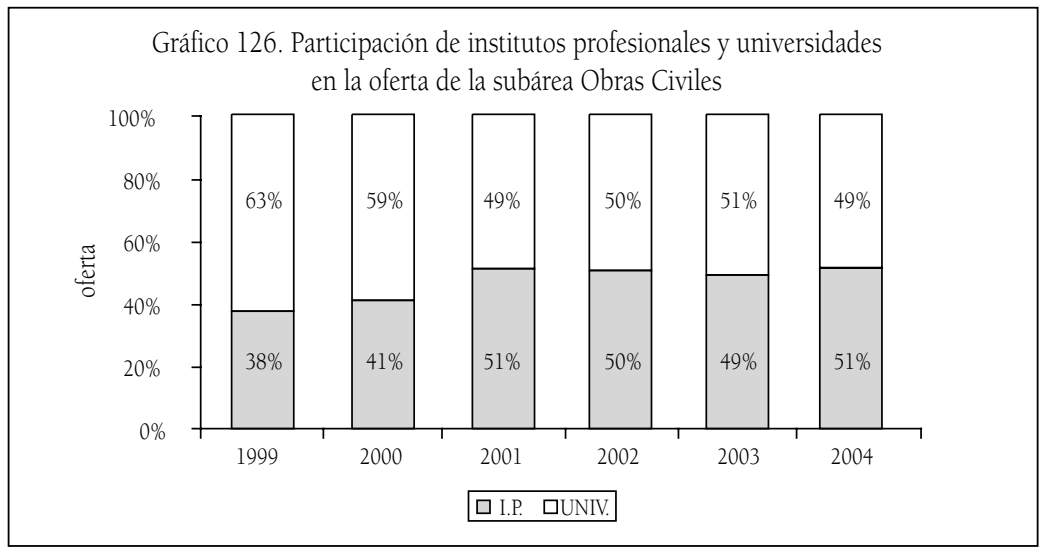


Gráfico 127. Participación de institutos profesionales y universidades en la matrícula de $1^{\text {er }}$ año en la subárea Obras Civiles

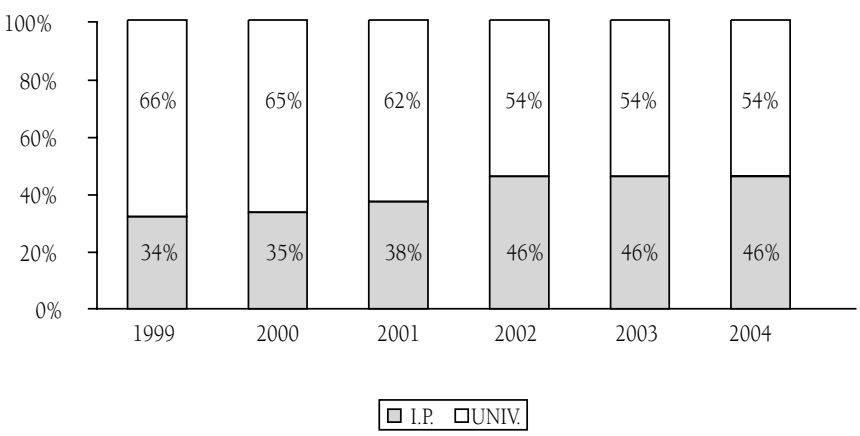

La matrícula ostenta un comportamiento que asemeja una parábola, con tendencia ascendente hasta el 2003 y descendente el 2004. Las carreras impartidas reproducen esta figura de modo menos pronunciado, lo que subyace a la disminución de la media de estudiantes por programa. Las regiones con mayor población (RM, Vy VIII) y la XII Región replican el patrón descrito. Ejemplos de patrones distintos son la II y la IX, donde la matrícula decae sostenidamente, fenómeno del que las instituciones no parecen tomar nota. En el otro extremo están la I, III, IV, VII y X que muestran estabilidad o crecimiento moderado tanto en el número de programas como en términos del número de estudiantes que captan. 
Gráfico 128. Evolución de la matrícula de 1er año en el conjunto de carreras en la subárea Obras Cibiles

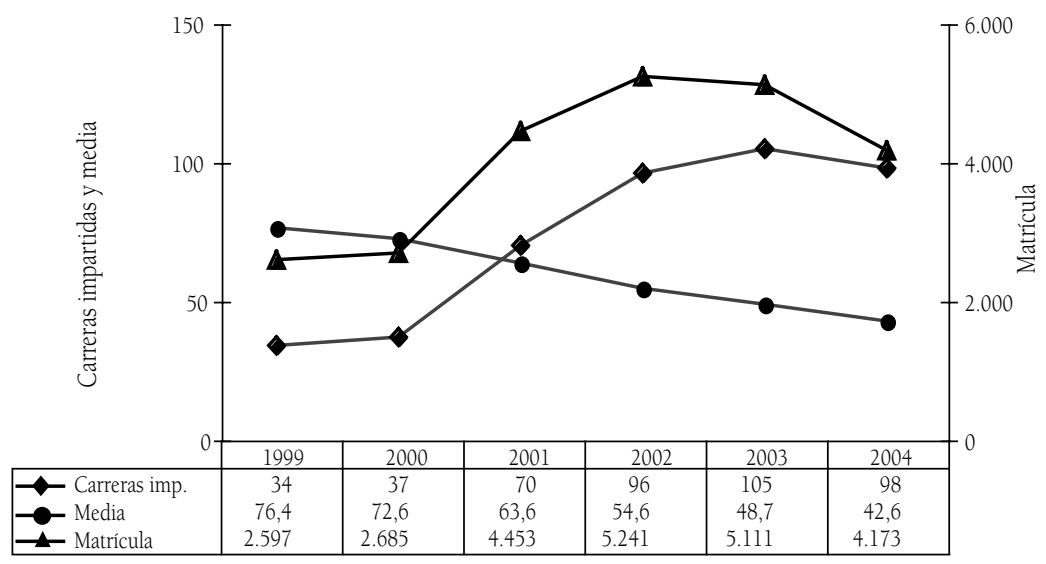

\section{Enfermería}

Enfermería, Obstetricia y Puericultura, más las carreras técnicas que componen esta subárea. Es otra categoría que incrementa su peso relativo en la oferta del país (de 1,5\% en 1999 a 3,0\% en 2004). Recién en 2003 aparece la participación de IP con 32\% de la oferta y 15\% de la matrícula, la cual sube rápidamente a 26\% en 2004.

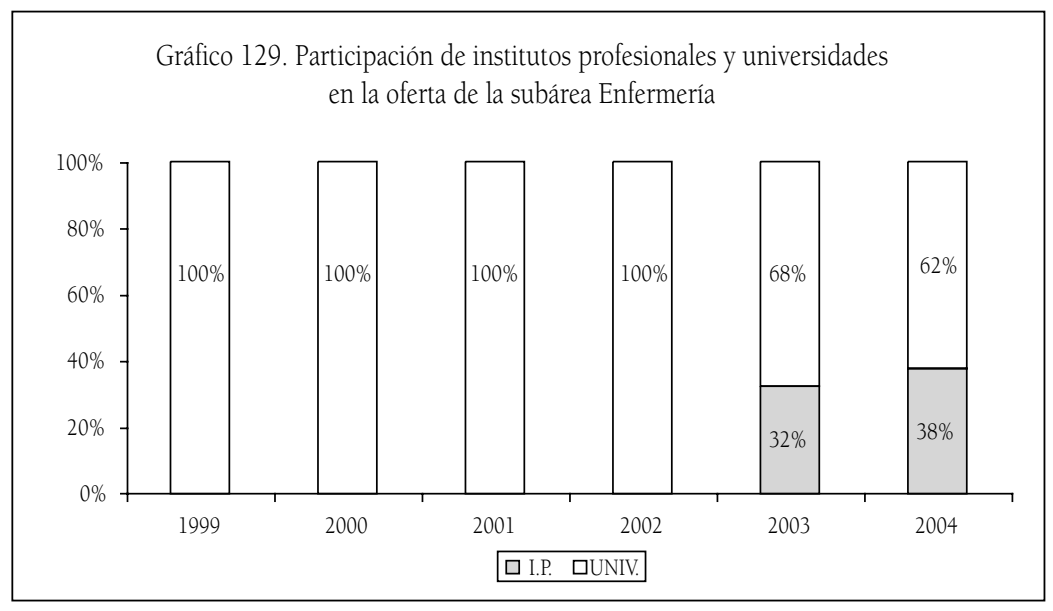




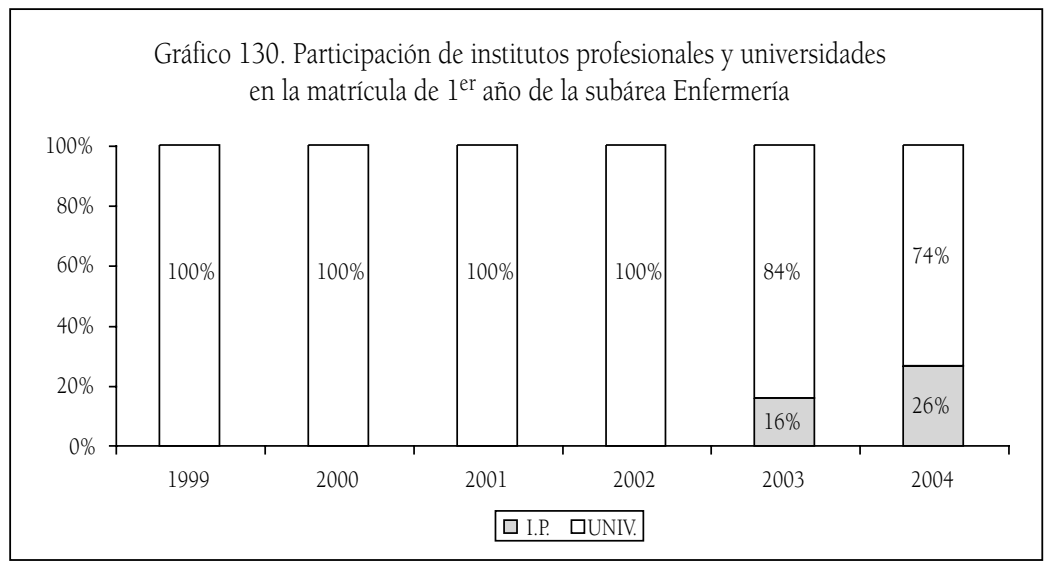

El número total de carreras impartidas se ha ido incrementando, especialmente los últimos dos años, tendencia que se reproduce en los indicadores de matrícula, aunque no con igual intensidad, a juzgar por la disminución del promedio de estudiantes por programa. La inscripción en programas de la subárea es explosiva durante los últimos dos años en todas las regiones salvo en la VI y en la Metropolitana (en esta última la matrícula baja a pesar de que se imparten nueve carreras adicionales). Será muy interesante observar cómo evoluciona la oferta futura y qué tipo de instituciones y de programas se benefician mayormente de lo que parece ser el interés creciente por Enfermería.

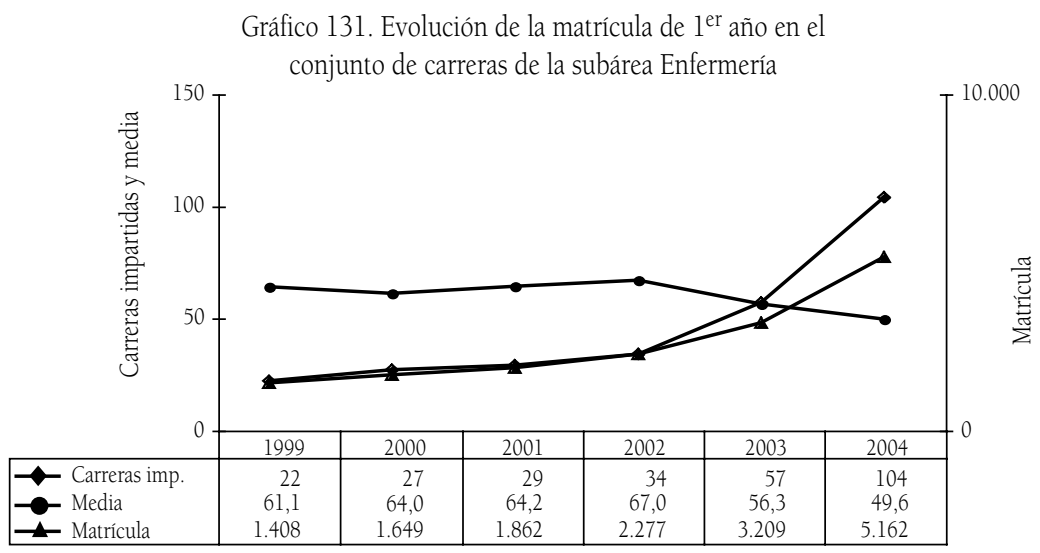




\section{Trabajo Social}

Incluye la carrera de Trabajo Social y carreras técnicas relacionadas, las que, en conjunto, representan el 3\% de la oferta total. La curva de participación en la matrícula muestra que el peso relativo de la subárea disminuye de modo más claro: de 3,8 pasa a captar al 2,5\% de estudiantes de primer año del país. El porcentaje más alto de participación de los IP en la matrícula se dio el 2002, cuando alcanzó el 64\%, tras lo cual reduce su peso relativo a 34\% en 2004 (con una oferta del 44\%). Se avizora que este porcentaje seguirá en declive, puesto que, en 2005, la carrera de Trabajo Social fue declarada exclusivamente universitaria.
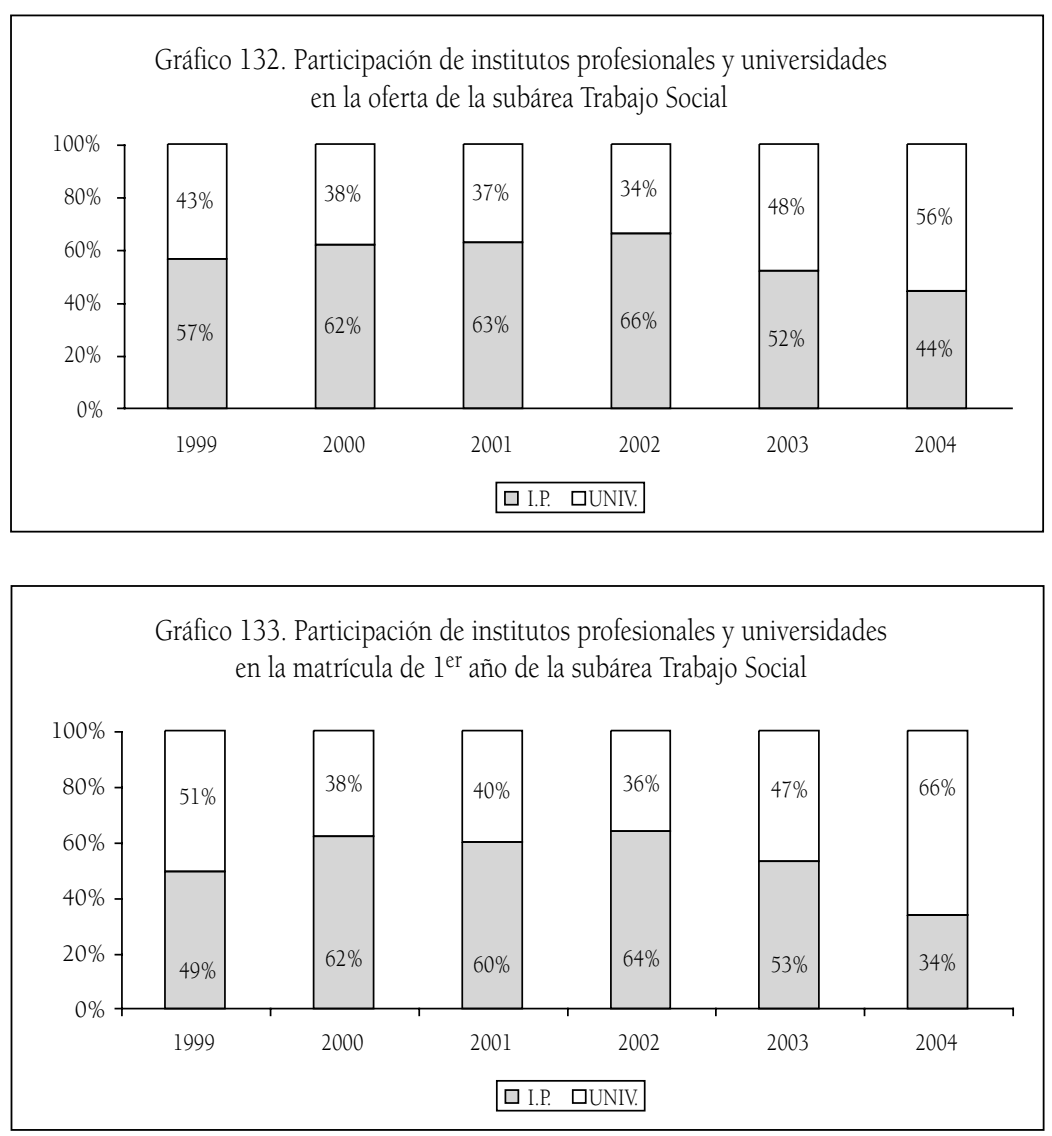
Los últimos dos años se eleva la cantidad de carreras impartidas, en tanto que la matrícula se mantiene relativamente estable, con la consecuente baja en el promedio de alumnos por programa. Cuesta encontrar correspondencias con este patrón al revisar la evolución de cada región; más aún, es difícil identificar regularidades o semejanzas entre regiones, pues pareciera que la matrícula (y en menor medida de la oferta) de la subárea es inestable durante el periodo estudiado. En la RM y en la XII Región, por ejemplo, se observa una curva de matrícula ascendente hasta 2001, que va en declive hasta 2003 y vuelve a subir el 2004. Para regiones como la II, V, VII, VIII, IX y X, el máximo de alumnos se inscribe en 2002 o 2003, tras lo cual la matrícula se contrae con más o menos notoriedad, sin que necesariamente lo haga el número de programas. La I Región destaca por un incremento reciente de matrícula frente al que cabe preguntarse si se mantendrá y en cuánta oferta adicional se traducirá.

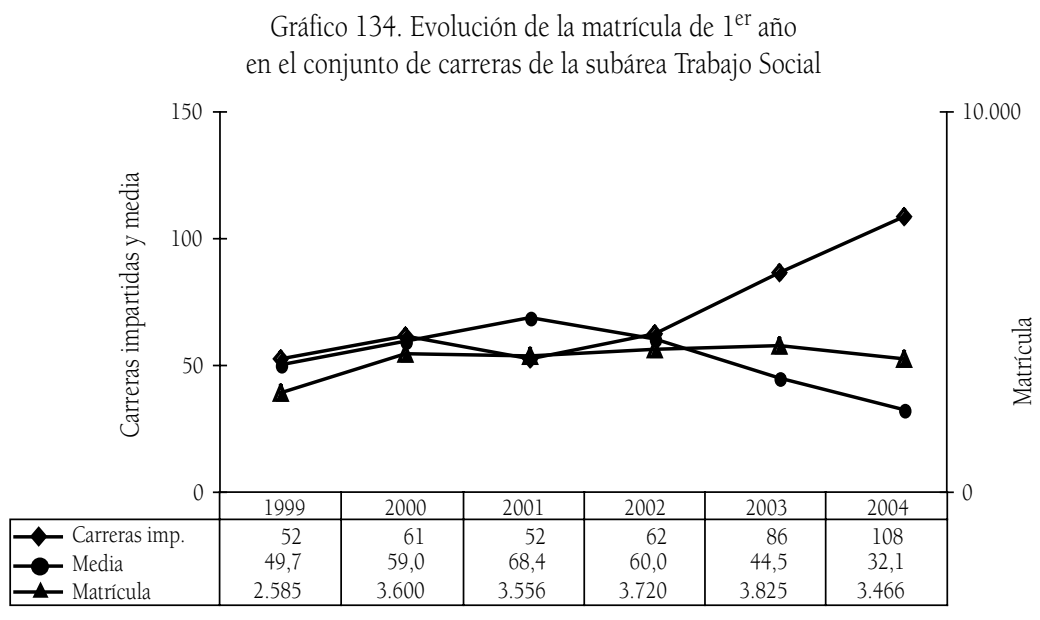

Arquitectura

Esta subárea comprende dos tipos de carrera: Arquitectura y carreras técnicas. En estos años, Arquitectura baja levemente su participación tanto en la oferta (hoy es 1,5\%) como en la matrícula total del país (hoy es $2 \%$ ). En lo concerniente a la distribución 
por tipo de institución, la oferta de los IP sube del 11 al 24\% y la matrícula sube desde un 8\%, en 2001, al 14\%, en 2004.
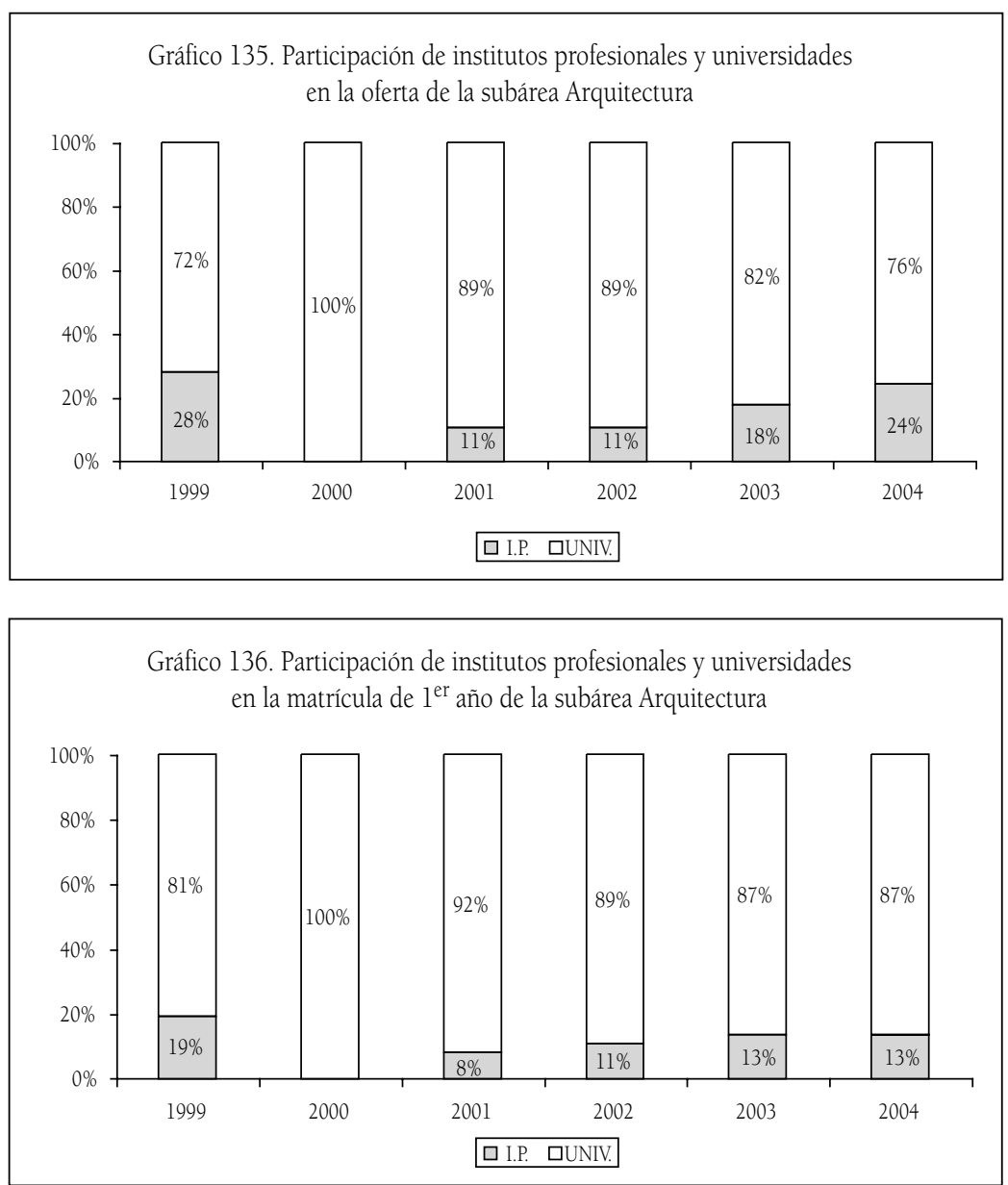

El conjunto de carreras impartidas en ambos tipos de instituciones se mantiene estable entre 1999 y 2002, al igual que la matrícula. A partir de entonces, el incremento de oferta se agudiza al tiempo que el de matrícula se estanca, con la consecuente disminución de la media de alumnos por programa. Excepto las regiones $\mathrm{V}$ y VII, donde el número de estudiantes se eleva, en todas las demás la matrícula se mantiene estable o, incluso, disminuye 
durante los últimos dos años, en paralelo con un aumento en el número de carreras impartidas, salvo en la V y IX donde, últimamente, no ha variado la cantidad de programas disponibles en el mercado.

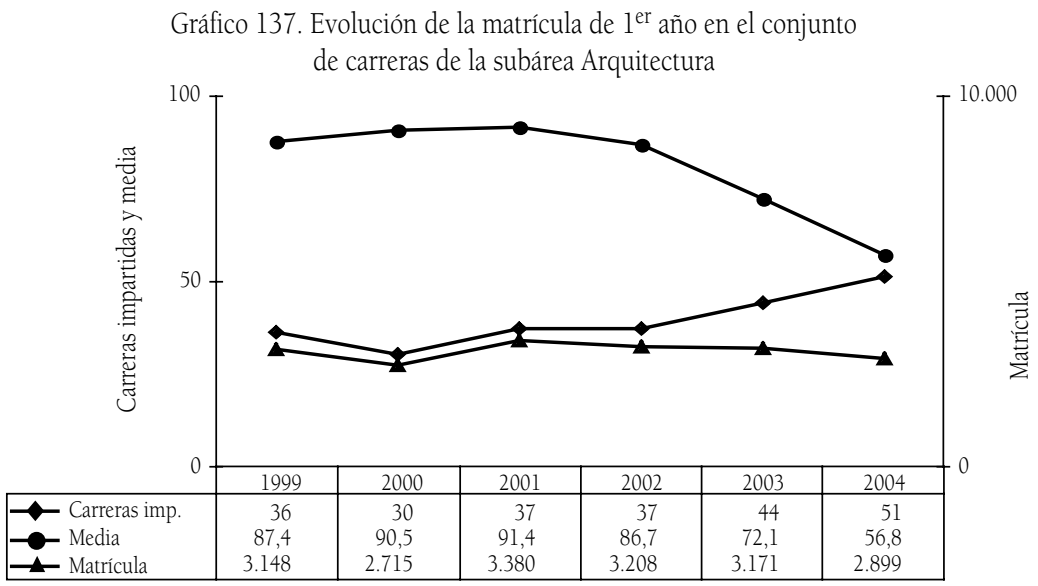

\section{Comentarios conclusivos a la cuarta sección}

Las conclusiones de la tercera sección de este informe ya dejan entrever que la diversificación por áreas del conocimiento no muestra evidencias de estar sucediendo a gran escala. Una primera pregunta que surge al adentrarse en las subáreas más "populares" es si el hecho de que éstas representen el 60\% de programas y de matriculados es signo de concentración excesiva o no en lo que a áreas del conocimiento se refiere. Responder esto no es fácil; sin embargo, la perspectiva general de la variedad de oferta disponible puede brindar algunos elementos de juicio: las 14 subáreas estudiadas, de un total de $68^{8}$, comprenden 47 descriptores de género $^{9}$, de un total de 185. En otras palabras, 47 categorías son

8 Por cierto, no se incluyen diplomados, postítulos ni posgrados.

9 Los descriptores de género son una clasificación del CSE para identificar los tipos de carrera que cada subárea comprende. Tienen como función facilitar la lectura y elaboración de datos mediante una clasificación siempre perfectible que, al mismo tiempo, intenta respetar las denominaciones que cada institución decide darle a sus programas. 
las que concentran el $60 \%$ de la oferta y la matrícula de primer año. Aunque esta información no despeje por sí sola la interrogante sobre la diversificación, propone un punto de referencia para futuras investigaciones o trabajos cuyo foco sea la distribución por áreas del conocimiento en la educación superior chilena, agregando dimensiones como el carácter técnico o profesional de los programas, su costo y su duración.

Un hallazgo interesante es que las subáreas que antaño concentraran porcentajes de matrícula y oferta superiores al $5 \%$, como Computación e Informática, Administración e Industrial, hoy retroceden en términos relativos. Por oposición, Derecho, Educación Básica y Enfermería ganan terreno, lo cual es consistente con los notorios incrementos absolutos que logran en estos seis años. Si bien las variaciones son pequeñas, porcentualmente hablando, podrían ser el anuncio de una redistribución que favorece a las pedagogías y a las carreras de Salud. El caso de Derecho, carrera tradicionalmente requerida, será interesante seguir explorando si su peso relativo se consolida o disminuye en los años venideros. Otro aspecto que queda pendiente es indagar con mayor detalle la función que las carreras técnicas (incluidas las que imparten los CFT) han tenido y tendrán en los desarrollos futuros.

En cuanto a la participación diferencial de universidades e institutos profesionales, estos últimos compiten de igual a igual con universidades dentro de las subáreas de Computación e Informática, Obras Civiles y Diseño. Administración y Contabilidad han tenido, históricamente, menos participación en la matrícula que en la oferta, lo que podría estar reflejando, simplemente, una estrategia distinta respecto de las vacantes. De todos modos, la participación relativa de los IP en Contabilidad disminuye, al tiempo que las cifras nacionales de inscritos en la subárea también, lo que sugiere que probablemente las universidades se ven menos afectadas por este cambio. Cabe preguntarse qué está ocurriendo con la subárea Industrial en este mismo sentido. 
El examen de los datos agregados sobre crecimientos absolutos de las subáreas en el país arroja conclusiones categóricas respecto del número de carreras impartidas: éstas crecen en forma sostenida y de modo particularmente intenso a partir de 2002. Con la matrícula se dan escenarios distintos, dependiendo de la carrera, pero en casi todas se aprecia que el promedio de alumnos por carrera decae desde 2001, de lo que se infiere que la tasa de crecimiento de la oferta es mayor que la de matrícula, situación patente sobre todo los últimos dos años.

Es importante hacer dos alcances, basados en la información que aporta el análisis de la situación regional. En primer lugar, los patrones de evolución regional están lejos de replicar las tendencias que se constatan por agregación en el conjunto de carreras de cada subárea estudiada. Sólo al mirar lo que ocurre en lo se puede llamar "micromercados" se aprecian las fluctuaciones de matrícula durante estos seis años, así como las respuestas de las instituciones de educación superior ante dicha variación en la demanda. Sería fácil aseverar, por ejemplo, que dada la desaceleración de matrícula se está alcanzando el "techo" de crecimiento; sin embargo, las curvas de las subáreas en varias regiones dan cuenta de contracciones que fueron seguidas por ciclos de expansión y, viceversa, antes de 2003. Más aún, si se piensa que algunas regiones recién están incursionando en la oferta de determinadas carreras, es probable que dicha fase de experimentación todavía proporcione muchas sorpresas en los años venideros.

En segundo lugar, los datos expuestos en este informe levantan una serie de interrogantes adicionales respecto de qué actores marcan la pauta de la expansión y la diversificación: si las instituciones o el interés de los estudiantes. Una pregunta en este sentido es: ¿tienden las instituciones a aprovechar al máximo su capacidad instalada, ofreciendo los programas que ya tienen consolidados hasta que, por efecto de estancamientos de matrícula, se ven impulsadas a explorar en áreas nuevas a las que apuestan con distintos grados de entusiasmo? Dicho de otro modo, en una 
región dada, donde no se ofrece un tipo de carrera, habría que ver si los esfuerzos de expansión se concentran en las carreras existentes y si esto se modifica sólo cuando éstas dejan de atraer el volumen de alumnos esperado, con lo cual sobreviene una apuesta por otras áreas que ya ostentan incrementos de matrícula en otras regiones. La diversificación, en esta lógica, sería un fenómeno que avanza conforme los estudiantes alientan esa transformación. So pena de especular en demasía, es mejor reservarse juicios categóricos a la espera de nuevos antecedentes.

Por el momento, baste señalar que este informe y los anexos publicados en la página Web del CSE tienen como fin principal ser un estímulo y una invitación para que más personas consulten en las bases de datos y estadísticas disponibles, y contribuir a la comprensión y al debate informado sobre la educación superior en nuestro país.

Nota: las cifras que sirvieron de base a las conclusiones de este informe están incorporadas en el sitio en Internet del CSE. http://www.cse.cl 